UNIVERSIDADE DE SÃO PAULO

FACULDADE DE ZOOTECNIA E ENGENHARIA DE ALIMENTOS

GUSTAVO VOLTANI VON ATZINGEN

Simulação, controle e automação de um forno tipo túnel utilizando tecnologia embarcada 
Gustavo Voltani von Atzingen

\title{
Simulação, controle e automação de um forno tipo túnel utilizando tecnologia embarcada \\ Versão corrigida
}

\author{
Apresentada à Faculdade de Zootecnia e \\ Engenharia de Alimentos da Universidade \\ de São Paulo, como parte dos requisitos \\ para a obtenção do Título de Doutor em \\ Ciências, na Área de Engenharia de Ali- \\ mentos \\ Orientador: Prof. Dr. Ernane Jose Xavier \\ Costa.
}

Universidade de São Paulo - USP

Faculdade de Engenharia de Alimentos

Programa de Pós-Graduação

Pirassununga, SP

16 de maio de 2017 
Ficha catalográfica elaborada pelo Serviço de Biblioteca e Informação, FZEA/USP, com os dados fornecidos pelo(a) autor(a)

Voltani von Atzingen, Gustavo

Simulação, controle e automação de um forno tipo

túnel utilizando tecnologia embarcada / Gustavo

Voltani von Atzingen; orientador Ernane Jose

Xavier Costa. -- Pirassununga, 2017.

$139 \mathrm{f}$.

Tese (Doutorado - Programa de Pós-Graduação em Engenharia de Alimentos) -- Faculdade de Zootecnia e Engenharia de Alimentos, Universidade de São Paulo.

1. Diferenças Finitas. 2. CFD. 3. Raspberry pi. 4. Arduino. I. Jose Xavier Costa, Ernane, orient. II. Título. 


\section{AGRADECIMENTOS}

Desejo agradecer ao meu orientador, o Prof. Dr. Ernane José Xavier Costa, pela oportunidade e ajuda, tanto no âmbito profissional como pessoal.

À minha família, em especial à minha esposa, Magali Adriana da Silva von Atzingen, pela paciência, compreensão, ajuda e encorajamento durante todo este período. Aos meus pais que sempre incentivaram e proporcionaram condições para meus estudos.

A todos os amigos do Laboratório de Física Computacional Aplicada (LAFAC) pela ajuda e aprendizado. Ao Aldo Ivan Céspedes Arce, Especialista em laboratório, pelo seu grande conhecimento nas áreas de software e hardware e paciência para me ensinar. Ao aluno Fernando Henrique Garcia pela ajuda nos experimentos e confecção das placas de circuito impresso. A Professora Ana Carolina de Sousa Silva, Professor Marcio Kassouf Crocomo e Camila Nardi Pinto pela revisão da tese.

A todos que contribuíram de forma direta ou indireta para a realização deste trabalho. 



\section{RESUMO}

ATZINGEN, G. V. v. Simulação, controle e automação de um forno tipo túnel utilizando tecnologia embarcada. 139 f. Tese (Doutorado) - Faculdade de Zootecnia e Engenharia de Alimentos, Pirassununga, 2017.

Baseado na grande evolução dos dispositivos eletrônicos nos últimos 35 anos e dos novos hardwares de baixo custo e alto poder computacional, esta tese tem como objetivo testar a seguinte hipótese: É possível o controle e automação de um forno em escala piloto com informações de sensores e simulação em tempo real utilizando computação embarcada de baixo custo. Para isto, modelagem matemática e simulação do perfil de temperatura do forno e do alimento foram realizadas para que o sistema de controle possa ter informação da temperatura no alimento em tempo real, contando apenas com os sensores fixos no forno. A informação desta simulação alimenta o controle PID, garantindo que o perfil de temperatura desejado para o aquecimento/cozimento do alimento seja obedecido, melhorando a qualidade do produto final. O sistema de controle possui duas unidades, a escrava que é localizada na lateral do forno é composta de um Arduino mini, da instrumentação para o controle dos sensores e atuadores do forno e a unidade mestre, que utiliza um Raspberry pi onde o software de controle com interface gráfica realiza as simulações, o controle PID e a comunicação via bluetooth com a unidade escrava. Experimentos foram realizados para testar e validar a simulação do perfil térmico do forno, do alimento e o controlador PID. Concluiu-se que é possível um controle de um forno industrial em escala piloto com simulação em tempo real utilizando computação de baixo custo.

Palavras-chave: Arduino, CFD, Diferenças Finitas, Raspberry Pi, 



\section{ABSTRACT}

ATZINGEN, G. V. v. Simulation, control and automation of a conveyor belt tunel oven with embedded technology. $139 \mathrm{f}$. PhD Thesis - Faculdade de Zootecnia e Engenharia de Alimentos, Pirassununga 2017.

Based on the dramatic evolution of electronic devices in the last 35 years and the recent advent of low cost computational hardware, embedded sensors have become a cost-effective solution for real time machine monitoring and simulation. The objective of this thesis is to present both software and hardware intended for the real-time simulation and control of a conveyor belt tunnel oven using low cost embedded hardware, to ensure high quality food production. For this purpose, mathematical modelling and simulation of the temperature profile inside the oven was performed in order to supply the control system with the calculated temperature of the food in real time, using only the fixed sensors inside the oven. This simulation information is passed to the PID controller, ensuring that the desired temperature profile for heating the food is achieved, improving the quality of the final product. The system has two units, a slave that is located on the main body consisting of an Arduino mini and the instrumentation for controlling the sensors and actuators. The second unit is the master unit, which utilises a Raspberry pi to host the control software, the graphical user interface the PID controller and manages the Bluetooth connection with the slave unit. Experiments were performed in order to test and validate the thermal profile simulation of the oven and the food, as well as to test the PID controller. It was concluded that it is possible to control a prototype scale industrial oven using real time simulation with a low-cost computation unit.

Key-words: Finite Diference, CFD, Raspberry Pi, Arduino 


\section{LISTA DE ILUSTRAÇÕES}

Figura 1 - Diagrama mostrando o sistema de controle de malha fechada. . .

Figura 2 - Resposta no tempo de um controlador proporcional em um sistema de segunda ordem com função de transferência $G(s)=\frac{1}{s^{2}+3 \cdot s+1}$ em função de três diferentes valores do parâmetro $K_{p}$ e com $K_{i}=0$ e $K_{d}=0 \ldots \ldots \ldots \ldots \ldots \ldots \ldots \ldots \ldots \ldots \ldots \ldots \ldots \ldots \ldots \ldots$

Figura 3 - Resposta no tempo de um controlador proporcional em um sistema de segunda ordem com função de transferência $G(s)=\frac{1}{s^{2}+3 \cdot s+1} \mathrm{em}$ função de três diferentes valores do parâmetro $K_{i}$ e com $K_{p}=1$ e $K_{d}=0 \ldots \ldots \ldots \ldots \ldots \ldots \ldots \ldots \ldots \ldots \ldots \ldots \ldots \ldots$

Figura 4 - Resposta no tempo de um controlador proporcional Integral e Derivativo em um sistema de segunda ordem com função de transferência $G(s)=\frac{1}{s^{2}+3 \cdot s+1}$ com três diferentes valores dos parâmetros $K_{p}, K_{i}$ e $K_{r}$

Figura 5 - Grade (stencil) que descreve a relação entre os pontos das diferenças finitas. Os eixos $x$ e $y$ possuem elementos com índices discretos representados por $i$ e $j$ e $n$ é o elemento temporal. . . . . . . . .

Figura 6 - Arduino Uno R3 - Principal placa da plataforma Arduino, com Atmega328pu e Comunicação USB. . . . . . . . . . . . . . . . . . 47

Figura 7 - Modelos do Raspberry Pi. . . . . . . . . . . . . . . . 51

Figura 8 - Imagem do forno em escala piloto, localizado no LAFAC, USP Pirassununga. . . . . . . . . . . . . . . . . . 58

Figura 9 - Visão frontal do forno. . . . . . . . . . . . . . . . 59

Figura 10 - Visão superior e lateral do forno. . . . . . . . . . . . . . . . . 60

Figura 11 - Diagrama da placa de controle desenvolvida para o forno. Diagrama completo no Anexo A.1. . . . . . . . . . . . . . . . 61 
Figura 12 - Corte lateral do forno com locais dos sensores. . . . . . . . . . . . 62

Figura 13 - Diagrama geral do funcionamento do sistema de controle. . . . . . 63

Figura 14 - Esquema elétrico da unidade escrava (parte da placa de controle do forno). . . . . . . . . . . . . . . . . . 64

Figura 15 - Protocolo de comunicação entre as unidades. Comando "SHA42 \nEsteira no sentido para frente com $42 \%$ da velocidade. . . . . . . 65

Figura 16 - Estrutura em árvore da pasta contendo o software de controle. . . 69

Figura 17 - Eixo de coordenadas para o modelo da temperatura no alimento. $\quad 75$

Figura 18 - Experimento para determinação do número de elementos $n$ e número de iterações $i$ a ser escolhido para o algoritmo de simulação da temperatura do forno. . . . . . . . . . . . . . .

Figura 19 - Resultado da simulação da temperatura do forno em função da profundidade. Condições do experimento: $\mathrm{R} 1=80 \%, \mathrm{R} 2=50 \%$, $\mathrm{R} 3=10 \%$ mantidas por 15 minutos. Leitura dos sensores em $\mathrm{t}=$ 15 minutos: $\mathrm{Ta}=27.1, \mathrm{~T} 1=180.2, \mathrm{~T} 2=170.8, \mathrm{~T} 3=155.0 . \quad$.

Figura 20 - Resultado da simulação adicionada a imagem do forno na interface de controle. $\ldots$

Figura 21 - Análise de sensibilidade de malha em função do número de elementos no eixo $r N_{r} \ldots \ldots \ldots \ldots \ldots$

Figura 22 - Temperatura no centro do alimento e no meio da superfície superior em função da temperatura para os dois softwares, Python/Fortran, e Comsol. . . . . . . . . . . . . . . . . . . . 86

Figura 23 - Comparação da simulação da temperatura no alimento em um corte central no eixo $x y$, utilizando o algoritmo desenvolvido em Python/Fortran e o software Comsol. . . . . . . . . . . . . . . .

Figura 24 - Teste do aquecimento com potência parcial, iniciando à temperatura ambiente. . . . . . . . . . . . . . . . . . 
Figura 25 - Teste das resistências, várias configurações de potência das resistências ........................ . 90

Figura 26 - Diagrama do processo de controle da temperatura no forno. . . . 92

Figura 27 - Experimento de malha aberta, 50 minutos potência máxima, 50 minutos desligado. . . . . . . . . . . . . . . . 93

Figura 28 - Experimento de malha aberta. Ligado 50 minutos, desligado 50 minutos. . . . . . . . . . . . . . . . . . . . 94

Figura 29 - Experimentos de malha aberta e simulação da evolução temporal. Temperatura da esteira e do ar no centro do forno. . . . . . . . . 96

Figura 30 - Teste de malha aberta para determinação inicial dos parâmetros $k_{p}, k_{i}$ e $k_{d}$ pelo método de Cohen-Coon. . . . . . . . . 98

Figura 31 - Simulação de malha aberta para determinação inicial dos parâmetros $k_{p}, k_{i}$ e $k_{d}$ pelo método de Cohen-Coon. . . . . . . . . . 100

Figura 32 - Experimento para verificação da eficiência do controlador PID. Setpoints: $300{ }^{\circ} \mathrm{C} 0-50$ minutos, $120{ }^{\circ} \mathrm{C} 50-100$ minutos, $250{ }^{\circ} \mathrm{C}$ 100 - 150 minutos e $180{ }^{\circ} \mathrm{C} 150$ - 200 minutos. . . . . . . . . . 101

Figura 33 - Experimento para verificação da eficiência do controlador PID. Setpoints: $200{ }^{\circ} \mathrm{C} 0-50$ minutos, $300{ }^{\circ} \mathrm{C} 50-100$ minutos e 200 ${ }^{\circ} \mathrm{C} 100$ - 150 minutos. . . . . . . . . . . . . . . . . 102

Figura 34 - Experimento para verificação da eficiência do controlador PID. Setpoints: $220{ }^{\circ} \mathrm{C} 0-50$ minutos, $180{ }^{\circ} \mathrm{C} 50-100$ minutos e 150 ${ }^{\circ} \mathrm{C} 100$ - 150 minutos. . . . . . . . . . . . . . . . . 102

Figura 35 - Layout da placa com as trilhas e locais para colocar os componentes.103

Figura 36 - Projeto da placa com componentes. . . . . . . . . . . . . . . . . . 104

Figura 37 - Placa de controle instalada no forno. . . . . . . . . . . . . . . . 105

Figura 38 - Biblioteca para a plataforma Arduino, disponível via gerenciador de pacotes da IDE. . . . . . . . . . . . . . . 106

Figura 39 - Formas de acessar a interface gráfica. . . . . . . . . . . . . . . . 107 
Figura 40 - Interface de controle, tela de controle manual. . . . . . . . . . . . 108

Figura 41 - Interface de controle, tela de ajustes. . . . . . . . . . . . . . . 110

Figura 42 - Tela de controle dos dados da interface gráfica com as opções de seleção e exportar dados, seleção de experimentos e calibração dos sensores. . . . . . . . . . . . . . . . . . . . . 111

Figura 43 - Interface de controle, tela com display gráfico das temperaturas nos sensores. . . . . . . . . . . . . . . . . . 113

Figura 44 - Interface de controle, tela com visualização da simulação do perfil térmico do forno e sobreposição na imagem do mesmo. . . . . . . . 113

Figura 45 - Interface de controle, tela do controle automático com perfil tempo x potência. . . . . . . . . . . . . . . . . . 114

Figura 46 - Interface de controle, tela do controle automático com perfil tempo $\mathrm{x}$ temperatura. . . . . . . . . . . . . . . . 115 


\section{LISTA DE TABELAS}

Tabela 1 - Codificação - Caractere ou grupo de caracteres e funcionalidade. . 66

Tabela 2 - Tempo para execução do algoritmo. Média de 10 repetições. . . . 79

Tabela 3 - Comparação entre predição da simulação e valor lido pelo sensor. $\quad 81$

Tabela 4 - Propriedades físicas dos alimentos de teste, cookie e cupcake. . . 85

Tabela 5 - Resultado das constantes da Equação 5.8 que melhor representa os dados experimentais. . . . . . . . . . . . . . . . 97

Tabela 6 - Resultado das constantes do controlador PID encontrado pelo método gráfico de Cohen-Coon. . . . . . . . . . . . . . 99

Tabela 7 - Resultado dos parâmetros ótimos do controlador PID encontrados pelo gradiente descendente. . . . . . . . . . . . . . . . . . . 99 


\section{SIGLAS}

- API - Application Programming Interface (Interface de Programação de Aplicação).

- ARM - Advance Risc Machine (Arquitetura de máquina risc avançada).

- CLP - Controlador Lógico Programável.

- ECR - Error Check Rule.

- EDP - Equação Diferencial Parcial.

- EEPROM - Electrically-Erasable Programmable Read-Only Memory (Memória programável apenas de leitura apagável eletricamente).

- FDM - Finite Diference Method (Método das Diferenças Finitas).

- FTCS - Foward in Time Central Space (Progressivo no tempo centrado no espaço).

- GPIO - General Purpose Input/Output (Entradas e saídas de propósito geral).

- GPL - General Public License.

- HDMI - High-Definition Multimedia Interface (Interface de multimídia de alta definição).

- IBGE - Instituto Brasileiro de Geografia e Estatística.

- IDE - Integrated Development Environment (Ambiente de desenvolvimento integrado).

- IoT - Internet of Things (Internet das Coisas).

- LCD - Liquid Crystal Display (Display de cristal líquido).

- MIT - Massachusetts Institute of Technology.

- PCB - Printed Circuit Board (Placa de circuito impresso).

- PIB - Produto Interno Bruto.

- PID - Parcial, Integral e Derivativo.

- PWM - Pulse Width Modulation (Modulação de Largura de Pulso) 
- RAM - Random Access Memory (Memória de acesso aleatório).

- RISC - Reduced Instruction Set Computer - Computador com um conjunto reduzido de instruções.

- SBC - Single Board Computer (Computador em placa única).

- SO - Sistema Operacional.

- SOR - Successive Over-Relaxation (Super Relaxações Sucessivas).

- SQL - Structured Query Language (Linguagem de consulta estruturada).

- SSL - Secure Socket Layer (Camada de conexão segura).

- UART - Universal Asynchronous Receiver/Transmitter (Receptor e transmissor assíncrono universal). 


\section{SÍMBOLOS}

- $\mathrm{G}=\mathrm{x} 10^{6}$, Giga.

- $\mathrm{W}=$ watt, unidade de potência (Joules/segundo).

- $\mathrm{s}=$ segundos.

- $\mathrm{T}=$ temperatura

- $\mathrm{t}=$ tempo.

- $\mathrm{V}=$ Volts, unidade de medida para potencial elétrico. 


\section{SUMÁRIO}

Agradecimentos . . . . . . . . . . . . . . 3

Resumo . . . . . . . . . . . . . . . 5

Abstract $\ldots \ldots \ldots \ldots \ldots \ldots \ldots \ldots$

Lista de ilustrações . . . . . . . . . . . . . . . . 8

Lista de tabelas . . . . . . . . . . . . . . . 12

Siglas . . . . . . . . . . . . . . . . . . . 13

Símbolos . . . . . . . . . . . . . . . 15

Sumário . . . . . . . . . . . . . . . 16

$1 \quad$ INTRODUÇÃO $\ldots \ldots \ldots \ldots \ldots \ldots$

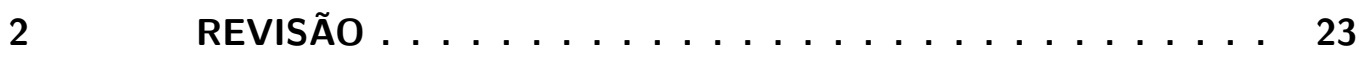

$2.1 \quad$ Panorama da tecnologia na indústria de alimentos . . . . . 23

2.2 Controle e automação na indústria de alimentos . . . . . . 25

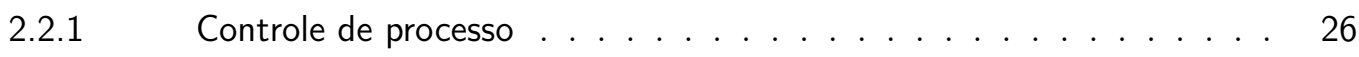

2.2.2 Controle PID - Proporcional Integral e Derivativo . . . . . . . . . 28

$2.2 .3 \quad$ Automação . . . . . . . . . . . . . . . . 32

2.3 Modelagem matemática e simulação aplicada à indústria de alimentos ......................... 33

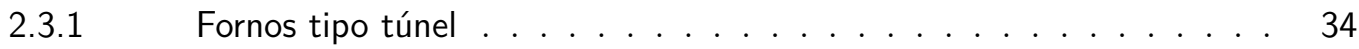

2.3.2 Processos forneamento . . . . . . . . . . . . 35

2.3.2.1 Transferência de calor no alimento . . . . . . . . . . . . 36 
2.3.2.2 Modelo matemático da condução de calor no alimento . . . . . . . . . . 37

2.3.3 Método das diferenças finitas aplicados à transferência de calor . . . . 40

2.3.3.1 Regime permanente ..................... 41

2.3.3.2 Regime não-permanente . . . . . . . . . . . . . . . . . 43

2.4 Sistemas embarcados em controle de processos . . . . . . . . . 44

2.4.1 Microcontroladores ..................... 46

2.4.1.1 Plataforma Arduino . . . . . . . . . . . . . . . . . . . . . 46

2.4.2 Computadores em placa única . . . . . . . . . . . . . . . . . . . . . 49

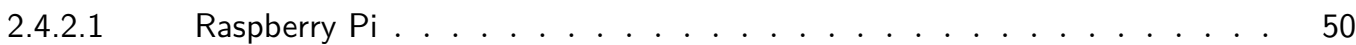

2.4.2.2 Internet das coisas . . . . . . . . . . . . . . . . . . 52

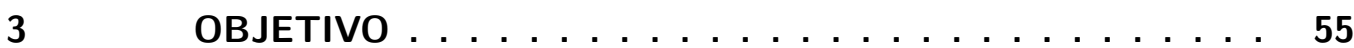

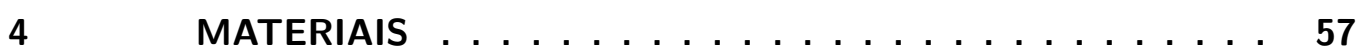

4.1 Forno tipo túnel em escala piloto . . . . . . . . . . . . . . . . . 57

4.1.1 Funcionamento do forno . . . . . . . . . . . . . . . . 57

4.1.2 Instrumentação para captura de dados e controle dos atuadores . . . 60

4.2 Sistema de Controle . . . . . . . . . . . . . . . . . . . . . . 62

4.2.1 Unidade escrava ..................... . . 63

4.2.1.1 Hardware ...................... 63

4.2.1.2 Protocolo de comunicação . . . . . . . . . . . . . . . . . . . . . . 64

4.2.1.3 Software ...................... . . 67

4.2.2 Unidade mestre . . . . . . . . . . . . . . . . . . 67

4.2.1 Hardware ........................ 68

4.2.2.2 Software ....................... 68

4.2.2.1 Persistência de dados . . . . . . . . . . . . . . . . . . . . . . . . . . . 70

$4.3 \quad$ Controle do processo . . . . . . . . . . . . . . . . . 71

4.3.1 Software controle PID . . . . . . . . . . . . . . . 71

4.3.2 Resposta no tempo ...................... 71 
4.3.3 Otimização dos parâmetros de controle . . . . . . . . . . . . . . 72

$4.4 \quad$ Simulação Numérica . . . . . . . . . . . . . . . . . 72

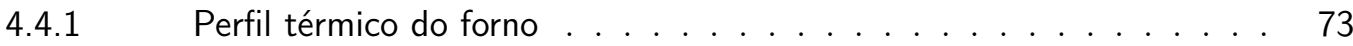

4.4.2 Perfil térmico do alimento . . . . . . . . . . . . 74

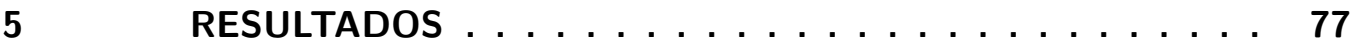

$5.1 \quad$ Simulação numérica $\ldots \ldots \ldots 77$

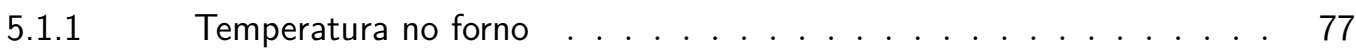

5.1.2 Temperatura no alimento . . . . . . . . . . . . . . 81

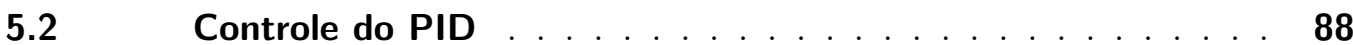

5.2.1 Controle por modulação de largura de pulso (PWM) . . . . . . . 88

5.2.2 Modelo da resposta potência-tempo-temperatura do forno . . . . . . 90

5.2.2.1 Controles e zonas de aquecimento . . . . . . . . . . . . . . . . 90 90

5.2.2.2 Determinação do modelo de resposta no tempo . . . . . . . . . . . . 92

5.2.3 Ajustes do controlador . . . . . . . . . . . . . . . . 97

5.2.3.1 Determinação dos parâmetros do controlador . . . . . . . . . . . . . . 97

5.2.3.2 Resultados do controlador . . . . . . . . . . . . . . . . . . . . . 101

$5.3 \quad$ Sistema de controle - escravo . . . . . . . . . . 103

5.3.1 Placa de controle . . . . . . . . . . . . . . . . 103

5.3.2 Software de controle . . . . . . . . . . . . . . . . 105

$5.4 \quad$ Sistema de Controle - mestre . . . . . . . . . . . 106

5.4.1 Controle manual . . . . . . . . . . . . . . . 108

5.4.2 Configurações . . . . . . . . . . . . . . . . . . . . 109

5.4.3 Armazenamento dos dados . . . . . . . . . . . . . . . . 110

5.4.4 Visualização dos dados . . . . . . . . . . . . . . . . . . . 112

$5.4 .5 \quad$ Controle automático . . . . . . . . . . . . . . . . . . . 114

5.4.5.1 Potência do forno $x$ tempo . . . . . . . . . . . . . . . . 114

5.4.5.2 Temperatura no forno $X$ tempo f . . . . . . . . . . . . . 114

5.4.5.3 Temperatura no alimento . . . . . . . . . . . . . . . 115 


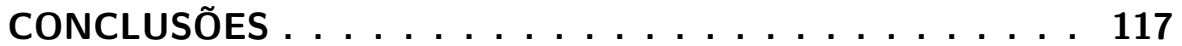

7 CONSIDERAÇÕES FINAIS . . . . . . . . . . . . . . . . . 119

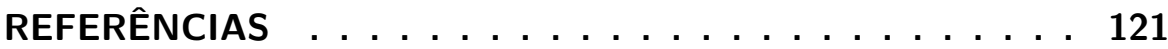

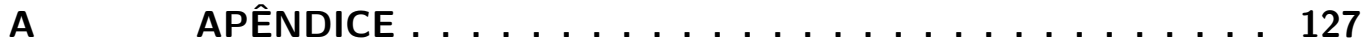

A.1 Diagrama Placa de controle . . . . . . . . . . . . . . . . 127

A.2 Controle PID . . . . . . . . . . . . . . . . . . . . 129

A.2.1 Controlador . . . . . . . . . . . . . . . . . . . . . . . 129

A.2.2 Modelo-resposta . . . . . . . . . . . . . . . . . . . . 130

A.3 Diferenças Finitas 1D Forno - Python . . . . . . . . . . . . . 131

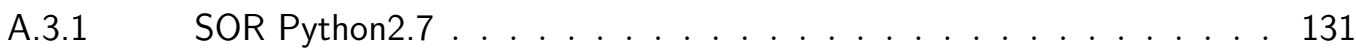

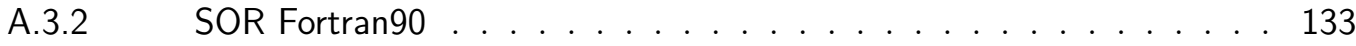

A.3.3 Análise de malha . . . . . . . . . . . . . . . . . . . . 134

A.3.4 Gráfico e imagem do forno . . . . . . . . . . . . . . . 135

A.4 Diferenças Finitas Cilindrica Alimento . . . . . . . . . . . . 136

A.4.1 Python $2.7 \ldots \ldots \ldots \ldots \ldots \ldots$

A.4.2 Fortran $-f 90 \ldots \ldots \ldots 138$ 



\section{INTRODUÇÃO}

No Brasil, a indústria de alimentos e bebidas é responsável por aproximadamente 9,5\% do Produto Interno Bruto (PIB). Além de empregar 1,63 milhão de pessoas, esta área manteve crescimento estável nos últimos 10 anos (IBGE, 2013). Nos períodos de desaceleração ou crise econômica este é um dos setores que é menos afetado visto que os cortes de consumo começam por produtos supérfluos e não por alimentos, e de fato em 2015 e 2016 houve um crescimento no ramo alimentício (FGV, 2016). O Agronegócio apresentou uma balança comercial com superávit de US\$ 5,6 bilhões em novembro de 2016 (FIESP, 2016), fazendo deste setor um ponto estratégico de investimento tecnológico. Este investimento é necessário também em virtude da mudança no padrão de consumo do brasileiro nas últimas décadas, que está migrando de produtos in natura para processados, que passaram de 56\% em 1980 para $70 \%$ em 1990 e 85\% em 2013 (ABIA, 2013).

O investimento em tecnologia para a produção de produtos processados, além de atender às novas demandas do mercado interno com produtos mais saudáveis, bemestar e comidas de preparo rápido, pode agregar valor ao alimento exportado, já que o lucro com produtos processados é muito maior do que com insumos brutos. No entanto, apesar de possuir um grande parque industrial alimentício, o Brasil ainda possui carências no setor tecnológico que dá suporte à indústria. A maioria das empresas de grande porte que atuam no Brasil importam seus equipamentos mais sofisticados ou possuem seus setores de desenvolvimento tecnológico fora do país (QUEIROZ, 2011).

De acordo com Ruiz, Britto e Souza (2014), no Brasil a área tecnológica aplicada a inovação industrial ainda é pouco desenvolvida e, então, as grandes empresas muitas vezes buscam assistência tecnológica fora do país, diminuindo os lucros do setor e gerando no Brasil apenas a mão de obra barata, contribuindo para o crescimento 
de uma indústria de caráter regressivo. Na indústria de alimentos, a automação da produção e processamento melhorou muito nas últimas duas décadas devido às tecnologias de controle, integrando dispositivos eletrônicos aos sensores e atuadores.

No entanto, os sistemas de automação industrial no Brasil não têm acompanhado tal evolução e ainda são muito caros e de difícil uso, além de serem todos de tecnologia importada e fechada. Neste cenário, a utilização de computadores em placa única SBC (Single Board Computer) para controle de processos industriais de pequeno e médio porte podem ser uma solução viável e de baixo custo.

Neste trabalho foi desenvolvido um software e hardware de controle e simulação em tempo real utilizando um sistema embarcado de hardware projetado para um forno tipo túnel em escala piloto para produção de biscoitos, com o objetivo de testar a seguinte hipótese:

"É possivel o controle e automação de um forno em escala piloto para processamento de alimentos com informações de sensores e simulação computacional em tempo real utilizando computação embarcada de baixo custo" 


\section{REVISÃO}

Revisão bibliográfica e fundamentação teórica.

\subsection{PANORAMA DA TECNOLOGIA NA INDÚSTRIA DE ALI- MENTOS}

O desenvolvimento tecnológico mundial da indústria alimentícia foi enorme nas últimas duas décadas. Foram feitos progressos e descobertas em todas as etapas, começando pelo plantio, passando pelo processamento até o armazenamento (SAGUY et al., 2013). No entanto, no Brasil também é necessário que as novas tecnologias de produção estejam mais acessíveis às pequenas empresas, dando a elas o suporte para que possam ser mais eficientes e entregar um produto de maior qualidade de forma competitiva. O estudo de novos sensores, equipamentos e métodos na produção de alimentos é o desafio para o futuro, já que será necessário atender uma população cada vez maior, que também tem se tornado exigente quanto ao produto que consome.

Integrar sensores e atuadores para controlar de forma automática o processamento de um produto sempre foi um dos principais focos dos setores de Pesquisa e Desenvolvimento (P\&D) das indústrias de alimentos. De acordo com (JÄMSÄJOUNELA, 2011), a importância da automação nos processos industriais aumentou dramaticamente nas últimas décadas, melhorando a qualidade e segurança dos produtos, reduzindo os custos de produção, gastos energéticos e emissão de poluentes. A utilização de modelos matemáticos e simulações integradas ao controle e automação cresceu notavelmente nos últimos 10 anos, principalmente devido ao aumento do poder computacional dos dispositivos eletrônicos, melhorando consideravelmente a automação industrial.

Padronizar a produção é o principal mecanismo para garantir a boa percepção 
dos clientes em relação aos produtos, especialmente na indústria de alimentos. A diminuição na variabilidade dos processos somente pode ser promovida com o estabelecimento de rotinas de produção que permitam a aquisição de informações e tratamento das mesmas, resultando em um controle que aumenta a eficiência da produção de forma que seja possível fornecer produtos com padrão de qualidade e evitar desperdícios na produção (HALEY; MULVANEY, 1995).

Para a produção e processamento de alimentos forneados, a etapa que apresenta mais perdas e problemas de controle é o aquecimento forçado, principalmente em fornos industriais. O monitoramento do ambiente interno de um forno de produção de alimentos é fundamental para padronizar algumas características importantes do alimento como a atividade de água, textura, coloração, crocância entre outros, além de evitar o desperdício energético. O perfil tempo-temperatura de exposição de um alimento ao processo de cozimento é um dos principais fatores que alteram tais características e portanto, é essencial o desenvolvimento de ferramentas e dispositivos eletrônicos que auxiliem no controle térmico.

A importância das técnicas de controle e automação aplicadas a qualquer processo industrial cresceu drasticamente nos últimos 20 anos, sendo atualmente indispensáveis para garantir a qualidade e segurança dos produtos e torná-los competitivos no mercado internacional. Apesar desta importância global, os investimentos são concentrados nos países mais desenvolvidos e em alguns países asiáticos, sendo toda a América do Sul responsável por apenas 4,9 \% dos investimentos tecnológicos em 2010 (JÄMSÄ-JOUNELA, 2011).

De forma geral, na indústria de alimentos, o desenvolvimento tecnológico busca garantir um padrão de qualidade nos produtos, produzindo da forma mais eficiente e controlada possível. Para que isto possa ocorrer, os conceitos de controle, automação, modelagem e simulação devem estar integrados à indústria de alimentos, constituindo uma das principais áreas de pesquisa da Engenharia de Alimentos.

Na indústria de alimentos, os processos envolvem a manipulação de insumos que 
terão suas propriedades físicas e químicas alteradas na linha de produção. Para controlar estas propriedades, o uso de sistemas de controle automatizados que respondam em tempo real (baseado no conhecimento das propriedades e características físicas do sistema bem como dos dados da linha de produção) garante uma melhora na qualidade do produto, segurança alimentar, menos desperdício de produtos, maior produção e segurança para os trabalhadores.

Para que isto possa ocorrer, é necessário implementar um sistema de controle e automação especificamente desenhado para o processo em questão, levando em consideração um modelo matemático do processo e a utilização de sensores e sistemas de medidas em tempo real, dando mais confiabilidade ao sistemas.

\subsection{CONTROLE E AUTOMAÇÃO NA INDÚSTRIA DE ALI- MENTOS}

A implantação de um processo de controle e automação industrial tem como objetivos gerais aumentar a produtividade, reduzir as perdas e aumentar a padronização dos produtos finais. No entanto, na indústria alimentícia, o controle do processamento de alimentos tem algumas particularidades que a diferenciam das demais áreas. Segundo (TRYSTRAM, 1994), as necessidades específicas que a indústria de alimentos deve considerar são:

- Aumento na higiene do processo de produção;

- Diminuição dos efeitos da variabilidade natural intrínseca dos produtos alimentícios;

- Diminuição dos efeitos perecíveis atribuídos a manipulação industrial;

- Garantia das propriedades sensoriais do produto final, garantindo a padronização e qualidade; 


\subsubsection{CONTROLE DE PROCESSO}

Monitorar parâmetros físicos e químicos por meio de sensores e utilizar instrumentação eletrônica para que os dados coletados possam ser interpretados e tratados são os passos iniciais na implantação de um sistema de controle. Na indústria de alimentos, os parâmetros mais comuns que necessitam de monitoramento são a temperatura, umidade, $\mathrm{pH}$, pressão, massa, volume, cor, forma, composição e geometria. Portanto, são necessários sensores adequados para medir estes arâmetros, de forma que estes sejam inócuos ao alimento, suportem as adversas condições do processo (temperatura, pressão, etc), possuam uma baixa resposta no tempo em comparação com o tempo do processo e sejam confiáveis (SELMAN, 1990).

Uma vez escolhidos os sensores e instrumentação adequados, é delineado o sistema de controle. Ainda segundo Selman (1990), controle é mais um problema estratégico do que um problema de hardware ou software e ele está na intersecção entre a instrumentação, métodos de produção, automação e aspectos bioquímicos do alimento. Por isto, o sistema de controle deve ser feito levando em consideração o ponto de vista de três áreas de engenharia: a Engenharia de Alimentos, a Engenharia de Processo e a Engenharia de Controle.

Os processos industriais, do ponto de vista do produto, podem ser separados em regime de operação de fluxo contínuo e batelada. Na indústria de alimentos, devido à especificidade de algumas etapas como esterilização, descanso, fermentação e cozimento, a realidade é mais complexa e na maioria das vezes, o que existe é um combinado de processos contínuos e batelada (TRYSTRAM, 1994).

O controle de processos térmicos em alimentos geralmente consiste em manter condições de operações específicas que já foram pré-determinadas e que garantam que as exigências de saúde alimentar sejam satisfeitas. Caso não haja um sistema de controle, quando ocorre algum desvio no processo e as condições de operação não são garantidas, é necessário corrigir o processo alterando o tempo para compensar, fazendo com que sejam gerados produtos fora da especificação sensorial (SIMPSON 
A. TEIXEIRA, 2006). Sistemas inteligentes buscam alterar as condições de controle em tempo real para garantir que o alimento passe pelas condições pré-determinadas mesmo com perturbações externas.

O objetivo do controle envolve atingir e manter os valores de referência para as variáveis de importância (sendo a principal a temperatura no alimento) por meio de manipulação dos atuadores como a potência das resistências, controle da combustão, micro-ondas, fluxo de ar forçado ou outro método de acordo com o sistema de aquecimento. Este tipo de controle, onde a atuação é calculada de acordo com os valores recebidos pelos sensores é chamada de malha de controle retroalimentada por feedback ou também malha fechada. Controles mais simples, como o de malha aberta não levam em consideração as informações dos sensores e agem de forma predeterminada (HALEY; MULVANEY, 1995), sendo que ambos são encontrados na indústria de alimentos, um por sua eficiência e outro pela simplicidade.

No controle de malha fechada, que é ilustrado na Figura 1, as leituras dos sensores são utilizadas como informação para se calcular a resposta dos atuadores. Estes alteram o sistema, e esta alteração pode ser medida pelos sensores novamente, sendo que este processo será repetido continuamente.

Figura 1 - Diagrama mostrando o sistema de controle de malha fechada.

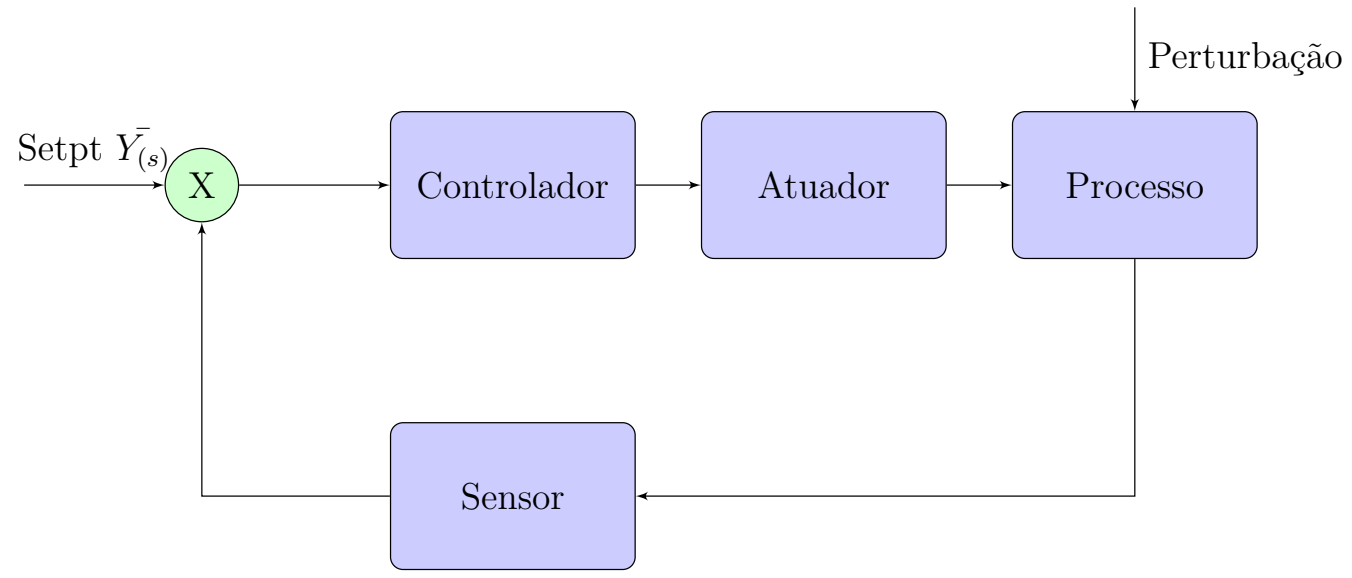

Fonte: Própria autoria. 
Um outro modelo de controle, que contrasta com o feedback, é o método de controle feedfoward, onde a perturbação que é introduzida no processo (ver Figura 1) é mensurada e as informações são enviadas diretamente ao controlador, de forma que este possa tomar as ações corretivas antes que o processo seja afetado. Tal tipo de controle é mais comum em processos de resposta temporal curta e altamente instáveis e por isto não é comumente encontrado na indústria de alimentos.

O controlador (Figura 1) deverá atuar de forma a levar e manter o sistema no valor desejado para a variável objetivo (que é chamada de setpoint). Para isto, este controlador deverá possuir o algoritmo adequado, sendo que este depende de como o sistema responde as perturbações no tempo, ou seja, qual é o modelo de resposta temporal do mesmo. Existem vários algoritmos e métodos de controle, porém um que se destaca pela sua simplicidade e eficiência é o controle PID.

\subsubsection{CONTROLE PID - PROPORCIONAL INTEGRAL E DERIVATIVO}

Num sistema de malha fechada, o controlador deve receber os dados dos sensores e o setpoint e deverá calcular como o atuador irá agir, de forma a atingir e manter o estado objetivo (OGATA; MAYA; LEONARDI, 2003). Existem várias formas de realizar este cálculo, desde um simples sistema ON/OFF que liga ou desliga o atuador baseado na diferença entre a leitura do sensor e o setpoint, controle PID, até mecanismos complexos, envolvento lógica fuzzy, redes neurais artificais, algoritmos evolutivos, filtro kalman entre outros. O controle Proporcional Integral e Derivativo (PID) é a estratégia de controle em malha fechada mais utilizada na indústria. Segundo Knospe (2006), estima-se que mais de 90\% dos controles em loop fechado utilizem alguma variante do controle PID, e na indústria química, este valor é de $97 \%$ (DESBOROUGH; MILLER; NORDH, 2000).

Este controle foi desenvolvido antes dos sistemas digitais, com a primeira análise matemática publicada por Minorsky (1922) e posteriormente implantada com sucesso pela primeira vez para controlar automaticamente a direção de navios da marinha 
americana na década de 1930 (BENNETT, 1986).

Na equação 2.2 temos o formato geral da resposta do controlador PID, dando a resposta $u(t)$ em função do erro obtido pela equação 2.1 .

$$
\begin{gathered}
e(t)=o b j(t)-y(t) \\
u(t)=K_{P} \cdot e(t)+K_{I} \int_{0}^{t} e(t) d t+K_{D} \frac{d}{d t} e(t)
\end{gathered}
$$

em que $e(t)$ representa o erro em um dado instante $t$, que é a diferença entre o valor desejado $o b j(t)$ e o valor atual no sistema fornecido pelos sensores $y(t)$. Na equação 2.2 , os parâmetros $K_{P}, K_{I}$ e $K_{D}$ são constantes pré-estabelecidas do controle. Alterações nestes parâmetros modificam o caráter do controle e a resposta $u(t)$ que é passada ao atuador.

Utilizando como exemplo um forno elétrico simples com controlador PID, que contém apenas um sensor de temperatura, uma resistência e um botão de ajuste de temperatura, o objetivo ou setpoint (obj(t) na Equação 2.1) seria o valor da temperatura escolhido pelo usuário no ajuste de temperatura. A variável $u(t)$ na Equação 2.2 seria a potência da resistência e $y(t)$ o valor da temperatura registrado pelo sensor. Em cada instante de tempo $t$, o valor da temperatura é lida, comparada com o setpoint (diferença entre o objetivo e o valor real) e o controlador PID é acionado para calcular a potência da resistência.

O termo proporcional, $K_{P}$, dá uma resposta ao sistema que é diretamente proporcional ao erro. Quando um controle é apenas Proporcional, com $K_{I}=0$ e $K_{D}=0$, o controle falha em atingir o objetivo no regime contínuo $(t \rightarrow \infty)$ para um valor pequeno $K_{P}$, já que $u(t)$ diminui quando $e(t)$ diminui. Portanto, este tipo de controle é efetivo quando o valor real está longe do setpoint porém não atua de forma suficiente quando o objetivo está próximo, levando a um offset no regime contínuo. Ao aumentar o valor de $K_{P}$ aumenta-se o valor de $u(t)$, podendo saturar a saída para 
o atuador, caso em que o controle terá o mesmo efeito de um controle ON/OFF.

(Figura 2).

Figura 2 - Resposta no tempo de um controlador proporcional em um sistema de segunda ordem com função de transferência $G(s)=\frac{1}{s^{2}+3 \cdot s+1}$ em função de três diferentes valores do parâmetro $K_{p}$ e com $K_{i}=0$ e $K_{d}=0$.

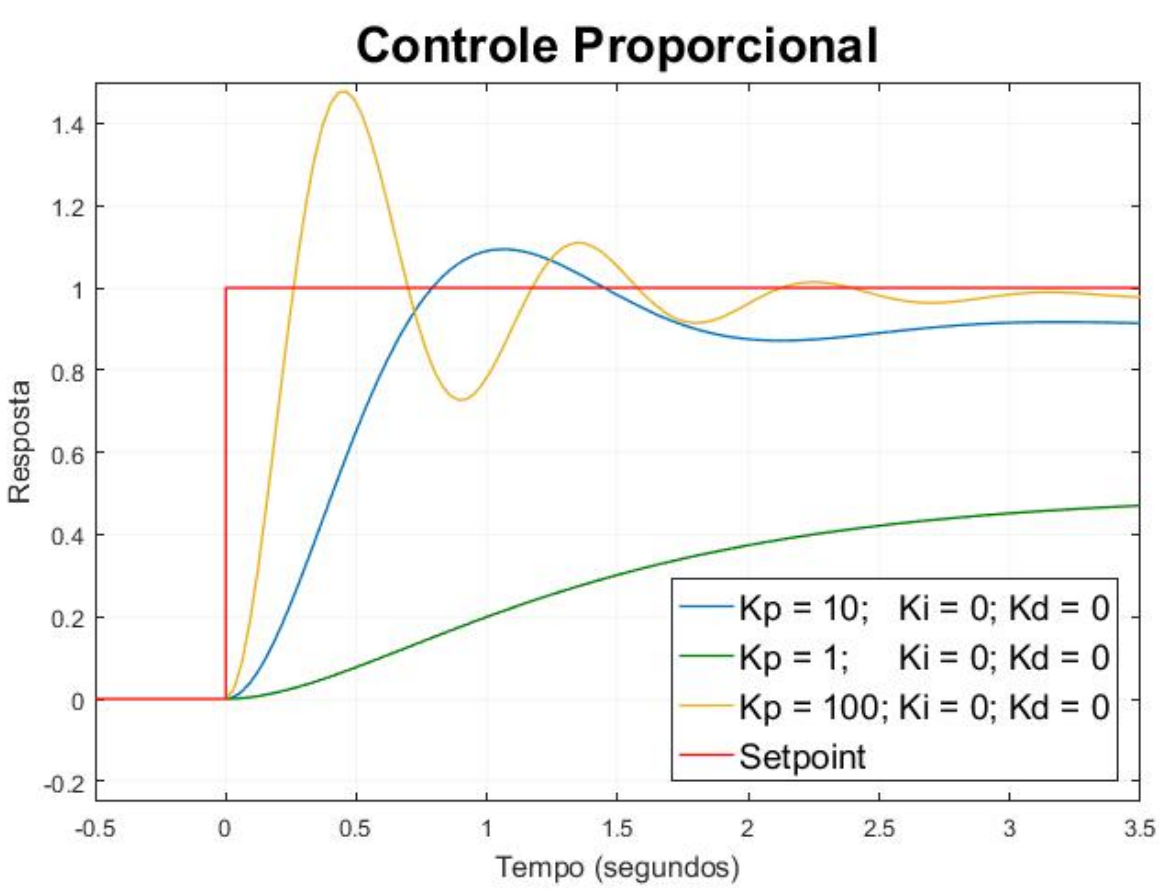

Fonte: Própria autoria.

Os estados anteriores do controle (passado) não tem influência num controle apenas proporcional, o que aponta para suas limitações em alguns casos. Quando $K_{I}$ é diferente de zero, o controle possui uma componente integral $\left(K_{I} \int_{0}^{t} e(t) d t\right.$ na Equação 2.2) e portanto este termo dependerá dos estados anteriores, ou seja, quanto e por quanto tempo foi o erro (Equação 2.1). A componente integral ajuda a eliminar o erro estático (offset), pois mesmo quando o valor atual se aproxima do setpoint, a componente integral não tende a zero como a componente Proporcional (Figura 3).

O termo Derivativo responde em função da variação do erro $e(t)$ no tempo. Por isto, ele prevê a posição futura de $e(t)$ e com isto diminui a oscilação e portanto o tempo que o sistema demora para chegar ao estado estacionário. Por este motivo, o 
Figura 3 - Resposta no tempo de um controlador proporcional em um sistema de segunda ordem com função de transferência $G(s)=\frac{1}{s^{2}+3 \cdot s+1}$ em função de três diferentes valores do parâmetro $K_{i}$ e com $K_{p}=1$ e $K_{d}=0$.

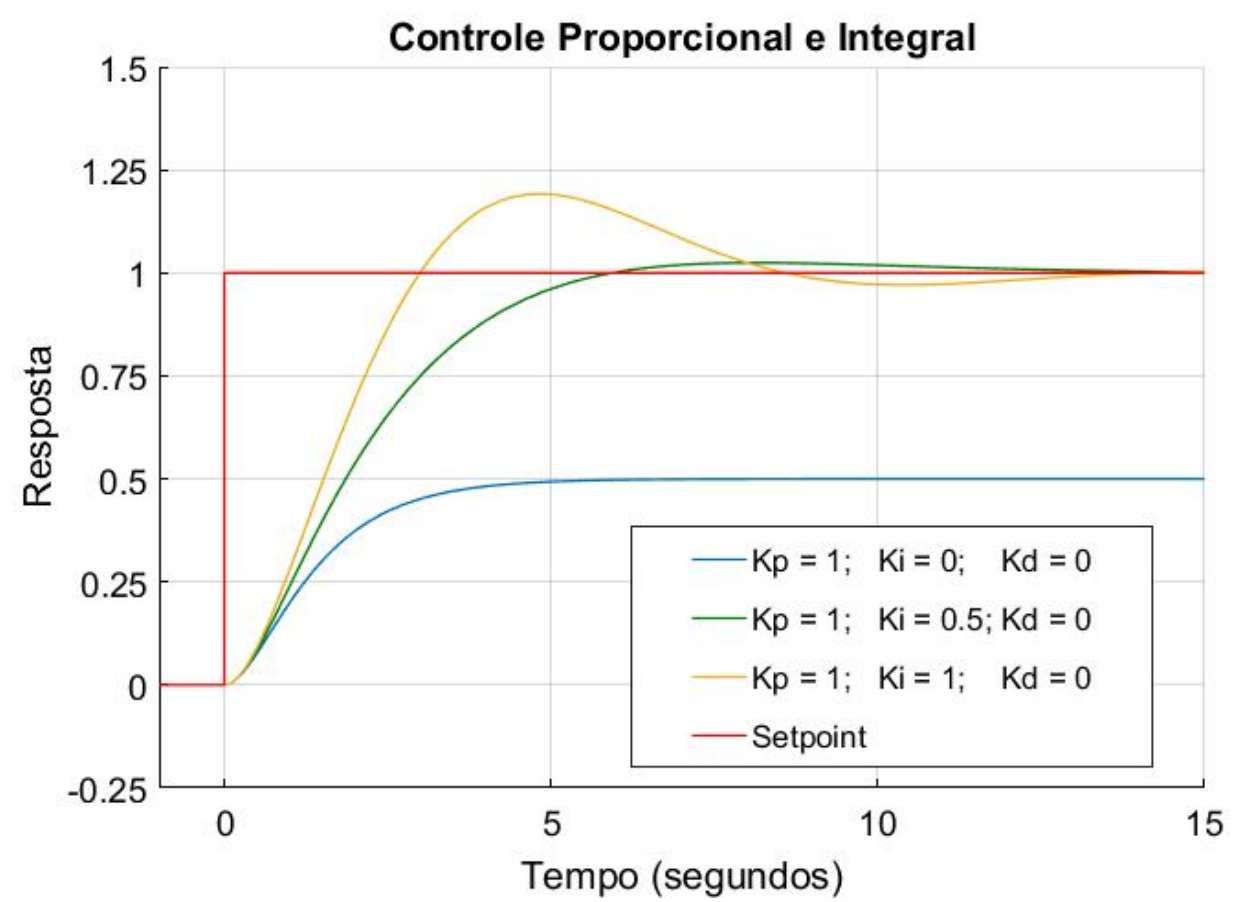

Fonte: Própria autoria.

controle Derivativo é aplicado utilizando valores não altos para $K_{d}$ e com algum tipo de filtro (via software ou hardware) para minimizar o ruído. Além disso, este controle também é aplicado em conjunto com o Proporcional e Integral (controle PID).

Para que o controle PID funcione de forma eficiente é necessário que os parâmetros $K_{p}, K_{i}$ e $K_{d}$ utilizados sejam os melhores possíveis, para evitar os problemas descritos acima e alcançar o setpoint o mais rápido possível com estabilidade. Este procedimento é chamado de sintonia ou tunning e apesar de existirem apenas 3 parâmetros a serem descobertos, sem um conhecimento do tipo de resposta impulsiva do sistema e suas características é difícil encontrar em qual intervalo se encontram os parâmetros para começar a sintonia. Na Figura 4 é apresentado um exemplo de controle PID com diferentes ajustes e a consequência no controle.

Existem diferentes métodos que vão do mais simples como a sintonia manual até 
Figura 4 - Resposta no tempo de um controlador proporcional Integral e Derivativo em um sistema de segunda ordem com função de transferência $G(s)=$ $\frac{1}{s^{2}+3 \cdot s+1}$ com três diferentes valores dos parâmetros $K_{p}, K_{i}$ e $K_{d}$.

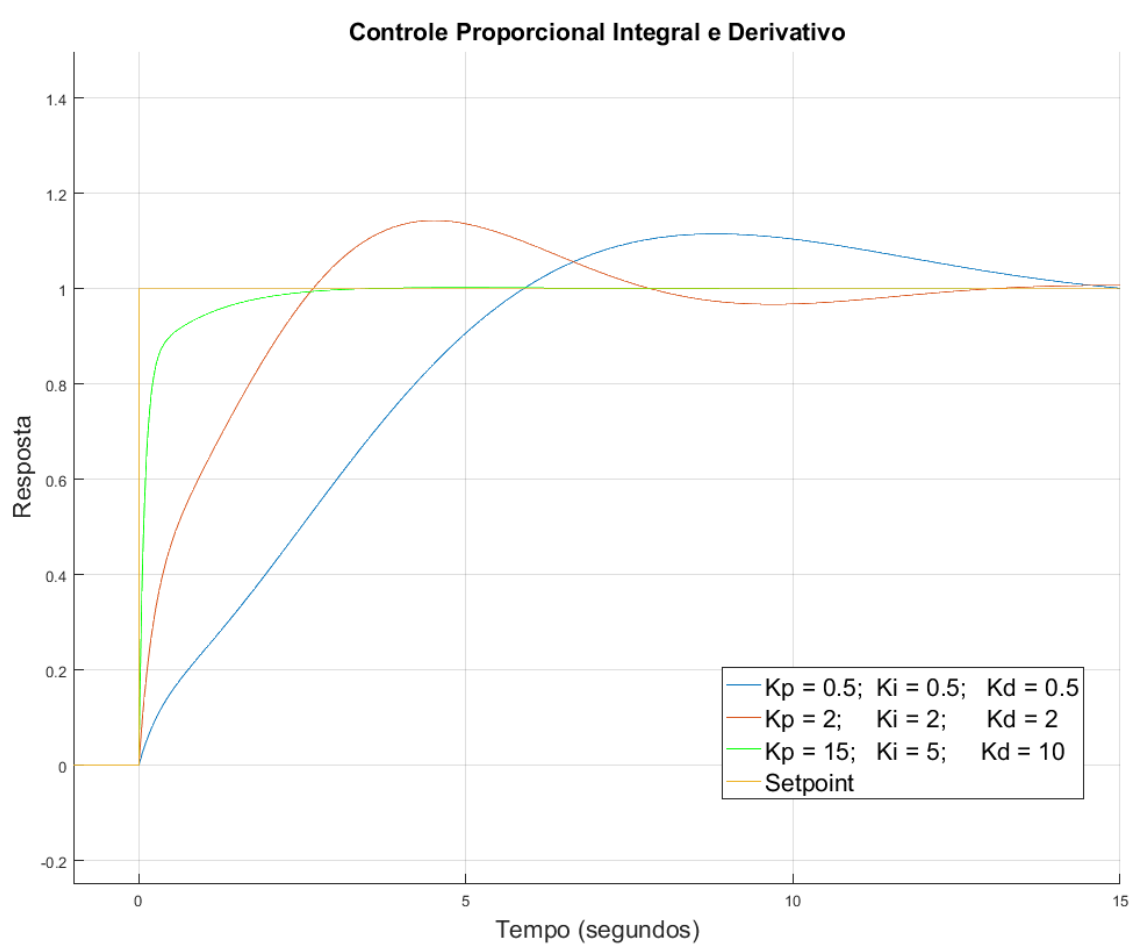

Fonte: Própria autoria.

sistemas automatizados com uso de aprendizado de máquina, sendo um dos mais utilizados na indústria o método de Ziegler-Nichols, o método de Cohen-Coon e o método manual (TEMEL SEMIH YAGLI, 2013).

\subsubsection{AUTOMAÇÃO}

Para que os conceitos de controle discutidos previamente possam funcionar em tempo real, as ações devem ser tomadas automaticamente pelo sistema. Portanto a automação é muito mais que uma forma de reduzir o número de trabalhadores braçais. Segundo Selman (1990), os objetivos particulares da indústria de alimentos para a utilização de automação são: 
- Qualidade e Confiabilidade;

- Segurança do Alimento;

- Flexibilidade e Manutenção;

- Aquisição de dados;

A qualidade, a confiabilidade e a segurança do alimento já foram discutidas nos benefícios do controle de processo (seção 2.2.1). A flexibilidade e a manutenção são facilitados pela automação, pois numa planta de produção de alimentos, muitos produtos dividem os mesmos equipamentos, portanto a vantagem está em alterar facilmente o sistema para a produção de vários produtos (ILYUKHIN; HALEY; SINGH, 2001).

A aquisição de dados ajuda a melhorar o sistema, observando as respostas dos atuadores em várias circunstâncias e verificando os pontos que podem ser aprimorados. O monitoramento dos dados pode servir também como uma forma de alerta para evitar problemas na produção.

\subsection{MODELAGEM MATEMÁTICA E SIMULAÇÃO APLICADA À INDÚSTRIA DE ALIMENTOS}

A modelagem matemática é a descrição de um sistema real por meio de equações matemáticas, de forma que, por meio destas equações possam ser entendidos os efeitos de diferentes componentes do sistema bem como prever o comportamento deste diante de diferentes cenários. A modelagem matemática é a base das ciências naturais, das ciências sociais e da engenharia, já que modelos podem ser testados, sendo validados ou refutados, passando assim pelo crivo do método científico. Do ponto de vista da Engenharia, o objetivo é analisar e otimizar sistemas, sendo que a descrição matemática dos mesmos possibilita que testes sejam feitos por meio de simulações, economizando tempo e dinheiro.

Na indústria de alimentos, os principais sistemas específicos a serem modelados são 
os relacionados à segurança do alimento, como crescimento bacteriano (MCCLURE et al., 1994), os processos de contaminação (LAU; WONG, 2000) e o processo de aquecimento/cozimento de alimentos (NICOLAS et al., 2014). Conhecer a fundo os processos térmicos envolvidos na produção de alimentos é essencial, já que estes representam um alto gasto energético e pequenas alterações no perfil de temperatura do alimento podem implicar em grandes mudanças sensoriais e perda do produto (GULATI; DATTA, 2013).

Como o perfil de temperatura adequado é necessário para a qualidade do produto final, muitos estudos tem sido realizados com o intuito de modelar o processo dos sistemas de aquecimento e os processos que ocorrem no alimento.

\subsubsection{FORNOS TIPO TÚNEL}

Existem vários sistemas e métodos para realizar o tratamento térmico necessário no processamento de alimentos, sendo que $95 \%$ dos processos industriais utilizam pelo menos um tipo de forno (CORPORATION, 1991). Os tipos de forno variam de acordo com o mecanismo de aquecimento, formato e maneira de operação. Dos mecanismos de aquecimento, os mais utilizados são a combustão a gás (propano, butano ou outra mistura) e resistência elétrica, representando $50 \%$ e $40 \%$ do uso industrial respectivamente (FISHER TODD BELL, 2002). Quanto ao tipo, existe uma enorme variedade nos tipos de fornos, porém para processos contínuos em alta velocidade o que mais se destaca é o forno tipo túnel (CORPORATION, 1991).

Os fornos tipo túnel estão disponíveis em diferentes tamanhos e configurações, de acordo com o perfil térmico e quantidade de alimento que precisam processar. Este tipo de forno possui uma cavidade ou câmara que é aberta nos dois lados (entrada e saída) e algum tipo de esteira que conduz o alimento de um lado ao outro. O aquecimento é normalmente feito por gás ou resistência elétrica nas partes superior e inferior, havendo controle independente em áreas diferentes do forno (zonas) para possibilitar diferentes temperaturas simultaneamente em posições diferentes (FISHER 
TODD BELL, 2002). Alguns fornos deste tipo utilizam fluxo forçado de ar aquecido para aumentar a transferência de temperatura ao alimento via convecção. O fluxo de ar também pode ser utilizado para controlar o perfil térmico através de estanques que garantem a diferença de temperatura em zonas distintas (CORPORATION, 1991).

Vários trabalhos foram realizados visando a otimização no processo de aquecimento em fornos tipo túnel. Zanoni, Pierucci e Peri (1994), estudaram o processo interno de assamento levando em consideração o transporte de calor e de massa que ocorre no interior do forno e dentro do alimento. O aquecimento do forno também foi abordado por Nicolas et al. (2014), que estudaram os processos de transferência de calor e massa que ocorrem dentro de um forno linear tipo esteira com áreas de aquecimento inferior e superior e zonas de exaustão de ar. Tal tipo de forno é o mais comum na produção de pães e biscoitos, e por este motivo este tipo de estudo ajudou a projetar fornos mais eficientes e que garantem o perfil de temperatura de forma mais adequada. Ainda em fornos tipo esteira, Illés Balázs (2014) estudou a velocidade do gás e o processo de convecção e Boulet et al. (2010) realizaram simulações utilizando dinâmica de fluido computacional (CFD) para resolver as equações do processo térmico dentro do forno.

\subsubsection{PROCESSOS FORNEAMENTO}

Quando um alimento é forneado (assado), uma série de mudanças físicas, químicas

e bioquímicas ocorrem no alimento. Modelar e otimizar os processos que ocorrem no assamento é fundamental na industria, para se alcançar eficiência energética e qualidade do produto (VRIES; SLUIMER; BLOKSMA, 1989; HAYAKAWA; HWANG, 1981). O modelo matemático permite quantificar as interações entre o produto e o ambiente do forno e as mudanças no produto assado (SAKIN; KAYMAK-ERTEKIN; ILICALI, 2007).

Estudos do modelo de assamento variam conforme o alimento mas em geral envolvem um processo simultâneo de transferência de calor e transferência de massa (ÖZIL- 
GEN; HEIL, 1994; VRIES; SLUIMER; BLOKSMA, 1989; HAYAKAWA; HWANG, 1981; KAISER, 1974; HAYAKAWA; HWANG, 1981).

O aquecimento do alimento aciona uma série de alterações físicas e químicas que levam a expansão da massa, evaporação de água, formação de poros, desnaturação de proteínas, formação de crosta entre outros (SABLANI et al., 1998). Como o processo é muito complexo e depende de muitas variáveis, os estudos e modelos desenvolvidos apresentam simplificações. Lostie et al. (2002) desenvolveram um modelo matemático do processo de assamento em termos do perfil de temperatura e umidade que ocorre em duas etapas, o aquecimento e a formação da crosta. Na primeira etapa ocorre maior mudança no perfil de temperatura e na segunda ocorre maior mudança no perfil de umidade. Este modelo também foi utilizado por Sakin, Kaymak-Ertekin e Ilicali (2007), que estudaram o assamento de cupcakes em duas etapas. A importância de cada uma das etapas varia de acordo com o tipo de alimento assado, bem como a complexidade do perfil resultante. Arogba (2001) mediu o perfil de umidade e temperatura em biscoitos finos e encontrou uma relação linear entre a umidade e a temperatura, permitindo simplificar o modelo ou seja, conhecendo-se o perfil térmico do biscoito serão conhecidas suas propriedades.

\subsubsection{Transferência de calor no alimento}

Nos fornos tipo túnel (exceto os fornos com aquecimento por micro-ondas), durante o assamento, o calor é transferido para o alimento por três processos: radiação advinda das superfícies do forno quente, por condução da superfície que está em contato com o alimento e por conveç̧ão pelo ar em volta do mesmo. Os três processos transferem energia para o alimento pela superfície, e então o calor é difundido até o centro por condução (SABLANI et al., 1998). A importância que cada um dos três processos (radiação, condução e convecção) tem no aquecimento do alimento dependem da geometria do forno, tipo de fonte de calor e funcionalidades do mesmo (fluxo de ar forçado ou não, aquecimento direto ou indireto ente outros). 
Conhecendo as condições de transferência de calor do forno para o alimento durante o tempo de assamento, é possível modelar o aquecimento do alimento como um processo de condução, supondo que a densidade $\rho$, a condutividade térmica $k_{\vec{r}}$ e o calor específico a pressão constante $C_{p}$ dependem da temperatura (AROGBA, 2001), (LOSTIE et al., 2002).

\subsubsection{Modelo matemático da condução de calor no alimento}

O processo de transferência de calor pode ser modelado aplicando um dos princípios mais básicos da Física, a conservação da Energia (E). O problema geral consiste em resolver a Equação advinda da conservação de Energia para encontrar a temperatura em todos os pontos do sistema em função do tempo, ou seja, encontrar $T(\vec{r}, t)$. Utilizando o princípio da conservação de Energia à um elemento infinitesimal de volume podemos escrever a Equação 2.3:

$$
\frac{\partial E_{\text {armazenada }}}{\partial t}=\frac{\partial E_{\text {dentro }}}{\partial t}-\frac{\partial E_{\text {fora }}}{\partial t}+\frac{\partial E_{\text {gerada }^{\prime}}}{\partial t}
$$

Onde $E_{\text {dentro }}$ e $E_{\text {fora }}$ se referem a energia para dentro e para fora do volume de controle, e $E_{\prime \text { gerada }}$ corresponde a reações químicas endotérmicas ou exotérmicas, mudança de estado ou absorção eletromagnética.

A Taxa de armazenamento de Energia no tempo $\frac{\partial E_{\text {dentro }}}{\partial t}$ que ocorre em um elemento de volume infinitesimal pode ser relacionada a temperatura por meio do Calor Específico pela Equação 2.4.

$$
\frac{\partial U}{\partial x} \cdot m=\rho \cdot c_{p} \cdot \frac{\partial T}{\partial t}
$$

Em que $U$ é a energia interna, $m$ é a massa, $\rho$ a densidade e $c_{p}$ é o calor específico à pressão constante.

A quantidade de Energia que entra menos a que sai em um elemento infinitesimal, em coordenadas cartesianas pode ser escrita utilizando a expansão em Série de Taylor 
(Equação 2.5), utilizando apenas o termo de primeira ordem.

$$
E_{\text {adicionada }}=-\left(\frac{\partial q_{x}}{\partial x} \cdot d x+\frac{\partial q_{y}}{\partial y} \cdot d y+\frac{\partial q_{z}}{\partial z} \cdot d z\right)
$$

Pela Lei de Fourier, os fluxos de calor que entram nos volumes de controle $q_{x}, q_{y}$ e $q_{z}$ podem ser escritas como

$$
\begin{aligned}
& q_{x}=-k_{x} \cdot(d y \cdot d z) \cdot \frac{\partial T}{\partial x} \\
& q_{y}=-k_{y} \cdot(d z \cdot d x) \cdot \frac{\partial T}{\partial y} \\
& q_{z}=-k_{z} \cdot(d x \cdot d y) \cdot \frac{\partial T}{\partial z}
\end{aligned}
$$

onde $k_{x}, k_{y}$ e $k_{z}$ são as constantes de condutividade térmica nos três eixos cartesianos. Substituindo a Equação 2.6 na Equação 2.3 e então temos a Equação 2.7 .

$$
E_{\text {entra }}-E_{\text {sai }}=\frac{\partial}{\partial x} \cdot\left(k_{x} \cdot \frac{\partial T}{\partial x}\right)+\frac{\partial}{\partial y} \cdot\left(k_{y} \cdot \frac{\partial T}{\partial y}\right)+\frac{\partial}{\partial z} \cdot\left(k_{z} \cdot \frac{\partial T}{\partial z}\right)+E_{\prime_{\text {gerada }}}
$$

Por último, temos o termo de "geração" de energia (Equação 2.7 e 2.3), que pode ser decorrente de reações químicas, sendo positivo para exotérmicas (termo fonte) e negativo para endotérmicas (sumidouro) ou também energia eletromagnética absorvida, como por exemplo micro-ondas.

$$
E_{\prime_{\text {gerada }}}=\dot{q}
$$

Com isto, temos a Equação geral da transferência de calor, que em coordenadas cartesianas é dada pela Equação 2.9.

$$
\rho \cdot c_{p} \cdot \frac{\partial T}{\partial t}=\frac{\partial}{\partial x} \cdot\left(k_{x} \cdot \frac{\partial T}{\partial x}\right)+\frac{\partial}{\partial y} \cdot\left(k_{y} \cdot \frac{\partial T}{\partial y}\right)+\frac{\partial}{\partial z} \cdot\left(k_{z} \cdot \frac{\partial T}{\partial z}\right)+\dot{q}
$$

Para se encontrar $T(\vec{r}, t)$ deve-se resolver a Equação diferencial 2.9, partindo de uma condição inicial conhecida $T(\vec{r}, 0)$ e aplicadas as condições de contorno do problema (fornecimento de calor em uma superfície, temperatura constante em uma face entre outras possíveis). Porém, como a Equação 2.9 é uma EDP (Equação Diferencial 
Parcial), na maioria dos casos reais ela não pode ser resolvida analiticamente e por isto algum tipo de aproximação que não comprometa os resultados deve ser feita.

Para resolver este tipo de problema de forma analítica é necessário que exista alguma simetria, geométrica ou de condições de contorno, que possibilitem manipulações na EDP (Equação Diferencial Parcial) para se encontrar a solução. Outra maneira de contornar o problema da resolução da EDP é desconsiderar termos menos significativos, que podem muitas vezes facilitar muito a solução da Equação. Quando a condutividade térmica é igual ao longo de todas as direções $\left(k_{x}=k_{y}=k_{z}\right)$, o meio é considerado isotrópico e então a Equação 2.9 pode ser escrita como

$$
\rho \cdot c_{p} \cdot \frac{\partial T}{\partial t}=k \nabla^{2} T+\dot{q}
$$

Em que $\nabla=\frac{\partial}{\partial x}+\frac{\partial}{\partial y}+\frac{\partial}{\partial z}$. Outro caso muito utilizado nos processos térmicos da indústria de alimentos é a solução da Equação de calor no regime permanente, em que a variação do perfil de temperatura em função do tempo é desprezível e, portanto a solução que se quer encontrar, $T(x, y, z, t)$, passa a não ser mais função de t e então temos $T(x, y, z)$. Com isto, a Equação 2.9 é drasticamente simplificada já que $\frac{\partial T}{\partial t}=0$ e então temos a Equação 2.11.

$$
k \nabla^{2} T+\dot{q}=0
$$

Para se resolver a Equação 2.11 ou 2.9, além de conhecer as condições iniciais (a temperatura em todos os pontos no instante $\mathrm{t}=0$ ) é preciso conhecer as condições de contorno, que no caso implicam em como o calor é introduzido no sistema. As condições de contorno mais encontradas no caso do aquecimento de alimento são as de Dirichilet, em que a temperatura em um ponto é especificada (como o alimento em contato com um material com temperatura conhecida) ou condições de contorno de Newmann, em que a derivada da temperatura em relação ao tempo (fluxo de calor) é especificada em algum ponto. 
Mesmo com a Equação 2.11, dependendo de $\dot{q}$ e também da geometria, pode não ser possível resolver o problema analiticamente. Nestes casos, existem vários métodos computacionais que podem ser utilizados.

\subsubsection{MÉTODO DAS DIFERENÇAS FINITAS APLICADOS À TRANS- FERÊNCIA DE CALOR}

O método das diferenças finitas é uma técnica utilizada para encontrar soluções aproximadas de uma ou de um conjunto de equações diferenciais. Basicamente, o método consiste em aproximar a derivada de uma função pela Equação 2.12, utilizando o teorema fundamental do cálculo, com um valor pequeno de $\Delta k$. Desta forma, quanto menor for o valor de $\Delta k$, maior será a precisão do cálculo uma vez que o limite de $\Delta k$ tendendo a zero resulta no valor exato da derivada, onde $\mathrm{k}$ é uma das variáveis da Equação a ser discretizada.

$$
\begin{gathered}
\frac{\partial}{\partial k} T(k, a, b, . .) \simeq \frac{T(k+\Delta k, a, b, . .)-T(k, a, b, . .)}{\Delta k} \\
\frac{\partial T}{\partial k}=\frac{T_{i+1}-T_{i}}{\Delta k}
\end{gathered}
$$

A Equação 2.13 representa a discretização da função $T(k)$ em elementos discretos de tamanho $\Delta k$. As derivadas de maior ordem podem ser obtidas aplicando a discretização da Equação $2.13 n$ vezes, sendo $n$ a ordem da derivada. Para $n=2$ por exemplo, aplicando a Equação 2.13 aos termos $T_{i+1}$ e $T_{i}$ da mesma Equação e então temos:

$$
\frac{\partial^{2} T}{\partial k^{2}}=\frac{T_{i+1}-2 \cdot T_{i}+T_{i-1}}{\Delta k^{2}}
$$

Desta forma, o resultado é um conjunto de equações algébricas que podem ser resolvidas para encontrar a solução discretizada da Equação. Quanto menor for $\Delta x$, maior será a precisão do método (desconsiderando os problemas de truncamento de 
variáveis de ponto flutuante), no entanto maior será a quantidade de equações e portanto, resolve-las exigirá maior poder computacional e memória.

Nos problemas de transferência de calor, a temperatura é função de mais de uma variável, e o método mostrado acima é aplicado em relação a todas as variáveis. O resultado é um conjunto de equações algébricas complexas para se resolver diretamente e, portanto, simplificações podem ser feitas de acordo com o caso, para facilitar a resolução numérica, como por exemplo a resolução do regime permanente em que $\frac{\partial T}{\partial t}=0$ ou alguma simetria geométrica que permita reduzir a dimensão do problema.

\subsubsection{Regime permanente}

No regime permanente, o método das diferenças finitas é aplicado à Equação 2.11, visto que a temperatura não varia com o tempo. Em uma dimensão, a Equação 2.11 é discretizada utilizando a Equação 2.14, o que resulta em:

$$
T_{k}=\frac{T_{k+1}+T_{k-1}+\frac{\dot{q_{k}} \cdot(\Delta x)^{2}}{k}}{2}
$$

Em 2 e 3 dimensões a Equação resultante é similar a 2.15, porém com termos discretizados também nas outras coordenadas. Como geralmente existe uma grande quantidade de equações, vários métodos de resolução podem ser aplicados, com vantagens e desvantagens que dependem da geometria, quantidade de dimensões e tipo de condições de contorno presentes no problema. As principais a serem destacadas são o método direto, o método de Jacobi, Gauss-Seidel e Sucessive Over-Relaxation (SOR).

No método direto, é montada uma Equação matricial no formato $\mathbf{A} \cdot \mathbf{x}=\mathbf{B}$, em que $\mathbf{A}$ é a matriz dos coeficientes das equações acopladas, $\mathbf{x}$ é a matriz das incógnitas (temperatura) e B é uma matriz conhecida de valores dada pelas condições de contorno do problema. Encontrar a matriz das temperaturas $\mathbf{x}$ se resume a um problema de encontrar a inversa da matriz $\mathbf{A}$, porém o problema é complexo quando 
o tamanho da matriz é grande uma vez que o custo computacional de encontrar a inversa de uma matriz cresce com o quadrado do número de linhas e colunas.

Além do método de resolução direta, existem formas iterativas de se resolver o conjunto de equações acopladas. Os método de Jacobi, Gauss-Seidel e SOR consistem obter a solução resolvendo ponto a ponto as equações, partindo de um "chute inicial"para a temperatura. Este cálculo é reiterado até que os valores da temperatura atinjam uma estabilidade e não se alterem significativamente.

Os quatro métodos citados variam na forma com que é feita a resolução das equações. No método de Jacobi (Equação 2.16), o calculo de $T_{k}^{i}$ é dado em função de $T_{k+1}^{i-1}$ e $T_{k-1}^{i-1}$, ou seja, em função da iteração passada.

$$
T_{k}^{i}=\frac{T_{k+1}^{i-1}+T_{k-1}^{i-1}+\dot{q}_{k} \cdot(\Delta x)^{2}}{2}
$$

Na Equação 2.16, $i$ representa a iteração e $T_{k}^{1}$, é um 'chute' inicial da temperatura para todo $k$. A Equação 2.16 é resolvida para todos os valores de $k$, repetidamente para $i=2, i=3$, e assim por diante até que não haja mais alterações significativas nos valores de $T_{k}$ em relação a iteração anterior, indicando que o algoritmo convergiu e foi encontrada a solução de $T_{k}$ para todo $k$.

O método de Gauss-Seidel (Equação 2.17), é um aprimoramento do anterior, e o cálculo de $T_{k}^{i}$ é feito em função de $T_{k+1}^{i}$ e $T_{k-1}^{i}$, e não da iteração anterior $(i-1)$, o que acelera o processo de convergência.

$$
T_{k}^{i}=\frac{T_{k+1}^{i}+T_{k-1}^{i}+\dot{q}_{k} \cdot(\Delta x)^{2}}{2}
$$

No método SOR, a atualização do valor $T_{k}^{i}$ leva em conta também um parâmetro chamado parâmetro de relaxação que aumenta a velocidade de convergência. Primeiramente, é calculada a diferença entre $T_{k}^{i-1}$ e $T_{k}^{i}$ encontrado pelo método de Gauss-Seidel. Essa diferença é então amplificada pelo fator $w$, o parâmetro de relaxação, sendo que $1<w<2$. Finalmente o valor $T_{k}^{i}$ real é encontrado, como é mostrado 
na Equação 2.18.

$$
T_{k}^{i}(\text { sor })=T_{k}^{i-1}+w \cdot\left(T_{k}^{i}(\text { Gauss }- \text { Seidel })-T_{k}^{i-1}\right)
$$

\subsubsection{Regime não-permanente}

No regime não permanente é necessário discretizar a Equação 2.9, visto que a derivada temporal não é igual a zero como no caso do regime permanente. Aplicando as discretizações descritas nas equações 2.13 e 2.14 a Equação 2.9, para um sistema em duas dimensões em coordenadas cartesianas obtemos a seguinte Equação:

$$
\frac{T_{i, j}^{n+1}-T_{i, j}^{n}}{\Delta t}=\alpha\left(\frac{T_{i+1, j}^{n}-2 T_{i, j}^{n}+T_{i-1, j}^{n}}{\Delta x^{2}}+\frac{T_{i, j+1}^{n}-2 T_{i, j}^{n}+T_{i, j-1}^{n}}{\Delta y^{2}}\right)
$$

em que $\alpha=\frac{k}{\rho c_{p}}$, i e j são os índices dos elementos discretizados nas direções x e y, e n é o índice de discretização no tempo.

Para resolver esta EDP, é necessário conhecer o perfil de temperatura no tempo inicial ( $T_{i, j}^{0}$ ) para todos os valores de i e j. Existem métodos diretos e indiretos de se encontrar a evolução no tempo. No método direto chamado de FTCM (foward in time centered in space - a frente no tempo e centrado no espaço), o valor a frente no tempo $T_{i, j}^{n+1}$ é encontrado conhecendo-se os valores no instante anterior a sua volta (por isso centrado no espaço), ou seja, os valores $T_{i+1, j}^{n}, T_{i-1, j}^{n}, T_{i, j+1}^{n}$ e $T_{i, j-1}^{n}$, como mostrado no stencil da Figura 5. O procedimento é feito para todos os valores $i$ e $j$ em um instante de tempo $n$, então $n$ é incrementado e o procedimento é repetido até se chegar no tempo final desejado. 
Figura 5 - Grade (stencil) que descreve a relação entre os pontos das diferenças finitas. Os eixos $x$ e $y$ possuem elementos com índices discretos representados por $i$ e $j$ e $n$ é o elemento temporal.

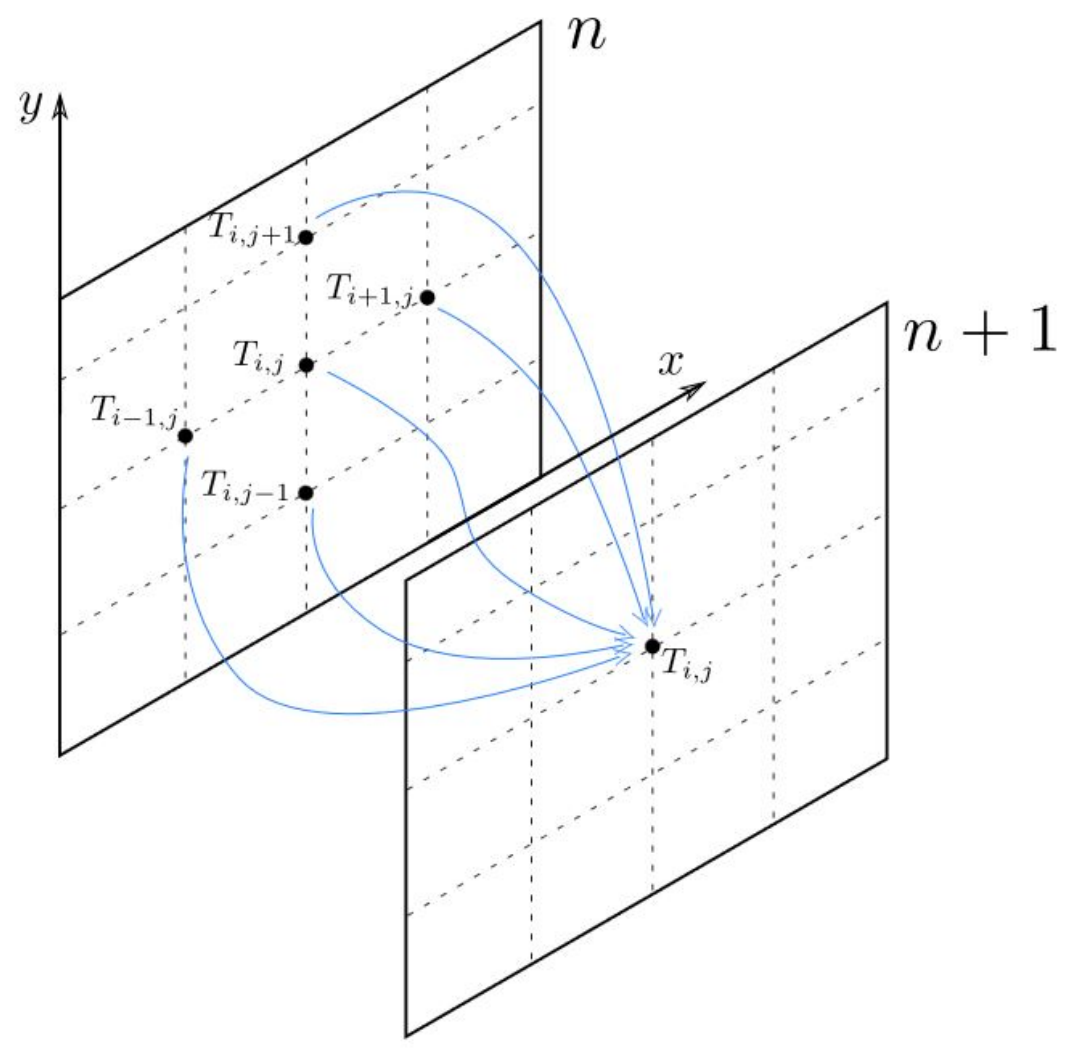

Adaptado de Hawke (2014).

\subsection{SISTEMAS EMBARCADOS EM CONTROLE DE PRO- CESSOS}

Os circuitos eletrônicos mudaram muito desde o início da era digital, com o poder computacional aumentando cerca de 10.000 vezes entre 1978 e 2010, dada a evolução nas técnicas de produção dos circuitos integrados, o que foi previsto pela lei de Moore tem se mantido verdadeiro até os dias de hoje, sem previsão de estagnação (MACK, 2015; FULLER; MILLETT, 2011). Além disso, o tamanho, preço e consumo dos dispositivos diminuíram sensivelmente, melhorando a facilidade de uso e conectividade. No entanto, os sistemas de automação industrial, principalmente no Brasil, não têm 
acompanhado tal evolução e ainda são muito caros e de difícil uso, além de serem em sua grande maioria de tecnologia importada.

Sistemas embarcados são dispositivos eletrônicos com poder computacional que fazem parte de um sistema mecânico/eletrônico maior. Estes dispositivos interagem com outras partes do sistema realizando operações lógicas em tempo real, assim como um PC (computador pessoal), porém os periféricos de entrada e saída de cada sistema embarcado são feitos para as suas funções específicas e portanto geralmente possuem menor custo, tamanho e gasto energético. Eles são encontrados vários dispositivos eletrônicos atuais, desde controles remotos de televisão, televisões, rádios, semáforos, radares, fornos de micro ondas, entre outros (MILECKI, 2015).

Dentro da indústria de alimentos, os sistemas embarcados mais importantes são os que controlam o processo de produção. Estes sistemas devem estar conectados aos sensores e a outros sistemas da indústria, processando os dados recebidos e tomando as decisões de controle que são enviadas aos atuadores. As alternativas de sistemas embarcados para este tipo de controle são os CLP's (Contror Lógico Programável), microcontroladores, computadores e sistemas mistos com processamento distribuído. Segundo uma pesquisa de Ilyukhin, Haley e Singh (2001), 88 \% das indústrias de alimentos utilizam os CLP's como principal forma de controle e em apenas $6 \%$ predominam sistemas distribuídos. Esta pesquisa também revelou que uma grande gama de marcas e sistemas comerciais são utilizados, inclusive dentro de uma mesma empresa, o que dificulta uma integração mais inteligente dentro do sistema.

Apesar do grande uso de CLP's dentro das indústrias de alimentos, estes dispositivos não tiveram a mesma evolução que os computadores portáteis e dispositivos móveis tiveram nos últimos 15 anos, com um grande aumento no processamento e redução no preço. Por este motivo, o desenvolvimento de sistemas de controle baseados em microcontroladores tem crescido muito, com placas que podem realizar as mesmas operações com tamanho e custo reduzido (HOEHN; SBENATY, 2005). Para controles mais complexos, que exijam um maior processamento de dados, os sistemas 
de computação de baixo custo baseados em hardwares similares a tablets e celulares também são uma alternativa emergente.

\subsubsection{MICROCONTROLADORES}

Microcontroladores são pequenas unidades de processamento que possuem todos os seus elementos de processamento e memória em um único chip e, portanto podem operar sem a necessidade de periféricos. Esta é a principal diferença entre um microcontrolador e um microprocessador, como os que são encontrados nos computadores. Por possuir todas as unidades em um único chip, seu processamento e memória são em geral muito inferiores a de um computador, porém as vantagens estão na quantidade de energia utilizada, tamanho e robustez.

Os microcontroladores surgiram na década de 1970 e tiveram um enorme avanço até o momento. Atualmente, existem centenas de empresas que produzem microcontroladores e suas especificações variam de acordo com o objetivo do mesmo dentro do sistema, podendo ir de chips minúsculos e baratos com velocidade da ordem de $\mathrm{kHz}$ e apenas um pino digital de entrada e saída a microcontroladores ARM ( $A d$ vanced RISC Machine - Máquina RISC Avançada), que possuem processamento e arquitetura superior aos microcontroladores RISC (Reduced Instruction Set Computer - Computador com um conjunto reduzido de instruções) tradicionais, atingindo processamento da ordem de GHz (MAZIDI et al., 2009).

\subsubsection{Plataforma Arduino}

Sistemas eletrônicos de hardware livre são projetados e oferecidos da mesma forma que um software livre, oferecendo todas as informações necessárias para se replicar um projeto, como diagrama de circuito, componentes e layout da placa de circuito impresso (POWELL, 2012). Com a difusão de microcontroladores de baixo custo, o conceito de hardware livre se integrou aos de software livre, sendo parte primordial no movimento maker, que teve grande impacto no desenvolvimento de novos produtos e 
também na educação voltada a tecnologia (MARTIN, 2015).

Dentro deste conceito de hardware livre surge a plataforma Arduino (Figura 6). Esta plataforma foi concebida em 2005 por uma equipe sediada na Itália liderada pelo pesquisador Massimo Banzi, que queria ensinar eletrônica e programação de computadores a alunos de design, para que eles usassem em seus projetos de arte, interatividade e robótica (ARAÚJO et al., 2013). O intuito da equipe era desenvolver uma plataforma para introduzir os conceitos de eletrônica e programação para leigos de forma intuitiva, simplificada e de baixo custo (BARRETT, 2013).

Figura 6 - Arduino Uno R3 - Principal placa da plataforma Arduino, com Atmega328pu e Comunicação USB.

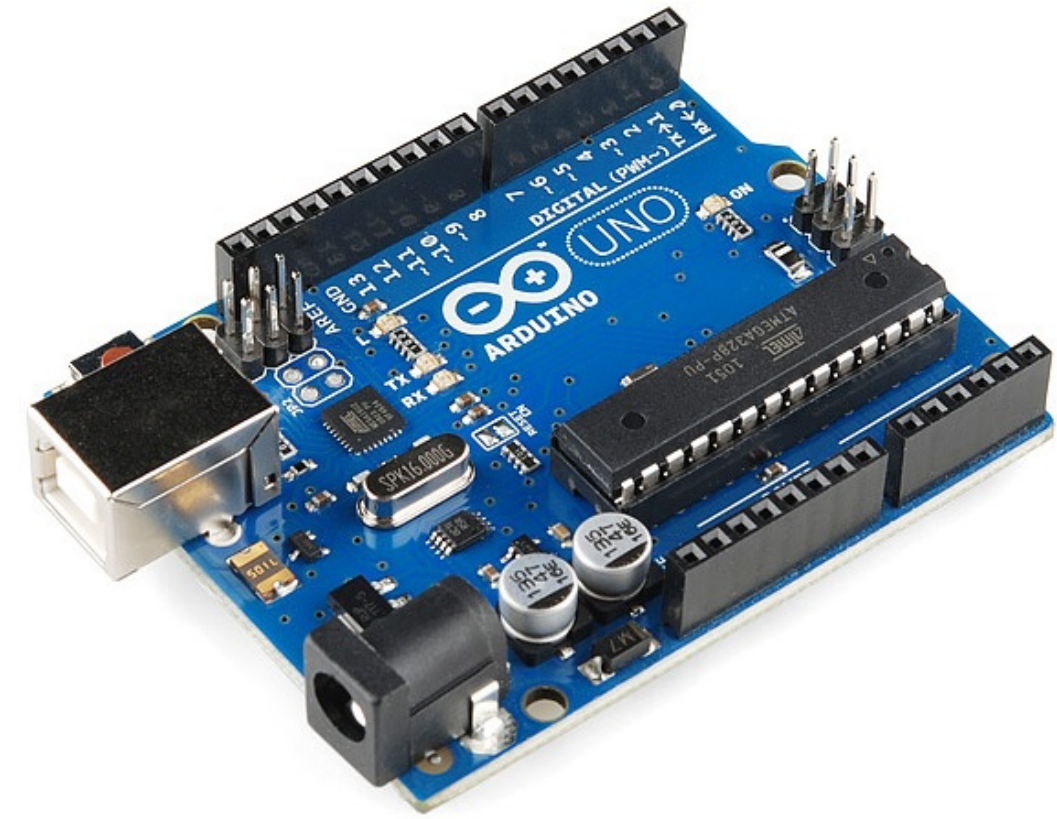

Imagem obtida em www.arduino.cc Acesso em 13/01/2017

O Arduino é uma plataforma para placas microcontroladoras que permite a leitura de sensores (analógicos e digitais), comunicação serial, e acesso aos GPIO's (General-purpose input/output - Entradas e saídas de propósito geral) para controle de motores, LEDs e outros dispositivos. A principal placa da linha Arduino, o Arduino Uno utiliza um microcontrolador $($ Atmel da linha Atmega, o Atmega328p-PU com um oscilador de $16 \mathrm{MHz}$ externo, um regulador de tensão de $5 \mathrm{~V}$, botão de reset, 
conector de alimentação, pinos conectores, e alguns LEDs para facilitar a verificação do funcionamento. A conectividade é feita diretamente por uma porta USB, tanto para gravar os programas quanto para comunicação serial. Além disso, a porta USB pode também fornecer a alimentação de $5 \mathrm{~V}$ para a placa.

A gravação dos programas na placa é controlada por um chip que faz a conversão USB para Serial, sendo nos primeiros modelos o CHIP FT232RL, que na terceira revisão do Arduino UNO foi substituído por um microcontrolador Atmega16U2, que tem o papel exclusivo de ser a interface entre a porta USB e o Arduino (D'AUSILIO, 2012). Este conceito é uma das chaves do sucesso da plataforma, já que a gravação dos programas pode ser feita diretamente na placa, não exigindo um gravador externo e uma fonte regulada como a maioria dos microcontroladores do mercado. Isto viabilizou a utilização de microcontroladores por pessoas que não tem acesso a um laboratório de eletrônica.

A programação do microcontrolador utiliza uma IDE (Integrated Development Environment - interface integrada de desenvolvimento) baseada no software Processing, que utiliza uma versão simplificada da linguagem $\mathrm{C} / \mathrm{C}++$ com uma camada de pós-processamento que adiciona funcionalidades e simplifica o seu uso (BUECHLEY et al., 2008). Esta Linguagem foi desenvolvida em 2001 no laboratório de mídia do MIT (Massachusetts Institute of Technology), e esta disponibilizada sobre a licença GPL (General Public License - Licença Pública Geral) e LGPL (GNU Lesser General Public License - licença menos pública GNU), sendo completamente open source e multi plataforma, podendo ser utilizado nos sistemas Windows, Linux e Mac OS. O Processing foi desenvolvido inicialmente para facilitar o uso de programação por artistas e ensinar programação de forma simples e visual e pela sua facilidade é utilizado atualmente por milhões de pessoas do ensino e prototipagem à produção de softwares (REAS; FRY, 2007).

Outra facilidade da plataforma Arduino é a padronização dos pinos de Entrada e Saída, possibilitando que uma série de circuitos de expansão, chamados de Shields, 
possam ser utilizados com as placas, dando funções extras ao microcontrolador, como comunicação Bluetooth, wi-fi, GSM, Relês entre outros. Estes Shields, assim como as próprias placas, podem ser produzidos por qualquer companhia já que o Arduino é um hardware livre. Com a popularização das placas, mais sensores, Shields e periféricos são produzidos para abastecer o ecossistema, o que torna o Arduino ainda mais popular, fazendo disto um ciclo positivo (MCROBERTS, 2011). O mesmo ciclo ocorre com a disponibilização de projetos com código aberto e dessa forma, quanto maior for o número de usuários da plataforma, maior será a quantidade de projetos livres e suporte disponíveis para o ecossistema.

Com o sucesso inicial da plataforma, todo um ecossistema foi criado ao redor do Arduino, com muitas bibliotecas e funcionalidades implementadas por terceiros, disponibilizadas livremente. Isto atraiu outras empresas e fabricantes de microcontroladores e placas integradas pois a quantidade de suporte a ferramentas disponíveis para o Arduino tornou a plataforma atrativa e muitas outras empresas adotaram a IDE do Arduino para seus microcontroladores e placas customizadas, como por exemplo o esp8266, teensy, intel galileo entre outros. Quanto maior a comunidade e ferramentas, mais usuários são atraídos, aumentando a comunidade e a quantidade de ferramentas. Este efeito "bola de neve" levou o Arduino a ser a referência atual em microcontroladores.

\subsubsection{COMPUTADORES EM PLACA ÚNICA}

Com o avanço e desenvolvimento de novos hardwares com mais memória e processamento e, principalmente devido à corrida tecnológica dos dispositivos móveis, surgiu nos últimos anos a computação de ultra baixo custo (Ultra Low Cost Computing - ULCC), que basicamente utiliza o hardware de smartphones e periféricos de entrada e saída em uma única placa (HEEKS; ROBINSON, 2013). Vários projetos têm se desenvolvido neste sentido, entre eles podemos citar o Raspberry Pi, Beaglebone, Intel Galileo e Edson, Arduino Yun, Orange pi entre outros. Tais projetos 
entregam placas de baixo custo (a partir de 5 dólares) que possibilitam aplicações em várias áreas como automação, robótica, equipamentos médicos (TEIKARI et al., 2012), ensino de computação e programação, aquisição dinâmica de dados, servidores web, monitoramento remoto e até controle de satélites (BERDAHL; LLIMONA, 2013), entre outras aplicações.

Existem vários modelos de computadores em placa única, que diferem nas suas especificações, preço, processamento, sistema operacional e tipo de licença. Levando em conta o preço, licença e a quantidade de usuários, o Raspberry Pi é a placa que mais se destaca no mercado atualmente, principalmente pelo tamanho da comunidade envolvida e suporte, trazendo estabilidade para o sistema.

\subsubsection{Raspberry Pi}

O Raspberry Pi é um computador em placa única do tamanho de um cartão de crédito (Figura 7a), desenvolvido pela Raspberry Pi Foundation, que se iniciou com o intuito de promover o ensino básico de computação com baixo custo em escolas de baixa renda.

O projeto foi concebido em 2006 como uma forma barata e simples de ensinar computação, programação e eletrônica às crianças. Em 2011 o projeto saiu do papel com o pré-lançamento do modelo A, que possuía 256 Mb de memória RAM (Random Access Memory) e uma entrada USB. Este modelo recebeu um upgrade (modelo B) em 2012 com o primeiro lançamento oficial em larga escala, contando agora com uma memória de $512 \mathrm{Mb}$ e duas entradas USB.

O Raspberry Pi 1 modelo B (o primeiro vendido em larga escala), Figura 7a, foi produzido em um único chip broadcom BCM2835, com um processador ARM de 700 MHz e 512 Mb de memória RAM. A memória física fica em um cartão SD de até 32 Gb e suporta uma série de sistemas operacionais baseados em Linux e a distribuição oficial da Raspberry Pi Foundation é um Linux Debian chamado wheezy. Este modelo possui duas entradas USB, uma porta Ethernet, uma saida HDMI, uma saída RCA, 
uma saída de vídeo e oito pinos GPIO (General Purpose Input/Output - Pinos de entrada/saída de propósito geral).

Em sequencia, novos modelos foram lançados consecutivamente. O modelo b+ surgiu em 2014, contando agora com 4 portas USB e 40 GPIO mas nenhuma alteração no processador. Em 2015 o modelo 2 foi lançado, alterando o processador para um ARM-cortex A7 quadri-core operando a 900 MHz e 1GB de memória RAM. Em 2016, o modelo 3 foi lançado (Figura 7c), contendo agora um ARM-cortex A53 quadri-core com instruções de 64 bits à 1.2GHz. Em 2016 também foi lançado o Raspberry Pi zero (Figura 7d), um modelo econômico, custando apenas 5 dólares e de tamanho reduzido, mantendo o processador do modelo $\mathrm{B}+$.

Figura 7 - Modelos do Raspberry Pi.

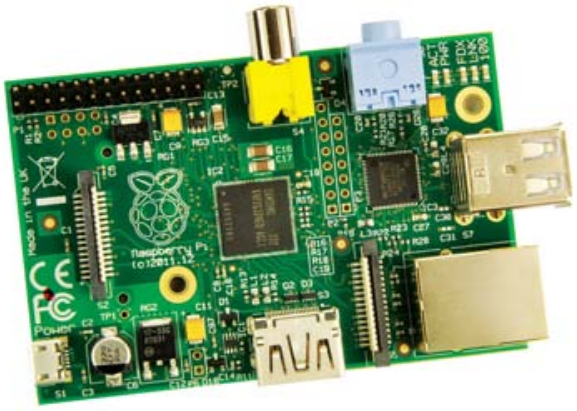

(a) Raspberry Pi 1 - Modelo B

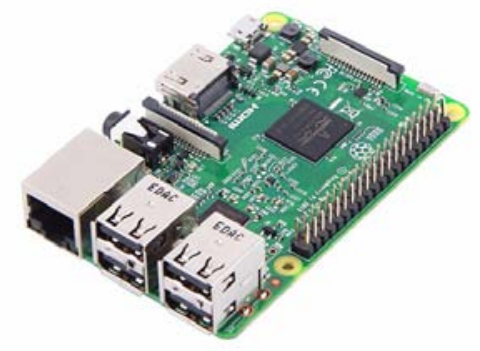

(c) Raspberry Pi 3

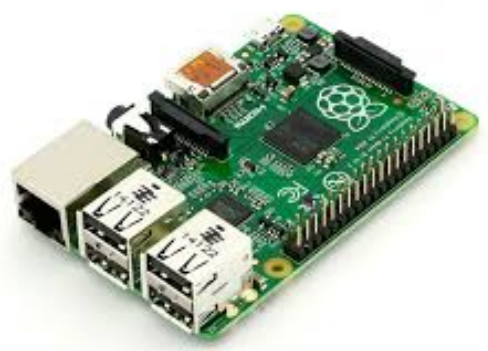

(b) Raspberry Pi - Modelo B+

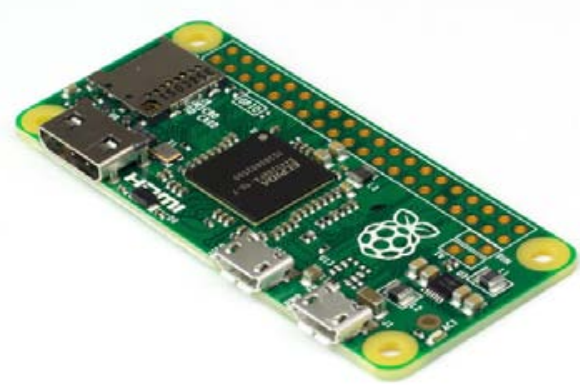

(d) Raspberry Pi zero

Imagens retirada de www.raspberrypi.org (acesso em 16.01/2017)

Por ser um projeto totalmente open-source ele usa uma distribuição Unix com 
licença GNU além de um hardware aberto. Com isto, o Raspberry Pi ganhou muitos adeptos rapidamente, sendo utilizado atualmente em várias áreas como ensino, processamento de dados, clusters, webservers, robótica e uma série de projetos embarcados.

$\mathrm{Na}$ área da educação, a placa tem sido utilizada devido ao seu baixo custo (Todos os modelos foram lançados a US\$35, exceto o Raspberry Pi zero, cujo valor é US\$5) e também por ser simples e acessível para o usuário entender e manipular o hardware. Nesta ultima década, dispositivos computacionais tem se tornado equipamentos fechados, que o usuário o encara como unidades lacradas de alumínio ou plástico, sem ideia do que esta dentro. Neste sentido, o Raspberry Pi possibilita ao usuário o entendimento das alterações no hardware assim como do software, já que pode utilizar várias distribuições de Linux, que possuem várias vantagens didáticas. Baseado nestas ideias, alguns projetos para ensino de computação em comunidades carentes utilizam esta plataforma como uma alternativa barata e poderosa como, por exemplo, o projeto de Haghighi e Cliff (2013).

Além de projetos educacionais, o Raspberry Pi é utilizado também em projetos de pesquisa de ponta, como por exemplo o satélite CCRMA (BERDAHL; LLIMONA, 2013) que envia placas para controlar pesquisas científicas em satélites. Na área da medicina, existem vários projetos de controle e desenvolvimento de equipamentos baratos Teikari et al. (2012).

\subsubsection{Internet das coisas}

No novo conceito de IoT (Internet of Things - Internet das Coisas), desenvolvido por Kevin Ashton em 2009, em um mundo onde objetos físicos estão integrados a uma rede de informações, os objetos se tornam "inteligentes" e podem interagir com o resto da rede (COVINGTON; CARSKADDEN, 2013).

Em 2015 existiam em torno de 10 bilhões de dispositivos conectados à internet, com a previsão de chegar a 34 bilhões em 2020. Com este mercado em crescimento, a 
expectativa é de que 6 trilhões de dólares sejam investidos em tecnologias e soluções para dispositivos IoT nos próximos 5 anos (LEE; LEE, 2015; INSIDER, 2016).

Neste cenário, computadores pequenos e de baixo custo como o Raspberry Pi são extremamente importantes já que podem servir como unidades móveis de processamento de dados (TEIKARI et al., 2012) bem como receber e processar dados de sensores numa rede de sensores interconectados (HAGHIGHI; CLIFF, 2013). Desta forma, o desenvolvimento de sistemas open source e open hardware de controle inteligente que utilizem as recentes tecnologias embarcadas de baixo custo conectados a internet é extremamente importante para a competitividade das empresas de pequeno e médio porte. 



\section{OBJETIVO}

Este trabalho tem como objetivo testar a seguinte hipótese:

"É possivel o controle e automação de um forno em escala piloto para processamento de alimentos com informações de sensores e simulação computacional em tempo real utilizando computação embarcada de baixo custo"

Para testar esta hipótese os seguintes objetivos específicos foram desenvolvidos:

- Modelagem matemática e simulação numérica do comportamento térmico do forno utilizando o método das diferenças finitas;

- Modelagem matemática e simulação numérica do aquecimento do alimento no forno em função do tempo;

- Implantação de um controle PID baseado na resposta das simulações do perfil térmico do forno e do alimento;

- Desenvolvimento de hardware e software de uma unidade de controle escrava no forno utilizando Arduino para controle dos atuadores e sensores;

- Desenvolvimento de um sistema de controle mestre com interface gráfica, utilizando um Raspberry pi, que realiza as simulações e o controle do forno;

- Validação do sistema de controle; 



\section{MATERIAIS}

\subsection{FORNO TIPO TÚNEL EM ESCALA PILOTO}

\subsubsection{FUNCIONAMENTO DO FORNO}

Todo o sistema de controle, as modelagens matemáticas e as simulações foram desenvolvidas no forno em escala piloto tipo túnel com esteira, localizado no LAFAC (Laboratório de Física Aplicada e Computacional), situado em Pirassununga, na Faculdade de Zootecnia e Engenharia de Alimentos da USP (Figura 8). Este forno foi desenvolvido por Pereira (2012) e pelos pesquisadores do LAFAC como parte de um projeto de automação de uma linha de produção industrial (FAPESP 2009/07593-1).

O forno, mostrado na Figura 8, possui 2,0 metros de comprimento por 0,5 metro de altura e largura, sendo revestido externamente por aço inox e placas de cerâmica refratária. O espaço interno do forno possui 2,0 metros de comprimento por 0,4 metros de altura e largura, espaço este que possui duas áreas principais, o topo e o lastro, que estão separados pelas esteira de transporte (Figura 9). A esteira é circular e tanto a entrada, como a saída do forno são abertas. 
Figura 8 - Imagem do forno em escala piloto, localizado no LAFAC, USP Pirassununga.

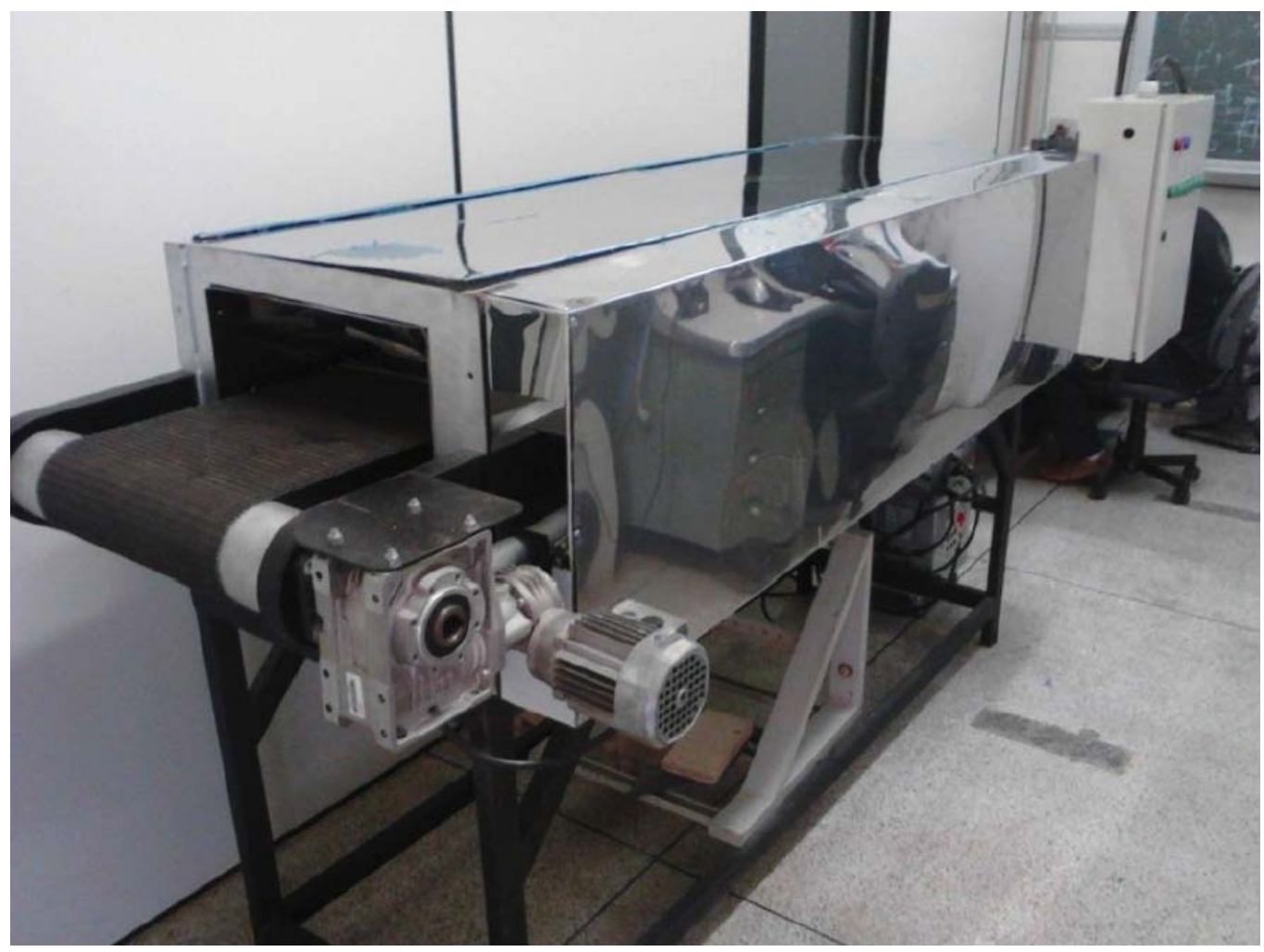

Fonte: Própria autoria.

O aquecimento do forno é feito por resistências que estão posicionadas ao longo da parte superior e inferior do forno, com três zonas de aquecimento independentes na parte superior e três na parte inferior, como ilustra a Figura 10a e 10b, com R1 no setor 1, R2 no setor 2 e R3 no setor 3 e as zonas de 4 à 6 na parte inferior. 
Figura 9 - Visão frontal do forno.

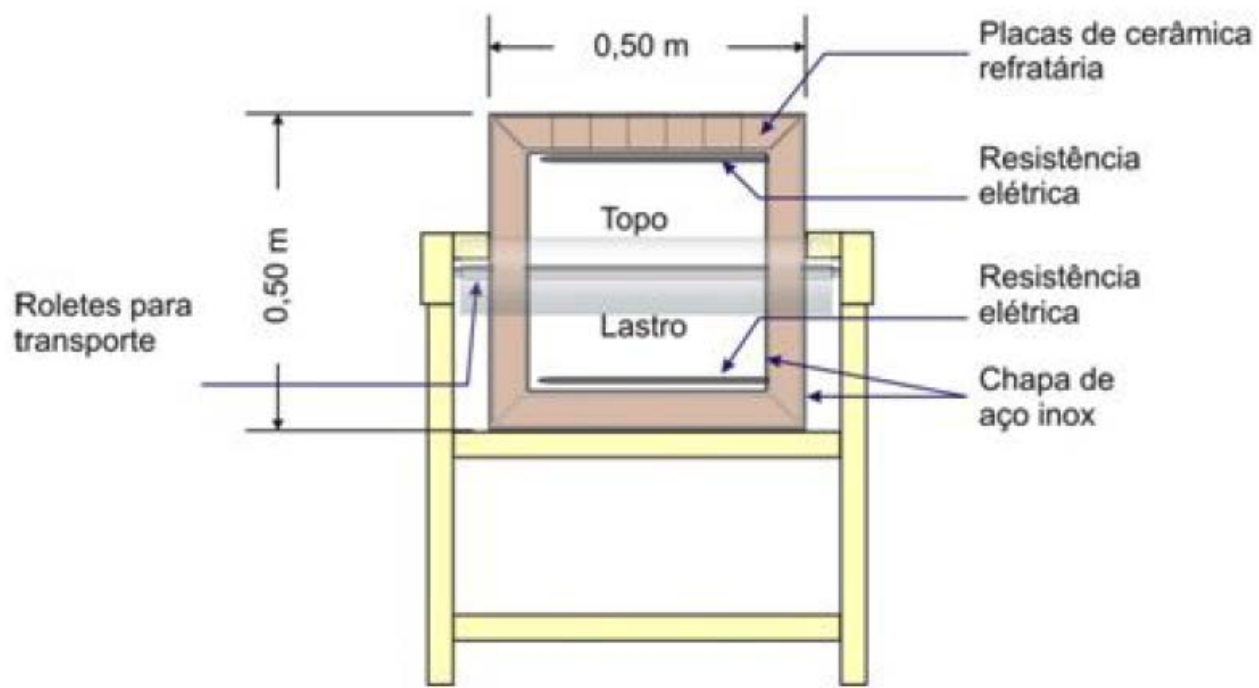

Adaptado de Pereira (2012)

A resistência total em cada um dos setores é formada por três resistores em formato de "W" e potência de 1200 watts cada. Juntas, elas possuem largura e comprimento de 0.4 metro e suas posições podem ser visualizadas na Figura 10b. As resistências inferiores e superiores estão superpostas verticalmente. As resistências são acionadas por contatores que por sua vez são controlados pelo sistema de controle desenvolvido para o forno (Seção 4.2) 
Figura 10 - Visão superior e lateral do forno.

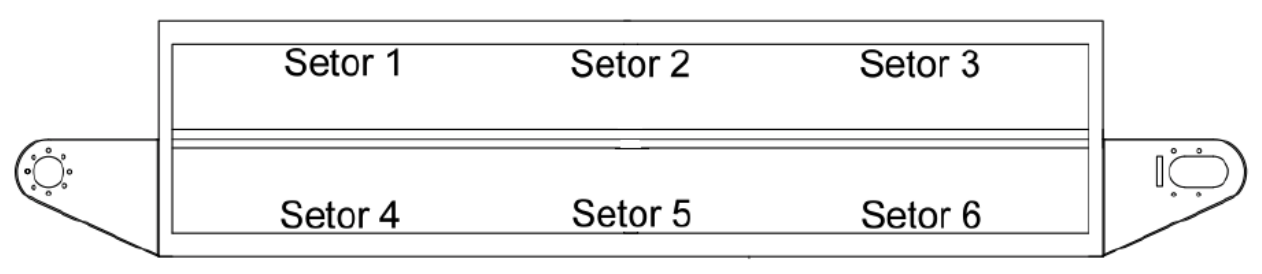

(a) Visão lateral do forno.

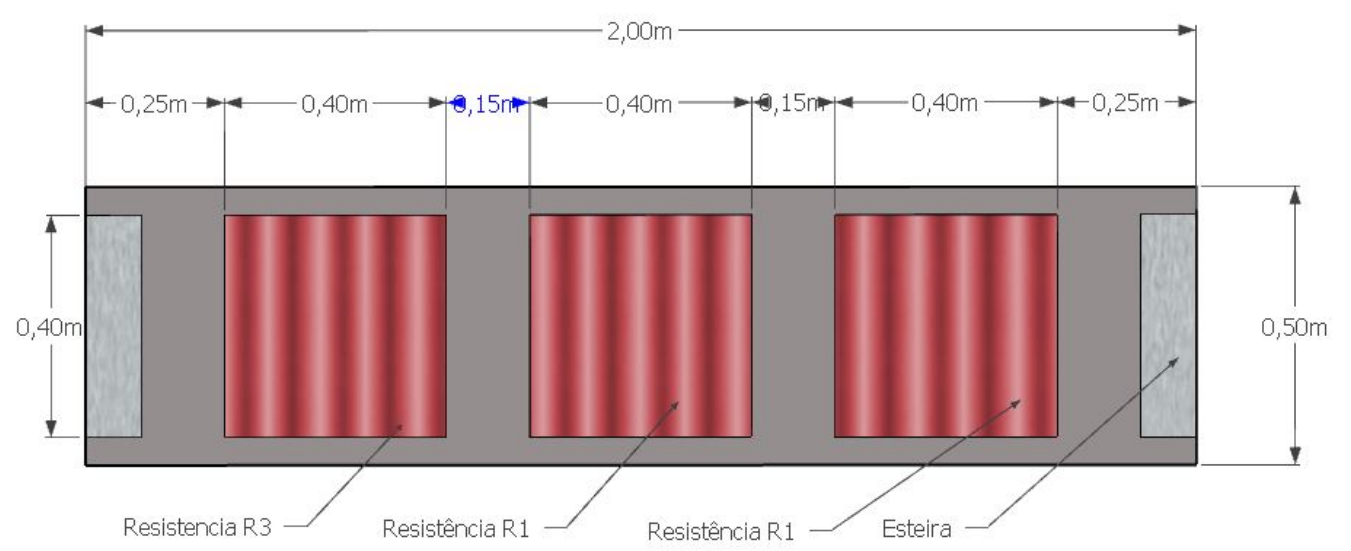

(b) Visão superior do forno.

Fonte: Própria autoria.

\subsubsection{INSTRUMENTAÇÃO PARA CAPTURA DE DADOS E CONTROLE DOS ATUADORES}

Para que o sistema de controle (Seção 4.2) possa efetuar a leitura dos sensores e controlar os atuadores, foi desenvolvida uma placa de controle (diagrama da Figura 11), englobando tanto a instrumentação para a leitura dos sensores termopar quanto o controle dos atuadores (resistências e motor da esteira).

O circuito elétrico e layout dos componentes foi desenvolvido utilizando o software Eagle-PCB versão 7.7. O layout escolhido foi de placa de cobre de lado único com 20x25 cm e foi feito utilizando a máquina de prototipação de PCB marca LPKF e os componentes foram soldados manualmente. 
Figura 11 - Diagrama da placa de controle desenvolvida para o forno. Diagrama completo no Anexo A.1.

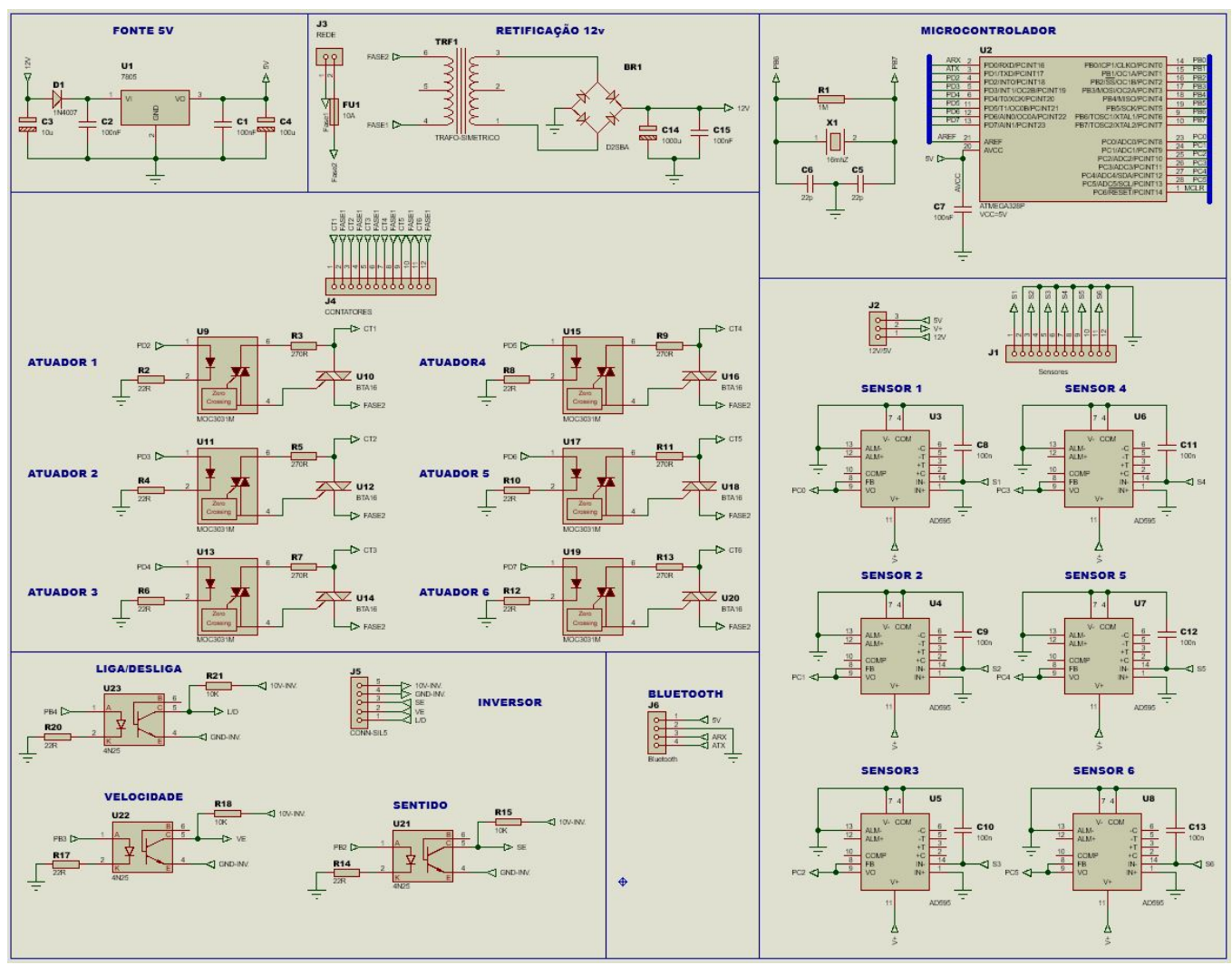

Fonte: Própria autoria.

O controle dos contatores que acionam as resistências foi feito utilizando acopladores óticos MOC3210 para isolar a parte de alta tensão do sistema (contatores) da parte de baixa tensão (Figura 11 - atuador). Dois sistemas de alimentação distintos foram usados para evitar que ruído de tensão fosse injetado no sistema de controle (Figura 11 - fonte). Para o controle do motor da esteira (um motor com inversor modelo CFW-08), foram usados três transistores BC337, conectados diretamente ao microcontrolador (Figura 11 - inversor).

Os sensores de temperatura utilizados no forno foram termopares tipo $\mathrm{k}$, ligados a amplificadores com compensação de junção fria AD595, com tensão de referência igual a 5V. No projeto inicial realizado por Pereira (2012), três sensores estavam posicionados na parte superior da esteira (setores 1, 2 e 3) e três na parte inferior 
(setores 4,5 e 6 ). Os sensores foram recolocados em posições que pudessem fornecer as informações necessárias para obter o perfil térmico das Seções 5.1.2 e 5.1.1. Para isso, um sensor foi colocado no centro da esteira, dois no topo entre as resistências 1 e 2 e 2 e 3 e os outros três na lateral, em altura média entre a esteira e o topo igualmente espaçados no sentido de profundidade do forno (Figura 12).

Figura 12 - Corte lateral do forno com locais dos sensores.

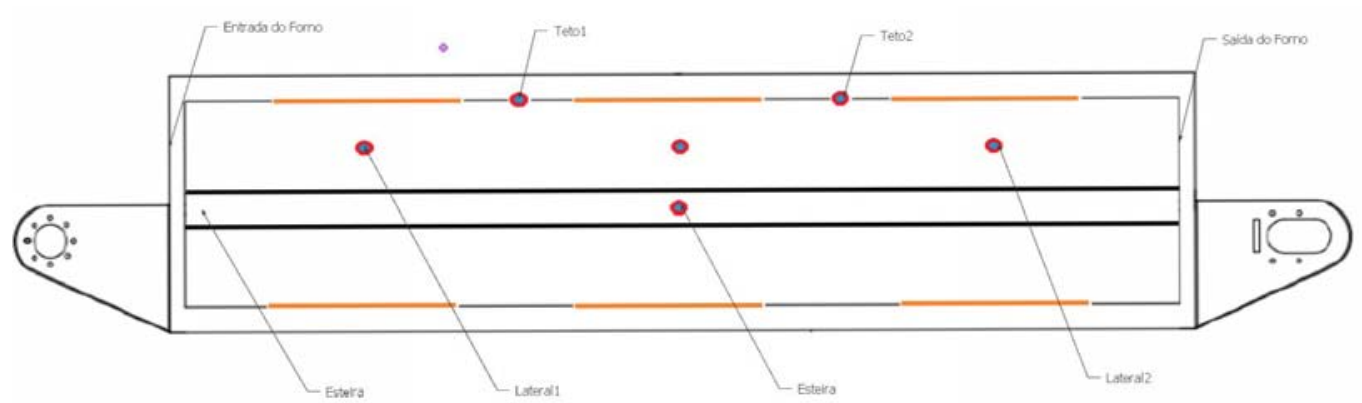

Fonte: Própria autoria.

\subsection{SISTEMA DE CONTROLE}

O sistema de controle do forno foi desenvolvido como mostrado na estrutura da Figura 13, com duas unidades funcionando de forma integrada. A unidade escrava localizada na lateral do forno realiza a interação com a instrumentação eletrônica para a leitura dos sensores e controle dos atuadores, os pré-processamentos e controles de baixo nível e se comunica com a unidade mestre. A unidade mestre é responsável pela interação com o usuário, controle de alto nível, simulação numérica, armazenamento de dados e ajuste de configurações.

Todo o projeto do sistema é aberto (software e hardware livre) e se encontra disponível em Atzingen (2016b) e Atzingen (2016a) sob licença MIT. 
Figura 13 - Diagrama geral do funcionamento do sistema de controle.

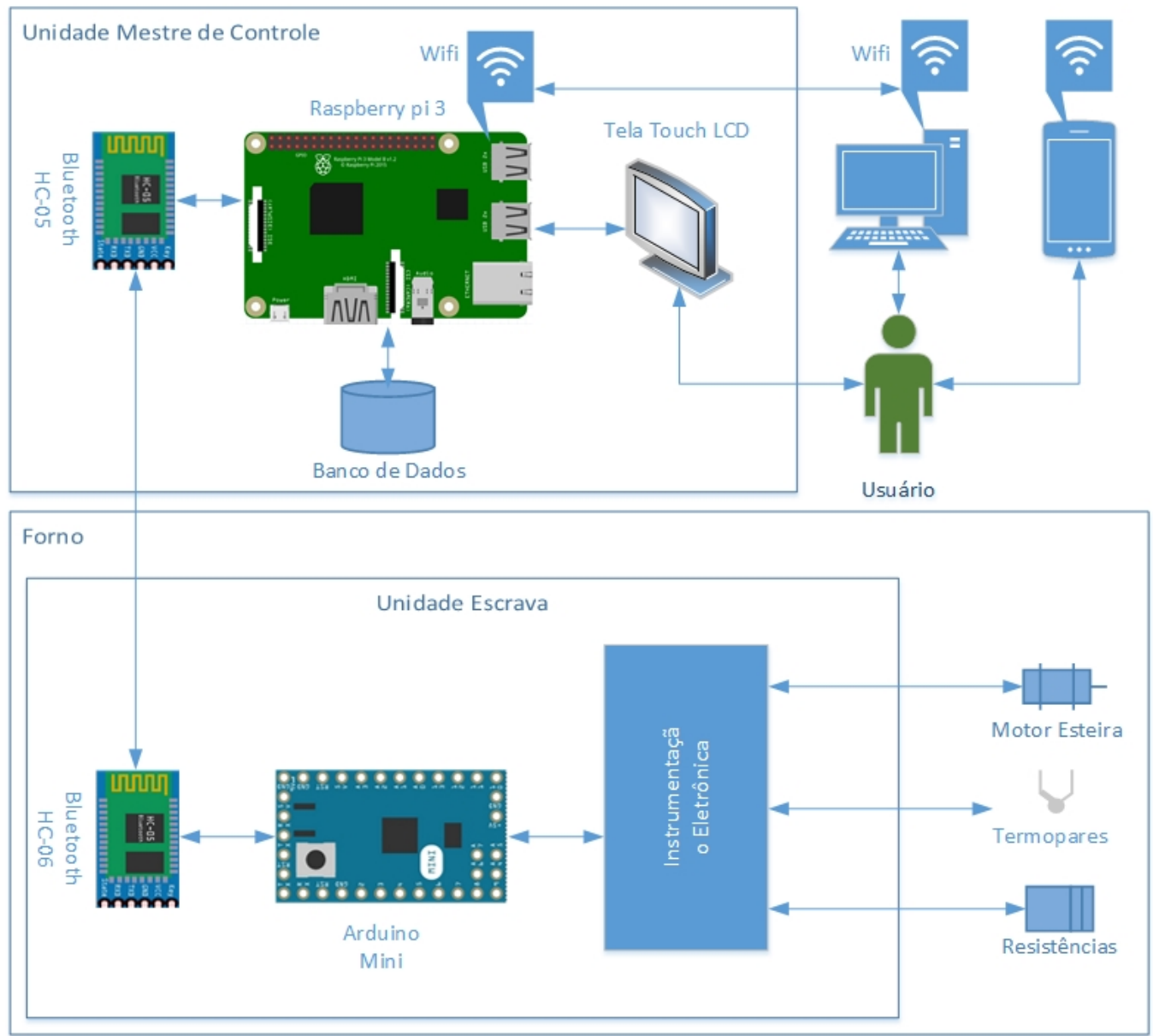

Fonte: Própria autoria.

\subsubsection{UNIDADE ESCRAVA}

A unidade escrava é uma parte da placa de controle do forno (hardware), situada na lateral do mesmo e isolada em uma caixa de controle (Figura 11) responsável pela lógica de controle (software) e comunicação com a unidade principal.

\subsubsection{Hardware}

Esta unidade consiste em um microcontrolador Atmega328p-PU, comunicador bluetooth serial HC-06 e as conexões para a instrumentação relativa aos sensores e atuadores (Figura 14). 
Figura 14 - Esquema elétrico da unidade escrava (parte da placa de controle do forno).
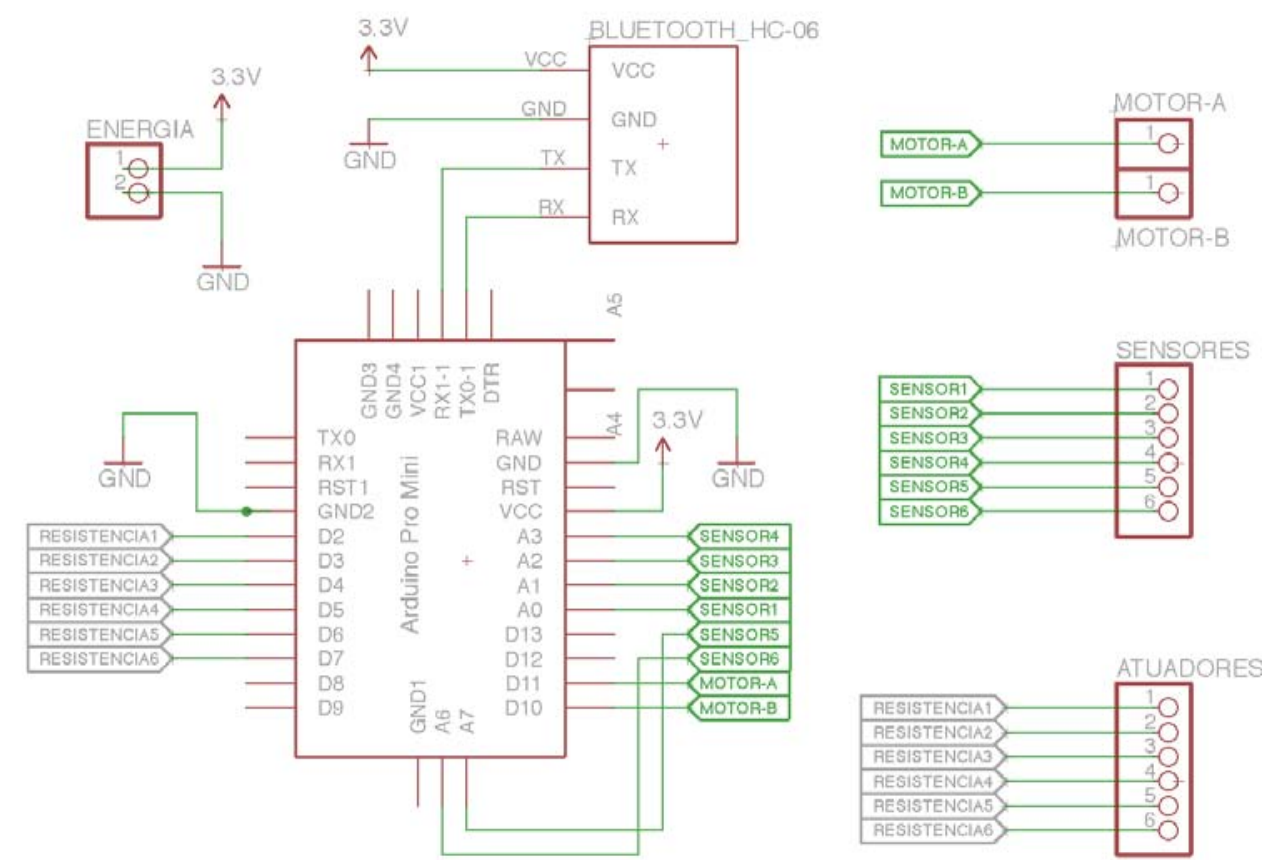

Fonte: Própria autoria.

Como este circuito faz parte da placa de controle, o mesmo software para montagem de diagrama e layout foi utilizado, facilitando a integração entre os dois circuitos da placa.

\subsubsection{Protocolo de comunicação}

Toda a comunicação entre a unidade mestre e a unidade escrava foi feita utilizando dois módulos bluetooth (um em cada unidade), modelo HC-05 e HC-06 da marca linvour, com comunicação serial assíncrona padrão RS232 e baudrate de 96000 bits/segundo.

O firmware de ambos os módulos foram alterados e configurados via comando AT para que as unidades se conectassem especificamente uma à outra pelo endereço de MAC (Media Access Control) ao iniciarem, evitando a necessidade de pareamento manual ou por software como é comum nos dispositivos bluetooth. 
Para a comunicação, foi criado o protocolo mostrado na Figura 15, no qual os dados são enviados como uma sequencia de bytes, e cada byte é traduzido como um caractere alfanumérico utilizando a Tabela ASCII (American Standard Code for Information Interchange - padrão americano para código de troca de informação). Todas as comunicações (independente do sentido) são compostas por um caractere de início, uma sequencia de caracteres de informação e um caractere de fim de comunicação (Figura 15).

Figura 15 - Protocolo de comunicação entre as unidades. Comando "SHA42 \n- Esteira no sentido para frente com $42 \%$ da velocidade.

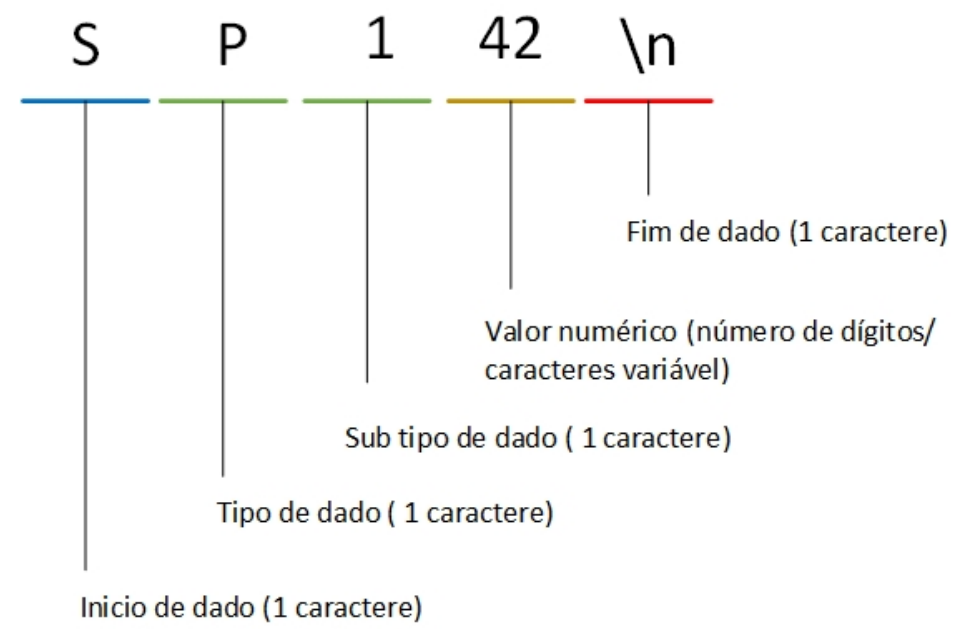

Fonte: Própria autoria.

A codificação dos caracteres e objetivo está descrita na Tabela 1, e foi escolhida para manter o padrão com outros dispositivos de controle desenvolvidos no LAFAC. Tanto a unidade mestre quanto a unidade escrava podem emitir e interpretar mensagens utilizando a codificação definida pelo protocolo mostrado na Figura 15 e por padrão os caracteres escolhidos são os da Tabela 1, podendo ser alterados no software da interface gráfica de controle e nas opções da biblioteca do software no Arduino.

Toda vez que uma nova mensagem é enviada, independente do sentido da transmissão, quando a outra unidade recebe a mesma, a mensagem é transmitido de volta como um eco, para que a unidade que enviou o sinal possa conferir que a outra 
Tabela 1 - Codificação - Caractere ou grupo de caracteres e funcionalidade.

\begin{tabular}{lcc}
\hline Informação & Caractere & Código ASCII \\
\hline Início de mensagem & $\mathrm{S}$ & 83 \\
Emergência & $\mathrm{E}$ & 69 \\
Pedido de temperatura & $\mathrm{T}$ & 84 \\
Ligar resistência (100\%) & 1 & 49 \\
Desligar resistência & 2 & 50 \\
Potencia PWM resistência & $\mathrm{P}$ & 80 \\
Pino da resistência & $1 . .6$ & $49 . .54$ \\
Esteira para frente & $\mathrm{H}$ & 72 \\
Esteira para tras & $\mathrm{A}$ & 41 \\
Esteira parada & $\mathrm{D}$ & 44 \\
Período PWM resistência & $\mathrm{U}$ & 85 \\
Verificação de status & $\mathrm{K}$ & 75 \\
Ajuste leitura ADC & $\mathrm{L}$ & 76 \\
Fim de mensagem & $\backslash \mathrm{n}$ & 10 \\
\hline
\end{tabular}

realmente recebeu o comando e está operando normalmente. 


\subsubsection{Software}

O software para o microcontrolador foi desenvolvido utilizando a plataforma arduino e implementa as seguintes funcionalidades:

- Realizar a comunicação com a unidade mestre;

- Realizar a conversão AD (Analógico/Digital) nos 6 sensores de temperatura;

- Calcular e retornar para a unidade mestre a média de leituras consecutivas, com o número de leituras e intervalo entre elas ajustável;

- Implementar um controle de potência independente para as 6 resistências, com um PWM (Pulsed Width Modulation - Modulação por largura de pulso) com período ajustável;

- Guardar os dados de ajustes na memória EEPROM para persistência em caso de desligamento;

As funcionalidades do software foram integradas em uma classe feita em $\mathrm{c}++$ chamada controleProcesso que aglutina as rotinas e facilita a manutenção do código bem como o uso por outros pesquisadores já que a complexidade é abstraída. A classe de $\mathrm{c}++$ obedece aos padrões do guia de estilo para bibliotecas do Arduino em termos de modularidade e simplicidade. Com os padrões da companhia atendido, a biblioteca foi submetida ao repositório oficial de bibliotecas que pode ser acessado pela IDE (ATZINGEN, 2016a).

\subsubsection{UNIDADE MESTRE}

A unidade mestre é responsável por receber e enviar os comandos para a unidade escrava, realizar os cálculos da simulação para o perfil de temperatura do forno e do alimento, receber e interpretar os comandos do usuário e armazenar as informações no banco de dados e realizar o controle PID enviando constantemente a unidade escrava as mensagens para realização de ajustes a serem aplicados durante o processo de aquecimento. 


\subsubsection{Hardware}

A unidade mestre é composta por um Raspberry Pi, um bluetooth HC-06 e uma tela LCD touch de 5 polegadas (Figura 13). A unidade central utilizada foi um Raspberry Pi modelo 3, com processador quadri-core funcionando a $1.2 \mathrm{GHz}, 1 \mathrm{~Gb}$ de memória RAM, Wifi embutido e 16 Gb de memória persistente em um cartão micro-SD classe 10 para armazenar o sistema operacional (Linux Debian Jessie com kernel 4.4) e o banco de dados.

O bluetooth HC-06 foi conectado diretamente aos GPIO's 14 e 15 do SBC, que possuem a funcionalidade de comunicação serial UART. O console serial foi desabilitado para evitar o conflito do uso da UART pelo kernel. O display capacitivo de 5 polegadas é conectado ao HDMI e diretamente aos GPIO's para acesso às funcionalidades touchscreen, dando controle total ao software diretamente pela tela.

\subsubsection{Software}

Todas as funcionalidades pela qual a unidade mestre é responsável (Seção em 4.2.2) são controladas pelo software de controle, cuja estrutura em árvore das pastas com arquivos de banco de dados, código fonte, imagens e outros podem ser visualizados na Figura 16. 
Figura 16 - Estrutura em árvore da pasta contendo o software de controle.
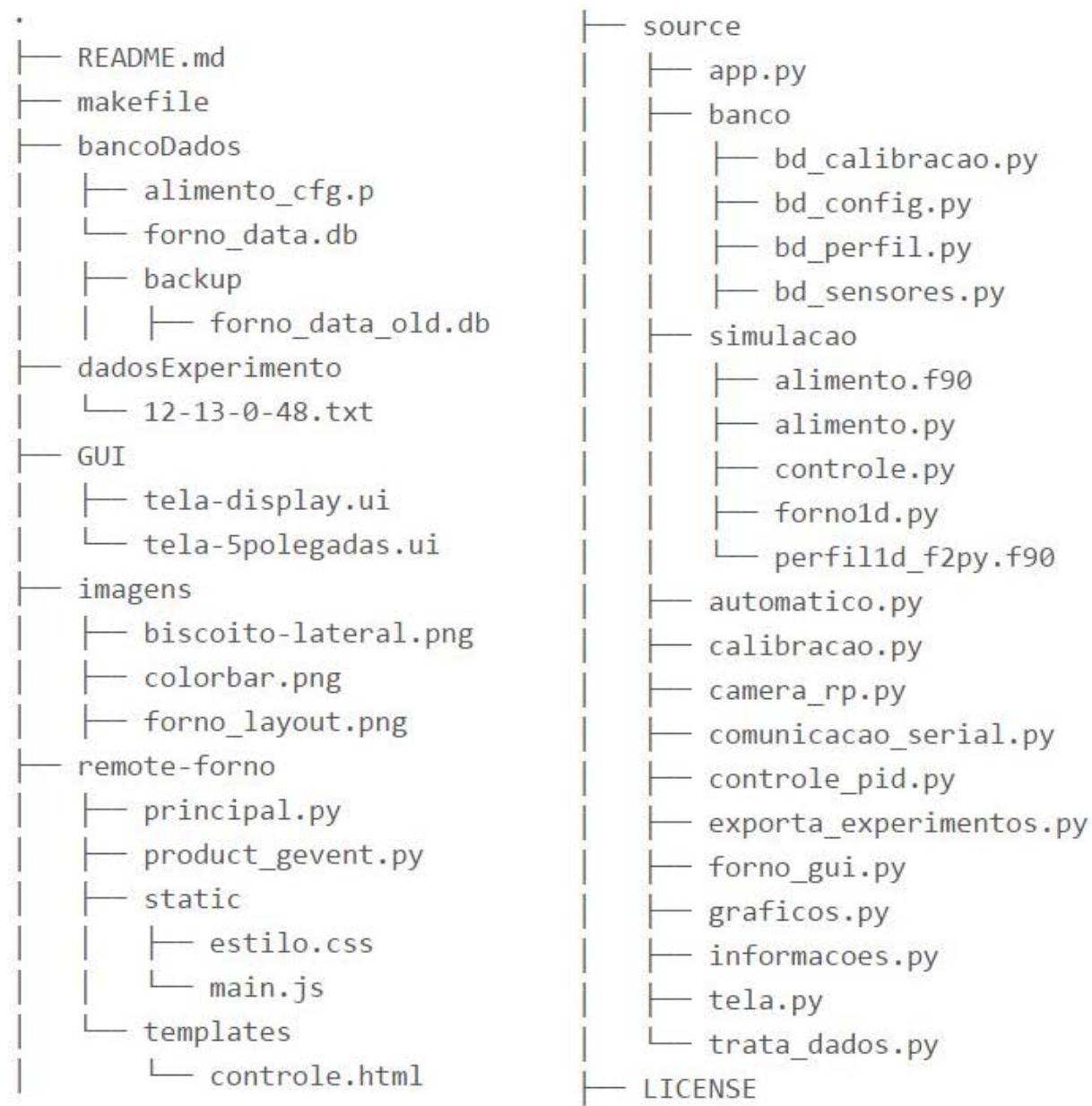

Fonte: Própria autoria.

Na interface gráfica, que é a parte central do software mestre de controle, o usuário tem acesso a todas as informações sobre o forno, pode fazer o controle manual ou automático (Seção 5.4.5), acessar, visualizar e exportar os dados dos experimentos (Seção 4.2.2.2.1).

A interface gráfica foi desenvolvida utilizando o conjunto de bibliotecas QT 4.1, que é um framework de plataforma cruzada para $\mathrm{c}++$ que possui um wrapper para Python, o PyQt4. Todo o layout da interface foi feito utilizando a ferramenta QtDesigner e convertido para a linguagem Python, versão 2.7.12, utilizando a ferramenta pyuic4. 
Todo o código fonte da interface gráfica está na pasta source (Figura 16), separado em scripts de acordo com a funcionalidade, sendo que cada script agrega classes e/ou funções com propósitos afins.

As classes e funções foram projetadas para serem modulares e possuírem flexibilidade, de modo que partes deste projeto possam ser reutilizados ou aproveitados de alguma forma para controle de outro tipo de automação industrial ou fornos de outro tipo e formato.

A interface gráfica pode ser visualizada de duas formas: pelo display LCD diretamente conectado ao Raspberry Pi ou por um computador utilizando o acesso remoto via VNC (Virtual Network Computing - Rede virtual de computadores). Devido a diferença de resolução na tela (800x480 no LCD contra 1080 pelo VNC), duas GUI's diferentes são apresentadas de acordo com o tipo do acesso. As informações sobre os layouts montadas no QtDesigner estão na pasta GUI da Figura 16.

Para acesso por dispositivos móveis uma interface mais simples apenas com os controles principais é disponibilizada na forma de um aplicativo web, feito utilizando o framework Flask para Python e toda a estrutura web está na pasta remote-forno, que pode ser acessado pela porta 5001 do Raspberry Pi com segurança TSL (Transport Layer Security) e login com senha.

\subsection{Persistência de dados}

Para persistência de dados, foi escolhido um banco de dados SQL (Structured Query Language - Linguagem de Consulta Estruturada), utilizando o software sqlite3, que possui uma biblioteca de interface nativa para Python. Foi escolhido o SQlite como gerenciado de banco de dados devido a facilidade de uso e migração e porque não existe concorrência de acessos já que o forno é controlado apenas por um usuário por vez.

$\mathrm{O}$ arquivo com todo o banco de dados está na pasta bancoDados mostrado na Figura 16, com o nome forno-data.db e as configurações de uso no arquivo cfg.p. As 
funções e classes que manipulam o banco de dados, para fazer consultas e inserções estão na pasta banco e separadas em arquivos de acordo com a afinidade.

\subsection{CONTROLE DO PROCESSO}

Para realizar o controle do processo, mantendo a temperatura no valor desejado numa posição do forno ou do alimento, foi desenvolvido um algoritmo de controle PID que foi integrado ao software de controle.

\subsubsection{SOFTWARE CONTROLE PID}

A classe PID, que foi desenvolvida utilizando a linguagem Python2.7, realiza o controle PID do forno, sendo usada pelo programa principal (que possui a interface gráfica com o usuário). O código da classe está disponível no Apêndice A.2.

\subsubsection{RESPOSTA NO TEMPO}

Para encontrar os melhores parâmetros do controle PID $\left(K_{p}, K_{i}\right.$ e $\left.K_{d}\right)$, foram feitos testes em malha aberta no forno para verificar a resposta da temperatura em função do tempo.

Foram realizados testes de subida e descida da temperatura no forno. Iniciando com temperatura ambiente, as resistências eram ligadas e mantidas no mesmo estado até a temperatura estabilizar e então desligadas e aguardando-se a queda até a temperatura ambiente. Estes testes em malha aberta foram realizados mantendo todas as resistências com a mesma potência, sendo que foram testados os valores de $25 \%$, $50 \%, 75 \%$ e $100 \%$, todos em triplicata.

Também foram realizados testes de malha aberta como o descrito acima porém ligando algumas resistências e deixando outras desligadas. As esteiras ligadas tiveram potência fixa de $100 \%$ e as configurações escolhidas para o teste foram:

- Todas as superiores ligadas, todas as inferiores desligadas; 
- Todas as superiores desligadas, todas as inferiores ligadas;

- as resistências centrais ligadas (inferior e superior) e as outras desligadas;

- as resistências laterais ligadas (inferior e superior) as centrais desligadas;

Com o perfil da resposta no tempo, este foi comparado com modelos de resposta impulsiva de primeira e segunda ordem e o método do gradiente descendente foi empregado para encontrar a melhor correlação entre os dados e os coeficientes do modelo.

\subsubsection{OTIMIZAÇÃO DOS PARÂMETROS DE CONTROLE}

Utilizando um modelo de Equação Diferencial de segunda ordem para a resposta da temperatura no tempo (tanto da temperatura da esteira quanto da temperatura do ar dentro da esteira), as constantes da EDO de segunda ordem foram encontradas para corresponder aos resultados dos experimentos de malha aberta. Estes parâmetros foram encontrados pelo método do gradiente descendente utilizando o pacote de computação científica scipy optimize (SCIPY, 2017)

Os valores iniciais de $K_{p}, K_{i}$ e $K_{d}$ foram encontrados utilizando o método de Cohen-Coon (TEMEL SEMIH YAGLI, 2013) baseado nos resultados dos experimentos de malha aberta. Com estes valores iniciais, foi aplicado um algoritmo de gradiente descendente que procura minimizar tempo para o controle atingir o setpoint e estabilizar, encontrando os parâmetros ótimos de $K_{p}, K_{i}$ e $K_{d}$. Estes parâmetros foram então testados em experimentos reais no forno para verificar a sua eficiência.

\subsection{SIMULAÇÃO NUMÉRICA}

As simulações do perfil de temperatura (tant o do forno como do alimento) foram realizadas utilizando o método das diferenças finitas, implementado inicialmente em Python 2.7. As rotinas computacionalmente mais intensas foram então convertidas para subrotinas de fortran90, resultando em uma API criada com o auxílio da ferra- 
menta f2py (F2PY, 2007), que compila as rotinas de fortran utilizando o compilador gfortran4.91 e cria um módulo que pode ser chamado diretamente pelo programa principal em Python.

\subsubsection{PERFIL TÉRMICO DO FORNO}

A simulação do perfil térmico do forno foi realizada para se conhecer a temperatura em função da profundidade no forno. Esta relação da temperatura em função da profundidade é utilizada na simulação da temperatura do alimento e no controle PID. As simulações numéricas foram feitas assumindo que a temperatura no interior do forno é regida pela Equação 2.9, e assumindo as seguintes simplificações:

- Modelo unidimensional, desconsiderando a altura e a largura do forno e levando em conta apenas a profundidade do mesmo;

- Não há convecção forçada;

- O regime permanente é atingido rapidamente em comparação com as grandezas de tempo envolvidas nos processos de assamento;

- O calor no sistema é adicionado apenas pelas resistências (das quais é conhecida a potência dissipada - Figura 10b);

- O forno é considerado um isolante térmico exceto pelas áreas abertas na entrada e saída, onde troca calor com o ambiente;

- A temperatura é conhecida na posição dos três sensores laterais (Figura 12) e à 0,5 metros da entrada e da saída do forno, onde existe equilíbrio térmico com a temperatura ambiente;

Assumindo o estado estacionário, em que $\frac{\partial T}{\partial t}=0$, a Equação governante passa a ser a Equação 2.11, que pode ser resolvida por diferenças finitas, separando-a em um conjunto de equações algébricas descrito pela Equação 2.15, com k variando de 1 a n.

Este conjunto de equações foi resolvido utilizando o método SOR, com a constante $w$ (Equação 2.18) escolhida utilizando a relação de otimização descrita em Young 
O valor de n (número de elementos $k=0 \ldots n$ na Equação 2.18) foi determinado por uma análise de sensibilidade de malha, variando este valor até que a diferença na simulação não fosse significativa. O número de iterações do método também foi descoberto por análise de sensibilidade de malha.

Para validação da simulação, os resultados de temperatura da mesma foram comparados com valores da temperatura de um outro termopar móvel colocado nas posições $0.2 \mathrm{~m}, 0.725 \mathrm{~m}, 1.275 \mathrm{~m}$ e $1.8 \mathrm{~m}$ de profundidade no forno.

\subsubsection{PERFIL TÉRMICO DO ALIMENTO}

A simulação do perfil térmico do alimento foi realizada para se conhecer a temperatura dentro do alimento em função do tempo, com o intuito de ajudar no controle do processo de forneamento em tempo real.

Para encontrar a temperatura em um instante de tempo $t$ no regime não permanente, foi utilizando o método numérico das diferenças finitas FTCS para resolver a Equação 2.10 (Seção 2.3.3.2). O modelo do alimento contém as seguintes simplificações:

- O formato do alimento é cilíndrico (disco), com raio > altura;

- A temperatura inicial do alimento (ao iniciar o processo de forneamento) é a temperatura ambiente;

- Em coordenadas cilíndricas (Figura 17), existe simetria em relação à coordenada $\phi$ e, portanto, a temperatura é dada em função apenas do tempo, e das coordenadas r (raio) e z (altura);

- A massa do alimento é homogênea;

- O calor específico do alimento é dependente da temperatura;

- O valor do coeficiente de condutividade térmica é dependente da temperatura;

- O volume do alimento depende da temperatura, com alteração apenas na altura do cilindro; 
- O alimento troca calor com o ambiente pelas faces superior, lateral e inferior;

- Na face inferior, o alimento troca calor com a bandeja por contato, assumindo que a temperatura na bandeja é a temperatura da esteira e portanto uma condição de contorno de Dirichilet;

- Nas laterais e face superior, o alimento troca calor por radiação e convecção com o meio (ar dentro da esteira);

Figura 17 - Eixo de coordenadas para o modelo da temperatura no alimento.

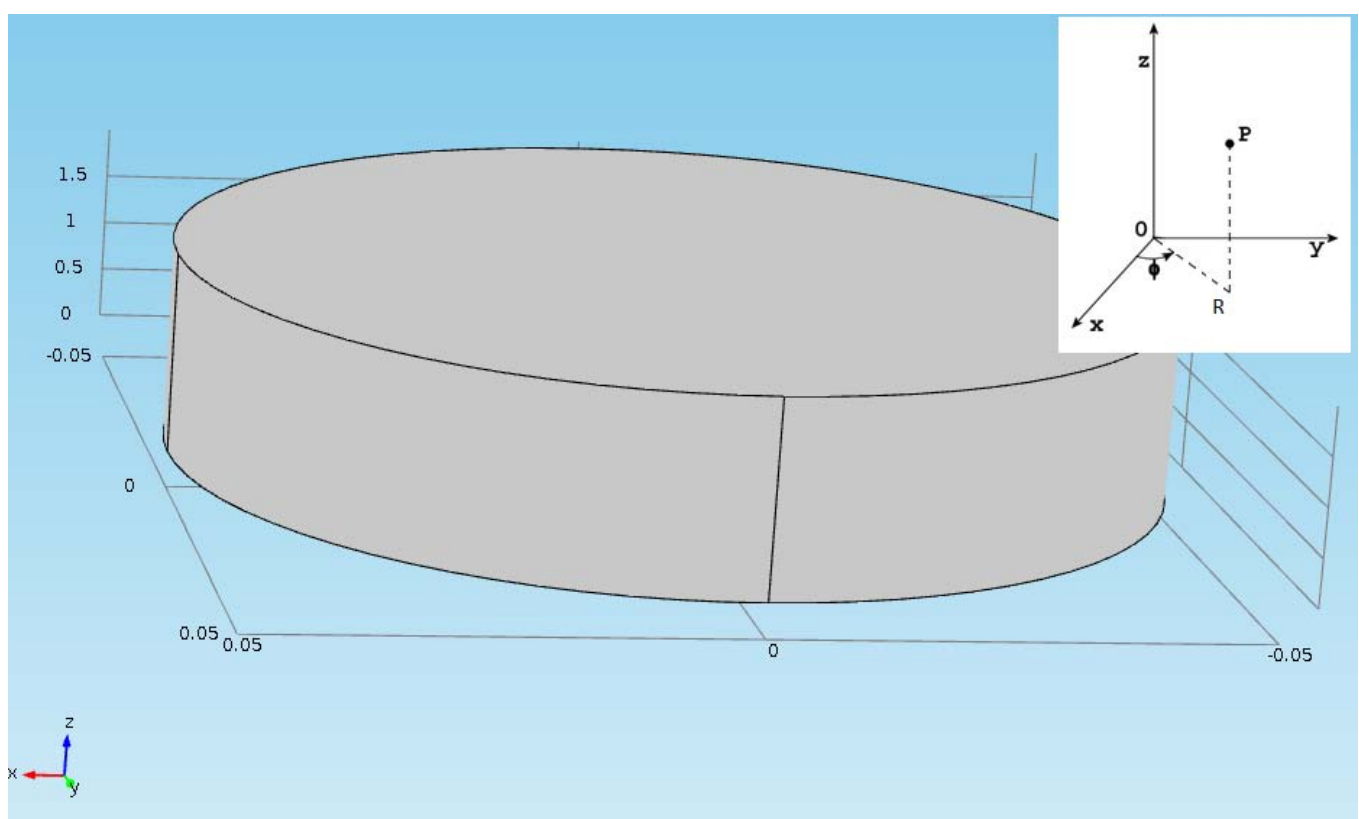

Fonte: Própria autoria. 



\section{RESULTADOS}

\subsection{SIMULAÇÃO NUMÉRICA}

Nesta Seção são apresentados os resultados das simulações que foram realizadas para se conhecer a temperatura ao longo da profundidade do forno (Seção 5.1.1) e dentro do alimento (Seção 5.1.2).

\subsubsection{TEMPERATURA NO FORNO}

O Algoritmo para realizar a simulação descrita na Seção 4.4.1, que calcula o perfil térmico do forno em função dos sensores de temperatura e da potência das resistências, feito em Python-2.7.12 e Fortran-90 é apresentado por completo nos Anexos A.3.1 e A.3.2 e a rotina principal que executa o método numérico é mostrado abaixo.

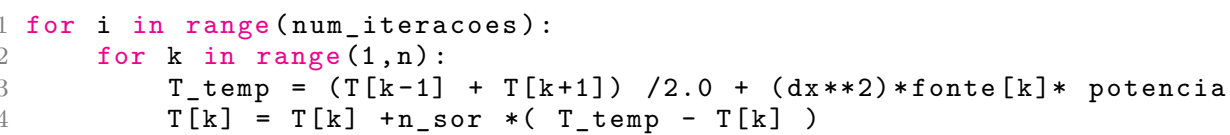

A Figura 18a mostra o resultado da análise de sensibilidade de malha, cujo algoritmo (que se encontra no Anexo A.3.3) foi utilizada para encontrar o número mínimo de elementos discretos $n$ que podem ser utilizados sem comprometer o resultado devido ao tamanho da malha. Para isto, o algoritmo (Apêndice A.3.2) foi chamado com valores de $n$ de 2 a 500 e calculada a diferença entre o resultado em função de $n$.

Com o resultado mostrado na Figura 18a, foi escolhido um valor de $n=50$ para as simulações por não existir variação significativa na simulação para valores de $n$ acima deste número. O valor ótimo para $w$, da Equação 2.18, foi calculado utilizando a relação $w \approx \frac{2}{1+\frac{\pi}{n}}$, de Young (1971), com $n=50$, o que resultou em um valor de $w=1.8818$, que foi utilizado nas simulações. 
O resultado da convergência do algoritmo (utilizando o valor ótimo de $w$ e $n=$ 50), pode ser visto na Figura $18 \mathrm{~b}$ na qual a norma da diferença entre o perfil de temperatura na iteração $T_{i-1}$ e $T_{i}$ é mostrado em função do número de iterações $i$. Com este resultado foi escolhido um número de iterações $i=30$, como um valor suficiente para a convergência do método sem comprometer a eficiência do software de controle.

Figura 18 - Experimento para determinação do número de elementos $n$ e número de iterações $i$ a ser escolhido para o algoritmo de simulação da temperatura do forno.

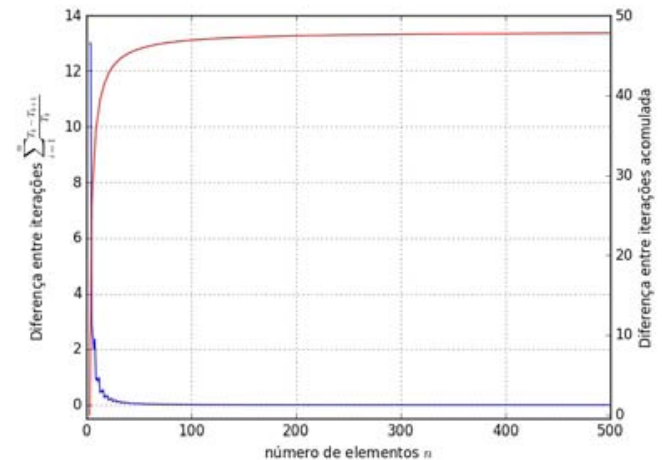

(a) Sensibilidade de malha para o algoritmo (b) SOR em 1 dimensão, com $n$ variando de 2 a 500 e $i=500$. Condições da simulação: $\mathrm{Ta}=27^{\circ} \mathrm{C}, \mathrm{T} 1=180^{\circ} \mathrm{C}, \mathrm{T} 2=220^{\circ} \mathrm{C}$, $T 3=180^{\circ} \mathrm{C}, R 1=R 2=R 3=80 \%$.

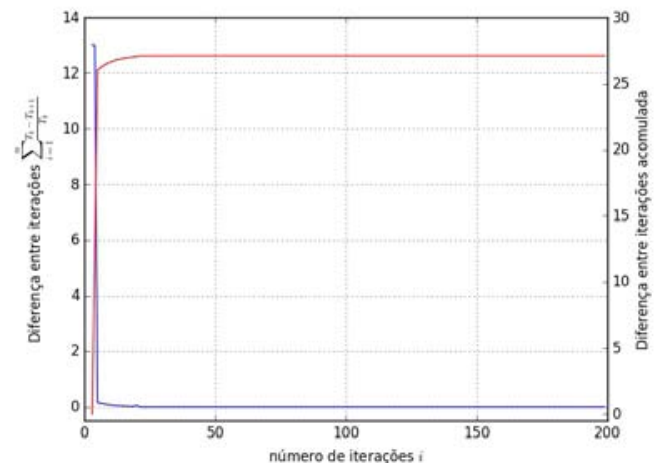

b) Convergência em função do número de iterações para o algoritmo SOR em 1 dimensão, com $i$ variando de 1 a 200 e $n=500$. Condições da simulação: $T a=27^{\circ} \mathrm{C}$, $T 1=180^{\circ} \mathrm{C}, \mathrm{T} 2=220^{\circ} \mathrm{C}, \mathrm{T} 3=180^{\circ} \mathrm{C}$, $R 1=R 2=R 3=80 \%$.

Fonte: Própria autoria.

O algoritmo com os parâmetros acima descritos foi implementado no software de controle, com uma rotina em Fortran que é chamada diretamente pelo programa principal em Python. A Tabela 2 mostra o tempo de execução do algoritmo nas duas linguagens, sendo executados no Raspberry Pi 3.

A conversão do algoritmo para um módulo em Fortran acelerou a resolução numérica em aproximadamente 6 vezes, sendo que o tempo de execução (0.21 segundos) consegue retornar o cálculo da simulação ao controle PID (que chama esta rotina e re- 
Tabela 2 - Tempo para execução do algoritmo. Média de 10 repetições.

\begin{tabular}{ccc}
\hline Linguagem & Tempo (segundos) & Desvio padrão \\
\hline Fortran & 0.22 & 0.012 \\
Python & 1.34 & 0.15 \\
\hline
\end{tabular}

cebe seu retorno) sem atraso, já que a rotina de leitura da temperatura ocorre a cada 5 segundos, quando uma nova leitura de temperatura é recebida do microcontrolador.

A execução do módulo desta simulação é chamada em um processo diferente do programa principal, possibilitando que este continue executando enquanto a simulação ocorre em paralelo, sem atraso ao programa principal, uma vez que a SBC que foi utilizada (Raspberry pi 3) possui 4 núcleos.

Para visualizar o resultado da simulação, o perfil calculado da temperatura em função da posição (Figura 19a) é convertido em um gráfico com mapa de cores (Figura 19b). Visando uma melhor experiência do usuário, a Figura 19b também é apresentado no software de interface com o usuário como uma composição com a imagem do forno obtida pela câmera (Figura 20), usando uma transformada afim na imagem com a ajuda da biblioteca openCV (OPENCV, 2016). 
Figura 19 - Resultado da simulação da temperatura do forno em função da profundidade. Condições do experimento: $\mathrm{R} 1=80 \%, \mathrm{R} 2=50 \%, \mathrm{R} 3=10 \%$ mantidas por 15 minutos. Leitura dos sensores em $\mathrm{t}=15$ minutos: Ta $=27.1, \mathrm{~T} 1=180.2, \mathrm{~T} 2=170.8, \mathrm{~T} 3=155.0$.
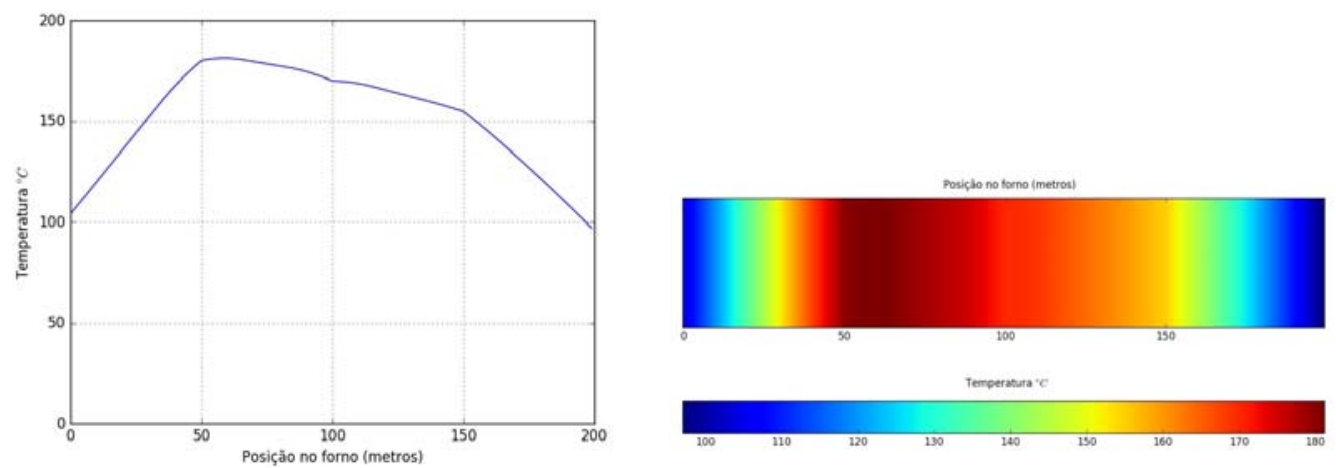

(a) Temperatura $\left({ }^{\circ} \mathrm{C}\right.$ ) em função da profun- (b) Visualização da Figura 19a em escala de didade do forno em metros. cores jet.

Fonte: Própria autoria.

Figura 20 - Resultado da simulação adicionada a imagem do forno na interface de controle.

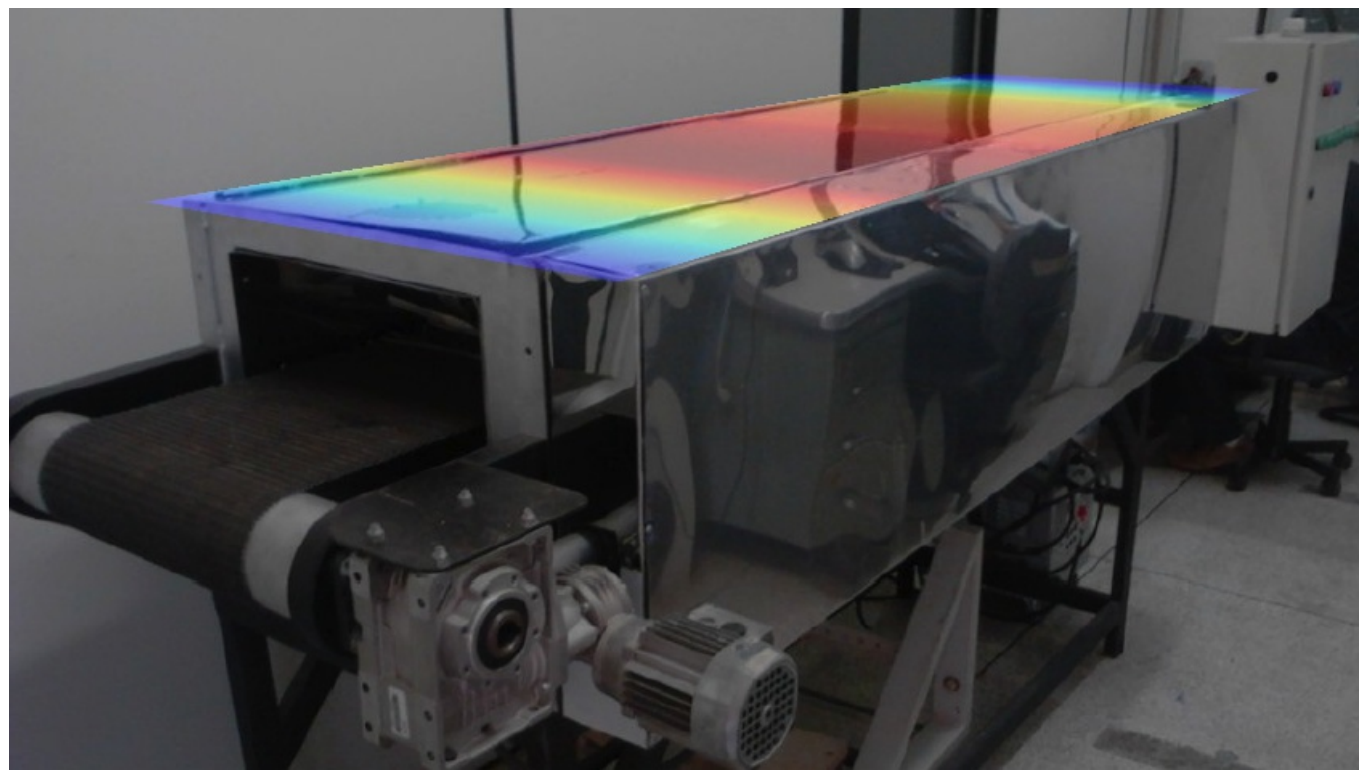

Fonte: Própria autoria.

O resultado da simulação apresentada na Figura 19a foi obtido utilizando os 
valores dos sensores após 15 minutos que as resistências R1, R2, e R3 permaneceram ligadas com potência de $80 \%, 50 \%$ e $10 \%$ respectivamente e as resistências inferiores (R4, R5 e R6) ligadas com $70 \%$ da potência total $(3600$ W). Para verificar o resultado da simulação, outro sensor termopar foi inserido nas posições $0.2 \mathrm{~m}, 0.725 \mathrm{~m}, 1.275 \mathrm{~m}$, $1.8 \mathrm{~m}$ de profundidade e os resultados estão na Tabela 3.

Tabela 3 - Comparação entre predição da simulação e valor lido pelo sensor.

\begin{tabular}{ccc}
\hline $\begin{array}{c}\text { Posição } \\
\text { metros }\end{array}$ & $\begin{array}{c}\text { Temperatura Sensor } \\
{ }^{\circ} \mathrm{C}\end{array}$ & $\begin{array}{c}\text { Temperatura Simulação } \\
{ }^{\circ} \mathrm{C}\end{array}$ \\
\hline 0,2 & 146.1 & 144.6 \\
0,725 & 190.0 & 186.5 \\
1,275 & 168.4 & 165.0 \\
1,8 & 124.5 & 126.1 \\
\hline
\end{tabular}

O resultado da simulação apresentou valores similares aos da leitura dos sensores (Tabela 3), mostrando que a simulação realizada foi útil para prever a temperatura em um ponto distante dos sensores. A informação da temperatura na profundidade em que o alimento se encontra é útil para alimentar as informações do controle PID e também é necessária para a simulação do perfil térmico do alimento.

É importante notar que por ser um forno em escala piloto, o alimento está sempre a pelo menos 0.35 metros de um sensor, tornando os resultados da simulação próximos a uma extrapolação de um perfil linear entre os pontos conhecidos. No entanto, para um forno industrial, que possui tipicamente 15 metros de comprimento, a simulação se torna crucial para evitar o uso de um número elevado de sensores no forno.

\subsubsection{TEMPERATURA NO ALIMENTO}

Para o cálculo da temperatura no alimento foi utilizado o método FTCS com as condições de contorno e simplificações assumidas na Seção 4.4.2. A Equação 2.10 foi convertida em coordenadas cilíndricas, considerando $\frac{\partial T}{\partial \phi}=0$ e aplicada a discretização descrita pelas equações 2.13 e 2.14. Isto leva à Equação 5.1 como descrito na Seção 
2.3.3.2 no desenvolvimento para a Equação 2.19.

$\frac{T_{i, j}^{n}-T_{i, j}^{n-1}}{\Delta t}=\alpha \cdot\left(\frac{T_{i+1, j}^{n-1}-2 \cdot T_{i, j}^{n-1}+T_{i-1, j}^{n-1}}{\Delta r^{2}}+\frac{1}{r} \cdot \frac{T_{i+1, j}^{n-1}-T_{i, j}^{n-1}}{\Delta r}+\frac{T_{i, j+1}^{n-1}-2 \cdot T_{i, j}^{n-1}+T_{i, j-1}^{n-1}}{\Delta z^{2}}\right)$

Sendo $\alpha=\frac{k}{\rho c_{p}}$, e $i$ e $j$ os índices dos elementos discretos nas coordenadas $r$ e $z$, $\Delta r$ e $\Delta z$ o tamanho destes elementos e $n$ o índice dos elementos discretos no tempo. Como o método FTCS segue o stencil da Figura 5, podemos isolar $T_{i, j}^{n+1}$ e calculá-lo em função do instante anterior $n-1$, o que significa rearranjar a Equação 5.1 no formato abaixo.

$T_{i, j}^{n}=T_{i, j}^{n-1}+\Delta t \cdot \alpha \cdot\left(\frac{T_{i+1, j}^{n-1}-2 \cdot T_{i, j}^{n-1}+T_{i-1, j}^{n-1}}{\Delta r^{2}}+\frac{1}{r} \cdot \frac{T_{i+1, j}^{n-1}-T_{i, j}^{n-1}}{\Delta r}+\frac{T_{i, j+1}^{n-1}-2 \cdot T_{i, j}^{n-1}+T_{i, j-1}^{n-1}}{\Delta z^{2}}\right)$

Devido a estabilidade condicional do método, a escolha do tempo $\Delta t$ deve ser relacionada aos parâmetros $\alpha, \Delta r$ e $\Delta z$ pela Inequação 5.3, descrita por Kreith, Manglik e Bohn (2012), para coordenadas cartesianas em duas dimensões.

$$
\alpha \frac{\Delta t}{(\Delta x)^{2}}+\alpha \frac{\Delta t}{(\Delta y)^{2}}+\alpha \frac{\Delta t}{(\Delta z)^{2}}<\frac{1}{2} .
$$

Considerando a transformação para coordenadas cilíndricas e da Equação 5.2, temos a Equação 5.4.

$$
\alpha \frac{\Delta t}{(\Delta z)^{2}}+\alpha \frac{\Delta t}{(\Delta r)^{2}}+\alpha \cdot \frac{\Delta t}{\Delta r}<\frac{1}{2} .
$$

Para resolver a Equação 5.2, um algoritmo foi desenvolvido em Python2.7 (Anexo A.4.1) com a rotina computacionalmente mais custosa convertida para Fortran-90 (Anexo A.4.2) como um módulo que pode ser chamado pelo programa principal. A parte principal do algoritmo é apresentada abaixo.

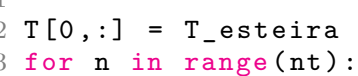




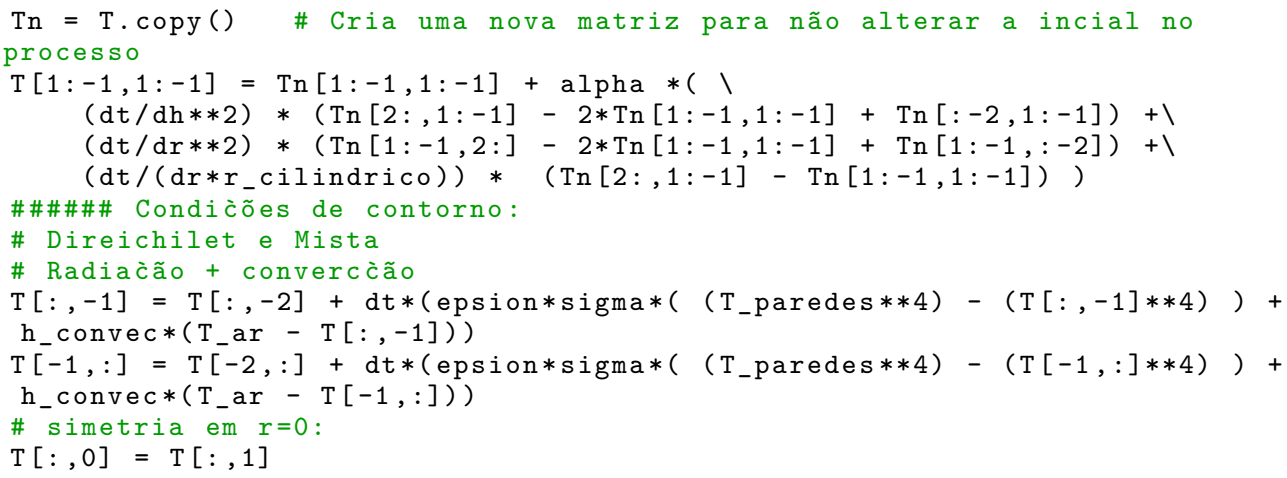

Os valores de $\Delta z$ e $\Delta r$ foram escolhidos por análise de sensibilidade de malha, variando o número de elementos na malha no eixo r entre 2 e 200, com o número de elementos no eixo z dependente de r pela Equação 5.5

$$
N_{z}=N_{r} \cdot \frac{H}{R}
$$

Em que H é a altura do alimento, R o raio do mesmo e $N_{z}$ e $N_{r}$ são os números de elementos da malha dos eixos $z$ e $r$ respectivamente. Para o valor de $\Delta t$ foi escolhido o valor de $\frac{1}{8}$ no lado direito da inequação 5.4 para garantir a estabilidade.

O parâmetro $N_{z}$ da Equação 5.5 foi utilizado para realizar uma análise de sensibilidade de malha cujo resultado é apresentado na Figura 21. Foi escolhido um valor de $N_{r}=30$, visto que a diferença na simulação é muito pequena para valores maiores. Pela interface de controle (Seção 5.4.5.3), o usuário poderá inserir e/ou escolher o tipo de alimento que será utilizado, fornecendo as informações sobre as propriedades físicas do mesmo. Para os testes da simulação, dois alimentos tipicamente utilizados em fornos tipo esteira foram escolhidos, o biscoito e o cookie, cujas propriedades relevantes para a simulação foram retiradas da literatura (HAYAKAWA; HWANG, 1981; SAKIN; KAYMAK-ERTEKIN; ILICALI, 2007; KULACKI; KENNEDY, 1978; BAIK et al., 1999; CAMPINAS, 2011) e se encontram na Tabela 4. Ao inserir um novo alimento, os valores da Tabela 4 são informados pelo usuário na interface gráfica e os valores são salvos no banco de dados do sistema de controle e são acessíveis em futuros experimentos. 
Figura 21 - Análise de sensibilidade de malha em função do número de elementos no eixo $\boldsymbol{r} N_{r}$

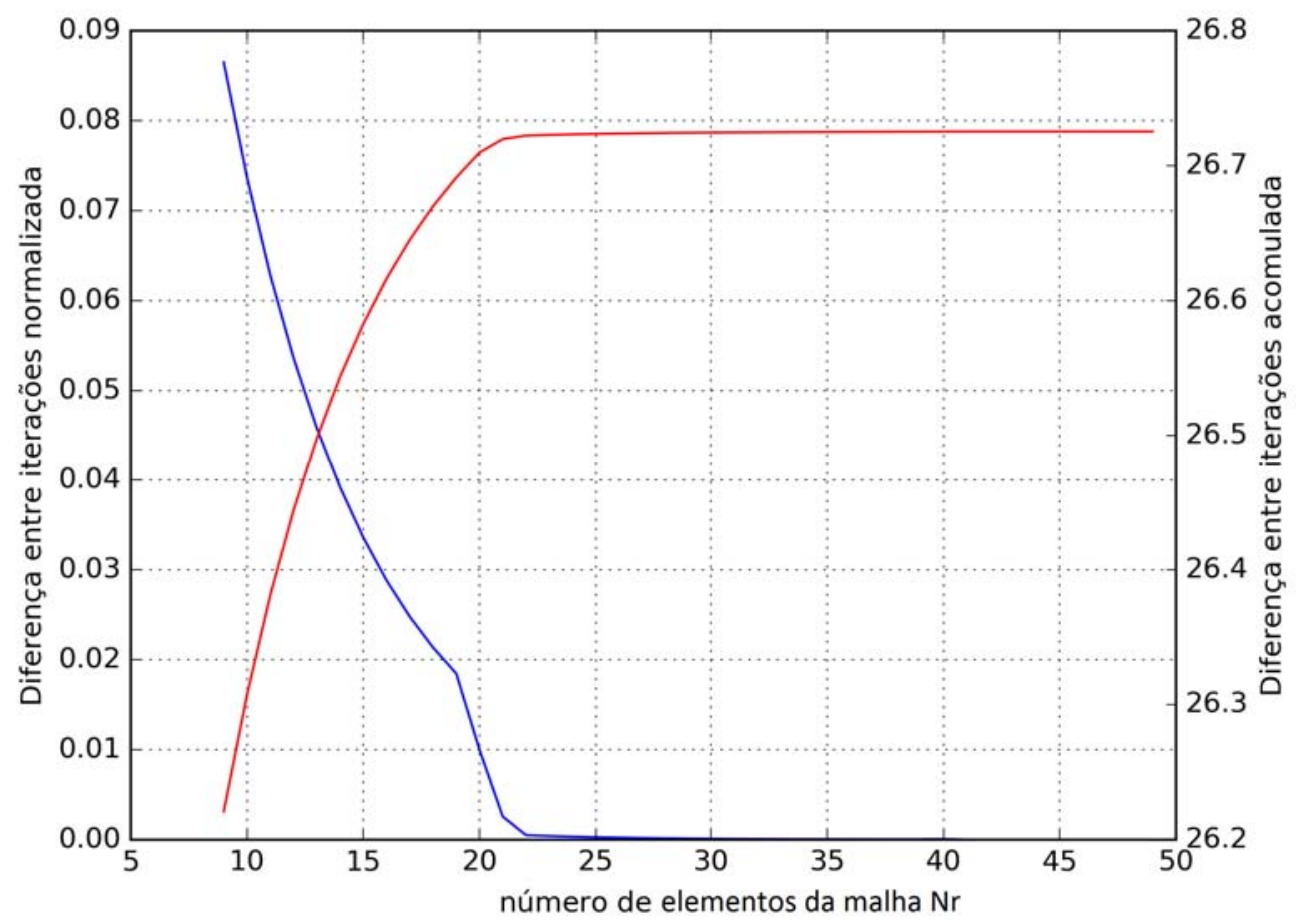

Fonte: Própria autoria.

O algoritmo foi testado utilizando as propriedades e dimensões do cookie da Tabela 4, em uma simulação de assamento mantendo a temperatura da esteira e parede interna do forno em $207{ }^{\circ} \mathrm{C}$ e o ambiente em $27{ }^{\circ} \mathrm{C}$ e tempo variando de 0 à 30 minutos. Para validar o algoritmo, o resultado desta simulação foi comparado ao resultado obtido pelo software Comsol5.0 (COMSOL, 2005), com as mesmas condições de temperatura, propriedades do alimento e geometria, com malha triangular fina. Os resultados comparando as simulações estão apresentados na Figura 22, que mostra a temperatura no centro do alimento em função do tempo até o fim do processo. 
Tabela 4 - Propriedades físicas dos alimentos de teste, cookie e cupcake.

\begin{tabular}{|c|c|c|c|c|}
\hline Sigla & Informação & Unidade & Cookie & cupcake \\
\hline $\mathrm{r}$ & raio do alimento & $\mathrm{cm}$ & 5 & 4 \\
\hline h & $\begin{array}{l}\text { altura do alimento } \\
\text { (inicial e final) }\end{array}$ & $\mathrm{cm}$ & $1.5-2.5$ & $1.5-4$ \\
\hline$k$ & $\begin{array}{l}\text { condutividade térmica } \\
\text { temperatura ambiente }\end{array}$ & $\frac{W}{m K}$ & 0.295 & 0.1064 \\
\hline$k$ & $\begin{array}{l}\text { condutividade térmica } \\
\text { temperatura final }\end{array}$ & $\frac{W}{m K}$ & 0.414 & 0.2064 \\
\hline$\rho$ & $\begin{array}{l}\text { densdidade tempera- } \\
\text { tura ambiente }\end{array}$ & $\frac{K g}{m^{3}}$ & 705 & 629 \\
\hline$\rho$ & $\begin{array}{l}\text { densdidade tempera- } \\
\text { tura final }\end{array}$ & $\frac{K g}{m^{3}}$ & 466 & 236 \\
\hline$h_{\text {conv }}$ & $\begin{array}{l}\text { coeficiente de convec- } \\
\text { ção }\end{array}$ & $\frac{W}{m^{2} K}$ & 5 & 4 \\
\hline$c_{p}$ & $\begin{array}{l}\text { Calor específico tem- } \\
\text { peratura ambiente }\end{array}$ & $\frac{J}{K g K}$ & 2420 & 2516 \\
\hline$c_{p}$ & $\begin{array}{l}\text { Calor específico tem- } \\
\text { peratura final }\end{array}$ & $\frac{J}{K g K}$ & 3182 & 2658 \\
\hline e & $\begin{array}{l}\text { emisividade corpo ne- } \\
\text { gro }\end{array}$ & 1 & 0.95 & 0.92 \\
\hline$T_{c}$ & $\begin{array}{l}\text { temperatura final } \\
\text { centro }\end{array}$ & ${ }^{\circ} \mathrm{C}$ & 200 & 190 \\
\hline$T_{s}$ & $\begin{array}{l}\text { temperatura final } \\
\text { superfície }\end{array}$ & ${ }^{\circ} \mathrm{C}$ & 210 & 195 \\
\hline
\end{tabular}

Na Figura 23 temos a mesma simulação descrita anteriormente, visualizada como um corte no plano $y z$ passando pelo centro do alimento no instante de tempo $t=1.000$ segundos. 
Figura 22 - Temperatura no centro do alimento e no meio da superfície superior em função da temperatura para os dois softwares, Python/Fortran, e Comsol.

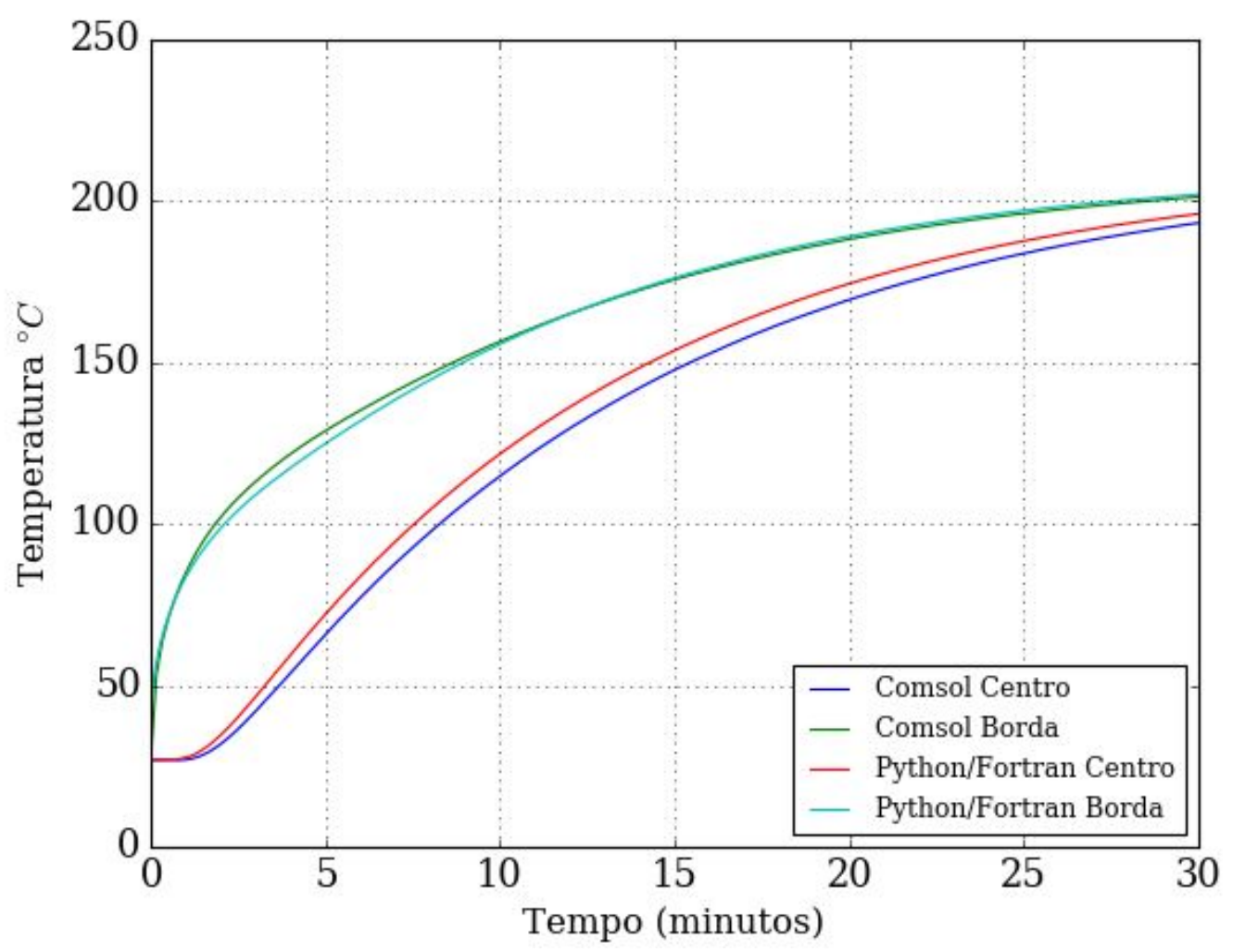

Fonte: Própria autoria.

Com os resultados apresentados nas Figuras 22 e 23, observamos uma concordância entre as simulações. O uso de um software de simulação como o Comsol traz facilidades como a interface gráfica, possibilidade de importar formas geométricas feitas em outros softwares e a abstração completa do método numérico utilizado. No entanto, o uso de um software de alto nível requer muito mais processamento e memória, o que dificulta o uso em sistemas embarcados como o Raspberry Pi. Além disso, por ser um software fechado, existem limitações no uso do mesmo como uma API que possa ser chamada por outro programa para simulação e coleta de resultados de forma flexível.

Para realizar experimentos com outros alimentos ou outras formulações, o usuário 
Figura 23 - Comparação da simulação da temperatura no alimento em um corte central no eixo $x y$, utilizando o algoritmo desenvolvido em Python/Fortran e o software Comsol.

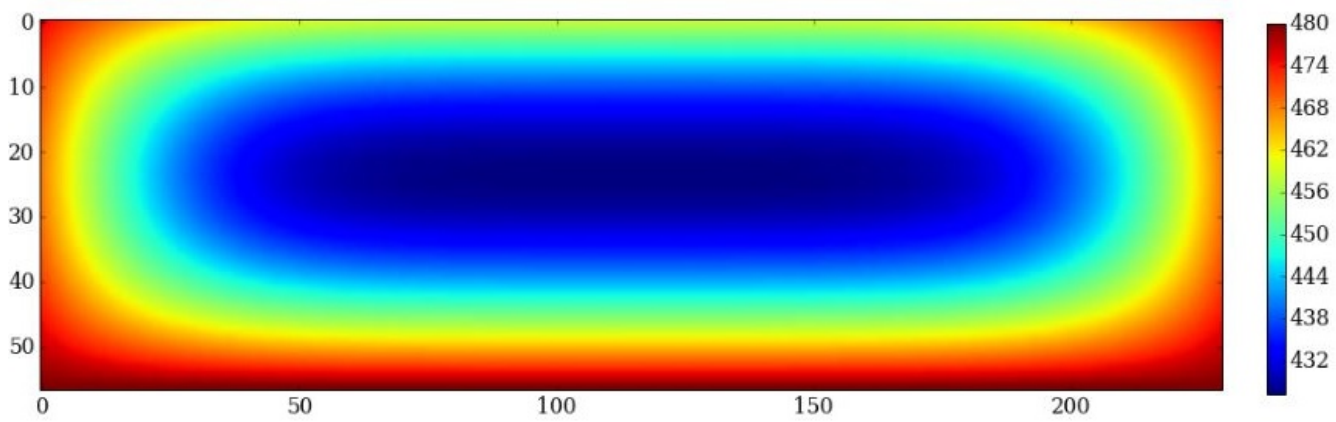

(a) Python/Fortran

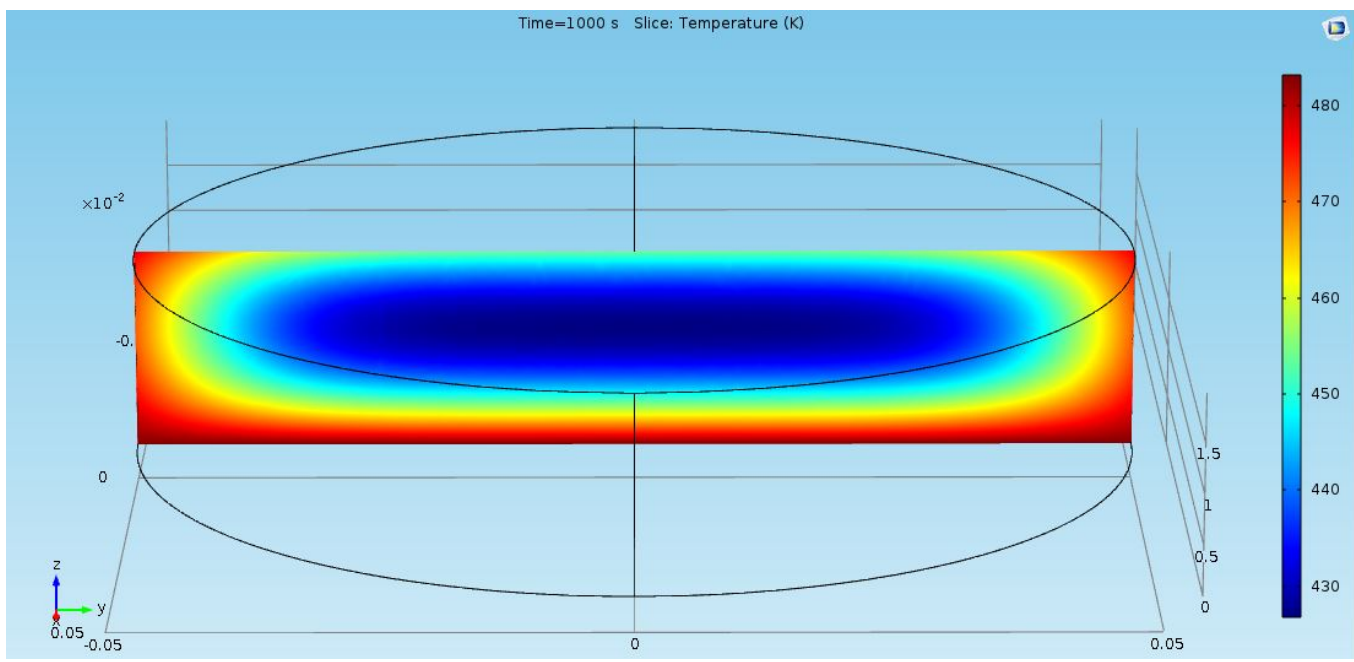

(b) Comsol5.0

Fonte: Própria autoria.

deverá fornecer os valores da Tabela 4, que podem ser obtidos na literatura (quando houver), experimentalmente ou pelo cálculo centesimal (CAMPINAS, 2011). Futuros experimentos poderão ser feitos para comparar a temperatura simulada com a real com o intuito de validar o modelo de simulação. 


\subsection{CONTROLE DO PID}

\subsubsection{CONTROLE POR MODULAÇÃO DE LARGURA DE PULSO (PWM)}

O controle da potência das resistências foi feito com um PWM, que envia um sinal modulado (ligado/desligado) e a razão entre o período ligado e desligado implicará na potência dissipada pela resistência. Este modo de controle foi escolhido para não haver necessidade de alterações no sistema de aquecimento já que o PWM foi implementado via software.

Os sistemas PWM geralmente utilizam uma chave de estado sólido como um transistor bipolar ou MOSFET, porém devido alta corrente que passa por cada resistor (aproximadamente 16.5 amperes), o forno utiliza um relê mecânico já que um de estado sólido seria consideravelmente mais caro.

A limitação do uso de um relê mecânico é o período mínimo do PWM que pode ser utilizado, já que a vida útil de um relê está ligada ao número de chaveamentos efetuados. Esta limitação, junto com o tempo que o chaveamento demora para ocorrer limitam severamente o período mínimo do PWM, que no software foi estabelecido com um limite inferior de 5 segundos.

O Arduino possui uma função nativa de controle PWM chamada analog Write (pino, valor), que produz um sinal PWM com período de 0.00204 segundos $(490 \mathrm{~Hz})$ utilizando o Timer0 do Atmega328p. Apesar da possibilidade de se alterar o período da função analog Write, não é aconselhável utilizar um valor tão alto de período como da ordem de segundos devido ao sobrecarregamento do Timer do microcontrolador, que também é utilizado para outras funções e por isso um método de controle de PWM foi desenvolvido e adicionado a biblioteca controleProcesso.

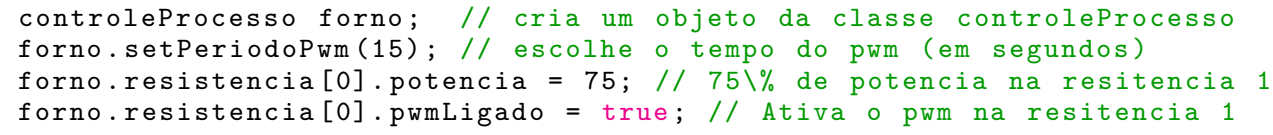

Nas linhas de código acima, temos um exemplo do uso da biblioteca controleProcesso, no qual na linha 1 é instanciado um objeto da classe mãe na biblioteca, na 
linha 2 o período do PWM é escolhido (em segundos), na linha 3 o valor da potência (em \% com valores inteiros de 0 a 100) é passado e na linha 4 o controle é iniciado. Com este exemplo é possível ver as facilidades e flexibilidade de utilizar a biblioteca, ao invés do usuário ter que alterar manualmente o código fonte.

A Figura 24, mostra a temperatura do sensor da esteira e do centro do forno nos testes do PWM, iniciando com a temperatura ambiente e mantendo as potências de $90 \%, 75 \%, 50 \%$ e $25 \%$ (Figura 24d, 24c, 24b e 24a respectivamente).

Figura 24 - Teste do aquecimento com potência parcial, iniciando à temperatura ambiente.

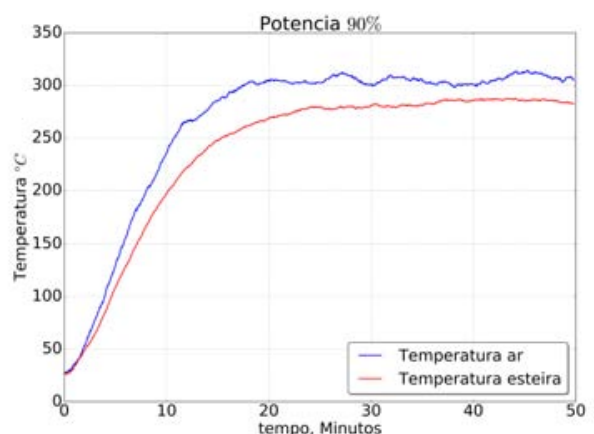

(a) Todas as resistências - PWM $90 \%$

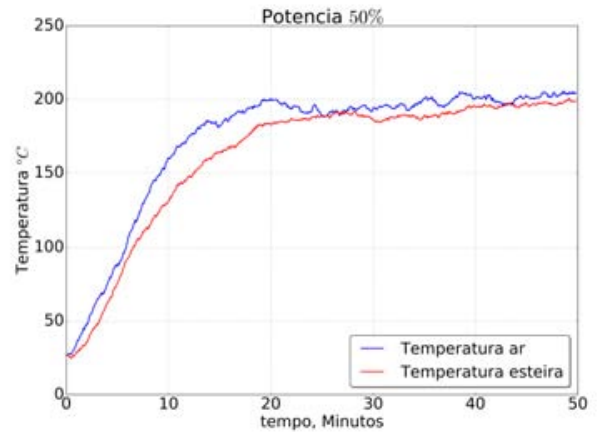

(c) Todas as resistências - PWM $50 \%$

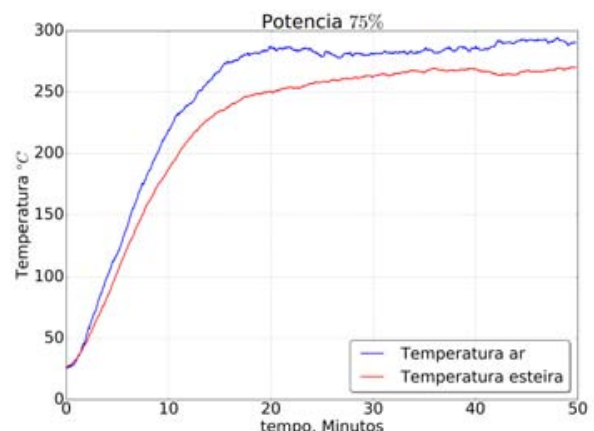

(b) Todas as resistências - PWM $75 \%$

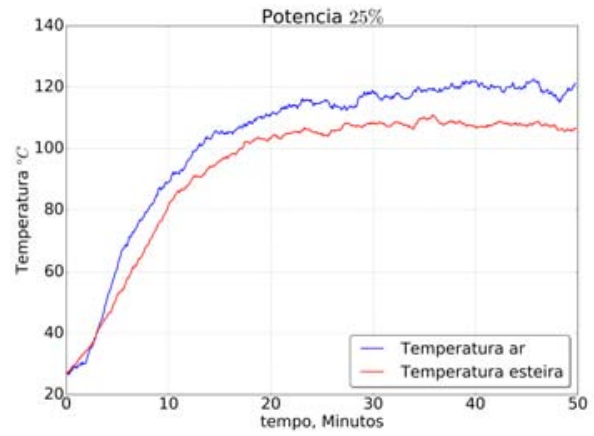

(d) Todas as resistências - PWM $25 \%$

Fonte: Própria autoria. 


\subsubsection{MODELO DA RESPOSTA POTÊNCIA-TEMPO-TEMPERATURA DO FORNO}

\subsubsection{Controles e zonas de aquecimento}

O forno foi inicialmente concebido para possuir três zonas de aquecimento, porém devido a falta de exaustores e fluxo de ar forçado que são comuns em muitos fornos industriais deste tipo, os experimentos (Figura 25a e 25b) mostraram que não é possível manter três zonas de temperatura completamente independentes devido a transferência de calor que ocorre no forno.

Figura 25 - Teste das resistências, várias configurações de potência das resistências

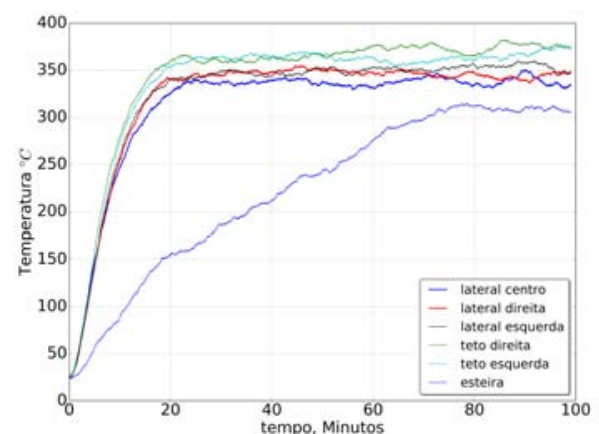

(a) Todas as resistências superiores ligadas $100 \%$, inferiores desligadas.

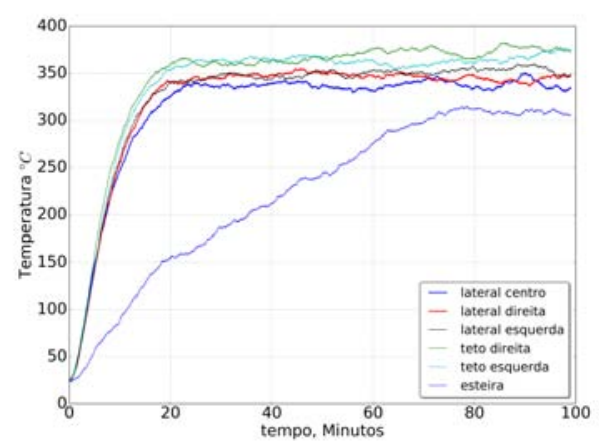

(c) Laterais inferiores e superiores liga- (d) das $100 \%$, centro superior e inferior desligadas.

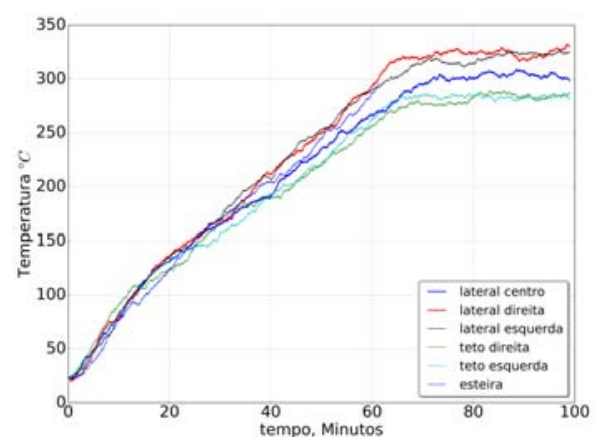

(b) Todas as resistências inferiores ligadas $100 \%$, superiores desligadas.

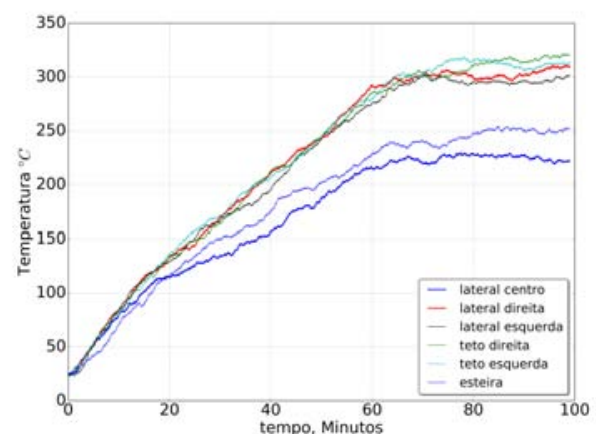

(d) Laterais inferiores e superiores desligadas, centro superior e inferior ligadas $100 \%$.

Fonte: Própria autoria.

Devido a esta dificuldade de manter zonas de temperatura separadas, foi escolhido 
utilizar um controle com um perfil de temperatura que varia em função do tempo e não da profundidade no forno, já que nos experimentos os testes com potências iguais mostraram que não há variação significativa da temperatura com a profundidade (Figura 25c e 25d.

Como discutido nas subseções 4.4.2 e 4.4.2, as temperaturas a serem controladas (objetivo) são a da esteira e do ar próximo ao alimento, que influenciam no processo de aquecimento do mesmo. Foram utilizados dois controles distintos atuando em conjunto. Como mostrado na Figura 26, o controlador 1 é o responsável por manter a temperatura no ar próximo ao alimento no valor desejado, utilizando a como informação a temperatura atual no ar (resultado da simulação numérica da temperatura no forno) controlando as resistências superiores. O controlador 2 é responsável por manter a temperatura da esteira, utilizando como informação o sensor da esteira.

Como a temperatura na esteira é afetada tanto pelas resistências inferiores como superiores, o estado das resistências superiores é utilizado pelo controlador 2 para calcular a potência das resistências inferiores (Equação 5.6) de forma que potência total necessária para se atingir a temperatura da esteira seja obtida.

$$
u_{2}(t)=u_{2-\text { parcial }}-u_{1}(t)
$$

Sendo $u_{2}(t)$ é a saída do controlador 2 que comandará a potência das resistências

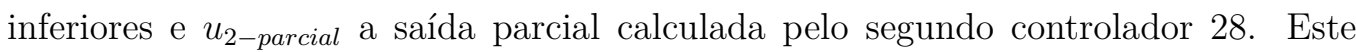
valor é o necessário para atingir a temperatura da esteira, porém a saída real para as esteiras inferiores é recalculada em função da potência nas resistências superiores $u_{1}(t)$, que foi ajustada pelo controlador 1. 
Figura 26 - Diagrama do processo de controle da temperatura no forno.

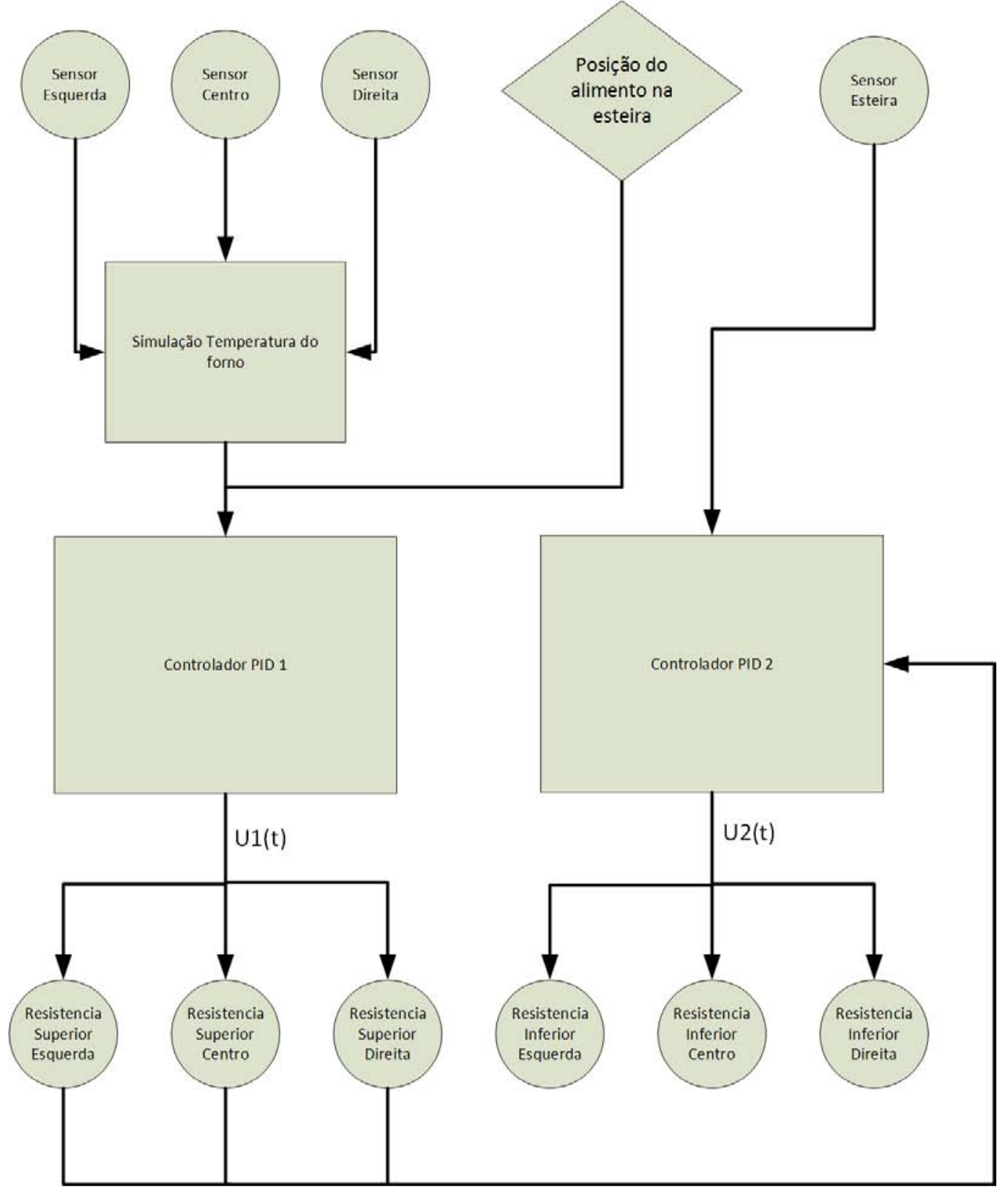

Fonte: Própria autoria.

\subsubsection{Determinação do modelo de resposta no tempo}

Os testes em malha aberta, descritos na seção 4.3.2 são apresentados na Figura 28, mostrando a temperatura no centro do forno e na esteira. Com os dados da resposta 
térmica do forno em malha aberta, foi testado um modelo de equação diferencial de segunda ordem para a temperatura, mostrado na Equação 5.8 .

$$
\begin{aligned}
& \frac{\mathrm{d}^{2} x}{\mathrm{~d} t^{2}}+\frac{\rho}{m} \frac{\mathrm{d} x}{\mathrm{~d} t}+\omega_{0}^{2} x-\frac{F(t)}{m}=0 \\
& \frac{\mathrm{d}^{2} T}{\mathrm{~d} t^{2}}+A \frac{\mathrm{d} T}{\mathrm{~d} t}+B \cdot T+C \cdot P=0
\end{aligned}
$$

Figura 27 - Experimento de malha aberta, 50 minutos potência máxima, 50 minutos desligado.

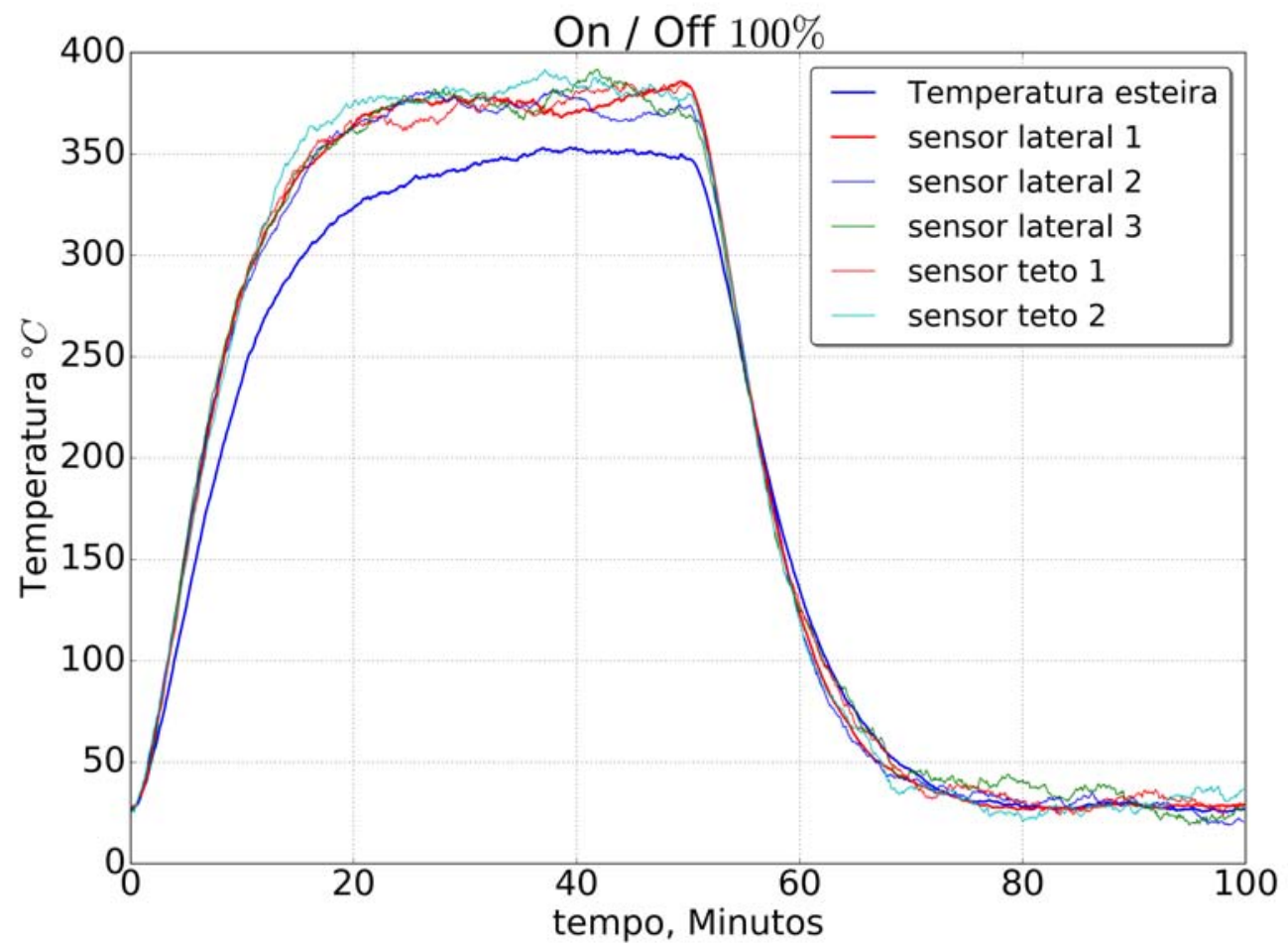

Fonte: Própria autoria.

Para dar um sentido físico a equação, podemos compará la ao sistema massamola amortecido forçado, que possui um formato similar (Equação 5.7) e pode ser tido como referência de modelo de segunda ordem.

Correlacionando a Equação 5.8 com a 5.7, notamos que o termo $A$ está ligado com a "inércia" do sistema (quanto maior este valor maior o tempo para se atingir a 
Figura 28 - Experimento de malha aberta. Ligado 50 minutos, desligado 50 minutos.

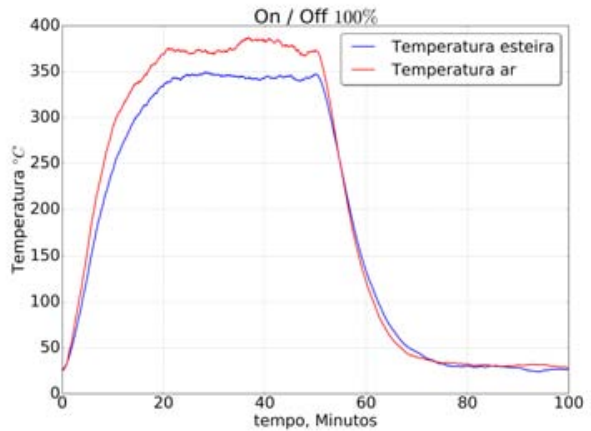

(a) Ligado com potência $100 \%$

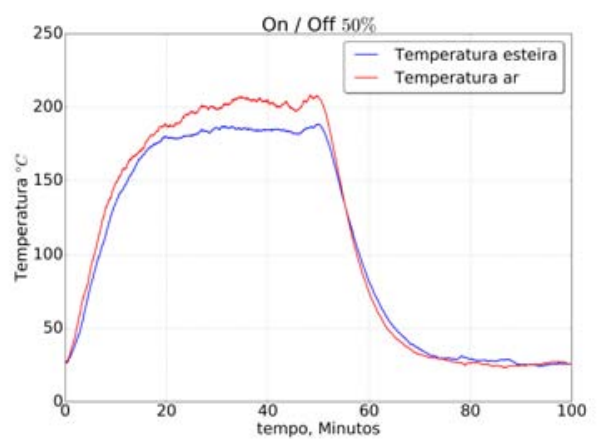

(c) Ligado com potência $50 \%$

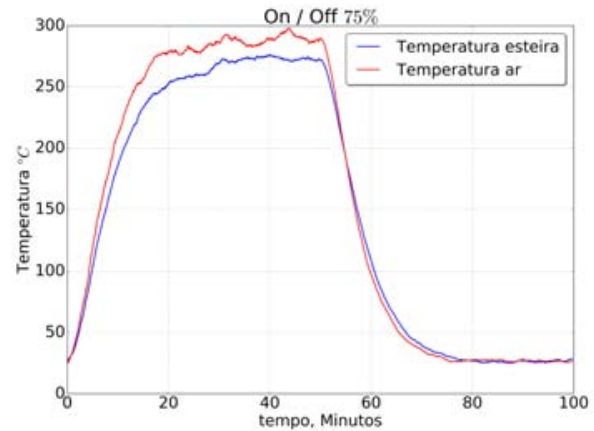

(b) Ligado com potência $75 \%$

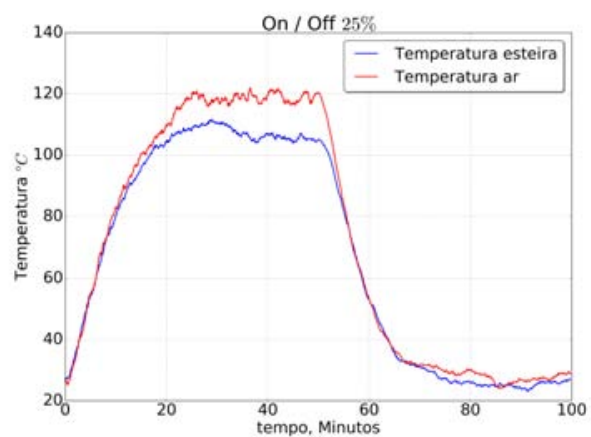

(d) Ligado com potência $25 \%$

Fonte: Própria autoria.

temperatura final), $B$ a "elasticidade" do sistema e $C$ a uma força externa, que para o modelo do forno é diretamente proporcional a Potência $P$ (em $\%$ de 0 a 100) das resistências.

Utilizando a Equação 5.8, foi construído uma função em Python2.7 (Seção A.2.2) para resolvê-la numericamente, separando-a em duas equações de primeira ordem e aplicando o método de Runge-Kutta de $4^{a}$ ordem através da biblioteca scipy para Python.

Esta função tem como entrada o período de evolução temporal que será calculado, o valor do elemento de tempo discreto $d t$, o valor da potência das resistências em função do tempo (um vetor com $\frac{t}{d t}$ elementos) e os coeficientes $A, B$ e $C$.

$T_{-}$sim $=$evolui_tempo( $t_{-}$final $\left.=20 * 60, \quad d t=0.01, A=10, \quad B=15, \quad C=200\right)$ 
No exemplo anterior, a função é chamada e retorna uma simulação de 20 minutos (20*60) que será calculada com passo de 0.01 segundos e as constantes da Equação 5.8 a ser resolvidas também são passadas como parâmetro à função, que retorna um vetor com tamanho $120.001(1+20 * 60 / 0.01)$ correspondente a temperatura no tempo com as condições fornecidas.

Com os resultados dos experimentos de malha aberta (Figura 28) e a função evolui_tempo, foi aplicado o algoritmo do gradiente descendente (utilizando o método optimize da biblioteca scipy) para encontrar os parâmetros $A, B$ e $C$ que minimizem a diferença entre a temperatura experimental e o resultado da função evolui_tempo, encontrando assim as constantes que definem a Equação 5.8, apresentados na Figura 29. 
Figura 29 - Experimentos de malha aberta e simulação da evolução temporal. Temperatura da esteira e do ar no centro do forno.
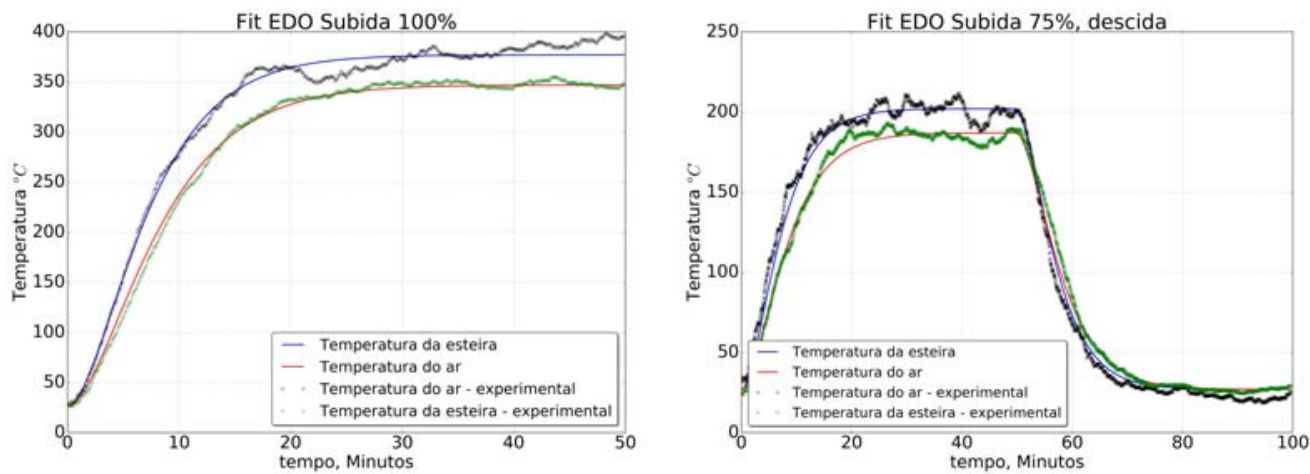

(a) Resistências ligadas na potência máxima, (b) $75 \%$ de potência com início em tempeinício em temperatura ambiente. ratura ambiente até 50 minutos. Resistências desligadas de 50 à 100 minutos.
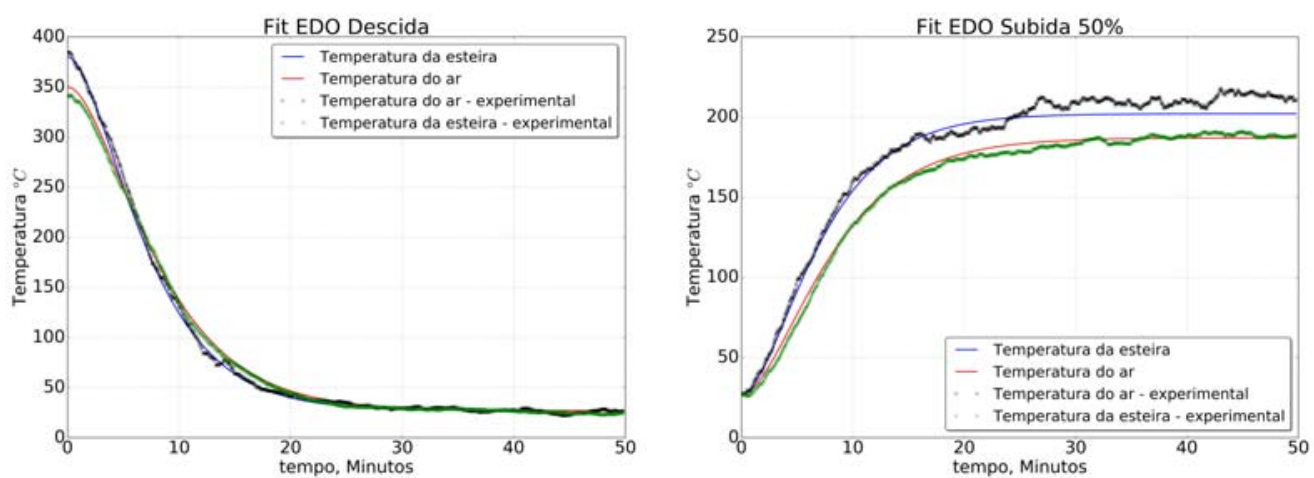

(c) Início em potência máxima com tempe- (d) $50 \%$ de potência, início em temperatura ratura estabilizada, todas as resistências ambiente.

desligadas em $t=0$.

Fonte: Própria autoria.

Os resultados dos parâmetros $A, B$ e $C$ encontrados pelo método do gradiente descendente estão na Tabela 5. 
Tabela 5 - Resultado das constantes da Equação 5.8 que melhor representa os dados experimentais.

\begin{tabular}{cccc}
\hline Constantes & $A$ & $B$ & $C$ \\
\hline Ar & $8.531 \cdot 10^{-3}$ & $1.806 \cdot 10^{-5}$ & $6.37 \cdot 10^{-5}$ \\
Esteira & $7.508 \cdot 10^{-3}$ & $1.406 \cdot 10^{-5}$ & $4.511 \cdot 10^{-5}$ \\
\hline
\end{tabular}

\subsubsection{AJUSTES DO CONTROLADOR}

Utilizando o modelo matemático encontrado na Seção 5.2.2, foram realizados os procedimentos para determinação dos parâmetros ótimos do controlador e então testes reais no forno para verificar a eficiência do mesmo.

\subsubsection{Determinação dos parâmetros do controlador}

Utilizando a EDO 5.8 com os parâmetros da Tabela 5, esta equação foi utilizada para simular a evolução temporal da temperatura do forno (ar e esteira), sob o controle PID. Foi desenvolvida uma função em Python, simulacaocontrole(Kp, Ki, $K d, t 0, t f$, setpoint), disponível no Anexo A.2.2, para realizar esta evolução temporal com o controle PID em função dos parâmetros $k_{p}, k_{i}$ e $k_{d}$. Para testar a eficiência do controle, a simulação foi testada em um perfil térmico iniciando a temperatura ambiente e realizando os seguintes setpoints:

- Setpoint $300{ }^{\circ} \mathrm{C}: 0$ - 50 minutos;

- Setpoint $120{ }^{\circ} \mathrm{C}: 50$ - 100 minutos;

- Setpoint $250{ }^{\circ} \mathrm{C}: 100$ - 150 minutos;

- Setpoint $180{ }^{\circ} \mathrm{C}: 150$ - 200 minutos;

Para encontrar os melhores valores para os parâmetros $k_{p}, k_{i}$ e $k_{d}$, foi criado uma função que realiza o perfil térmico descrito acima utilizando o a função simulacaocontrole e retornando a somatória da diferença entre o objetivo e a temperatura simulada. 
Minimizar a resultado desta função significa encontrar os melhores valores para os parâmetros $k_{p}, k_{i}$ e $k_{d}$ e portanto foi utilizado o método do gradiente descendente através da função optimize.minimize da biblioteca scipy (SCIPY, 2017), buscando minimizar a diferença entre a simulação e o setpoint ao longo do tempo.

A função optimize.minimize requer valor inicial para os parâmetros a serem encontrados pelo gradiente descendente, e estes foram encontrados pelo método de Cohen-Coon (TEMEL SEMIH YAGLI, 2013), utilizando os valores do ganho, tempo morto e $\tau$ encontrados graficamente em uma simulação de malha aberta apresentada na Figura 30

Figura 30 - Teste de malha aberta para determinação inicial dos parâmetros $k_{p}, k_{i} \mathrm{e}$ $k_{d}$ pelo método de Cohen-Coon.

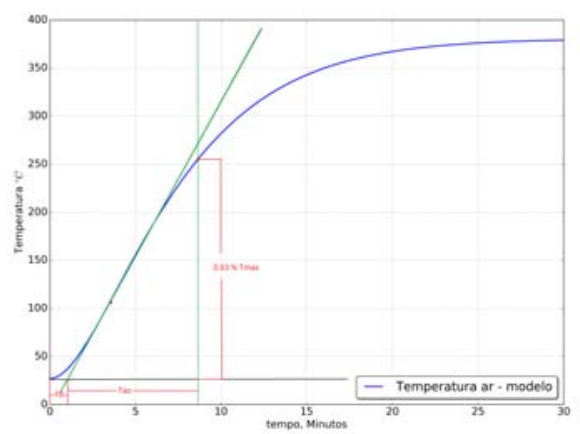

(a) Malha aberta, potência 100\% - Tempera- (b) Malha aberta, potência $100 \%$ - Tempetura do ar no centro do forno

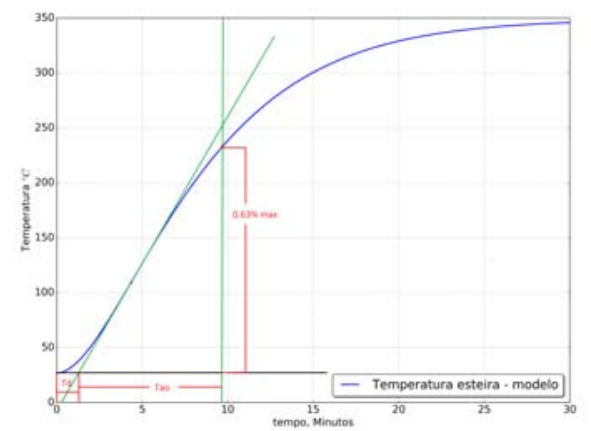
ratura da esteira

Fonte: Própria autoria.

Com os valores da Figura 30, (do ganho, tempo morto e $\tau$ ) foi calculado os parâmetros $k_{p}, k_{i}$ e $k_{d}$ utilizando a regra de Cohen-Coon (Equações 5.9, 5.10 e 5.11) e os resultados estão apresentados na Tabela 6 .

$$
\begin{gathered}
k_{c}=\frac{1.35}{g_{p}}\left(\frac{\tau}{t_{d}}+0.185\right) \\
K_{i}=\left(2.5 t_{d} \frac{\tau+0.185 t_{d}}{\tau+0.611 t_{d}}\right)^{-1}
\end{gathered}
$$




$$
K_{d}=\left(0.37 t_{d} \frac{\tau}{\tau+0.185 t_{d}}\right)^{-1}
$$

Tabela 6 - Resultado das constantes do controlador PID encontrado pelo método gráfico de Cohen-Coon.

\begin{tabular}{cccc}
\hline & & & \\
Constantes & $K_{p}$ & $K_{i}$ & $K_{d}$ \\
& & & \\
Ar & 34.12 & 0.0064 & 0.041 \\
Esteira & 39.02 & 0.0067 & 0.044 \\
& & & \\
\hline
\end{tabular}

Os valores da Tabela 6 foram utilizados como valor inicial no algoritmo do gradiente descendente, limitando a busca a duas ordens de grandeza acima e abaixo. O resultado da rotina scipy.optimize.minimize é mostrado na Tabela 7.

Tabela 7 - Resultado dos parâmetros ótimos do controlador PID encontrados pelo gradiente descendente.

\begin{tabular}{cccc}
\hline Constantes & $K_{p}$ & $K_{i}$ & $K_{d}$ \\
& & & \\
\hline Ar & 28.95 & 0.0807 & 0.042 \\
Esteira & 33.9 & 0.0063 & 0.041 \\
& & & \\
\hline
\end{tabular}

Na Figura 31a, uma simulação do controle com os parâmetros otimizados pelo GD (Gradiente Descendente) é apresentado em comparação com os valores obtidos pelo método de Cohen-Coon e por um controle ON/OFF. Pode-se notar que a rotina de otimização melhorou a resposta do sistema, diminuindo a oscilação sem prejudicar o tempo para atingir o setpoint. Na Figura 31b temos a mesma simulação com diferente escala, permitindo visualizar melhor a diferença entre os controladores. 
Figura 31 - Simulação de malha aberta para determinação inicial dos parâmetros $k_{p}$, $k_{i}$ e $k_{d}$ pelo método de Cohen-Coon.

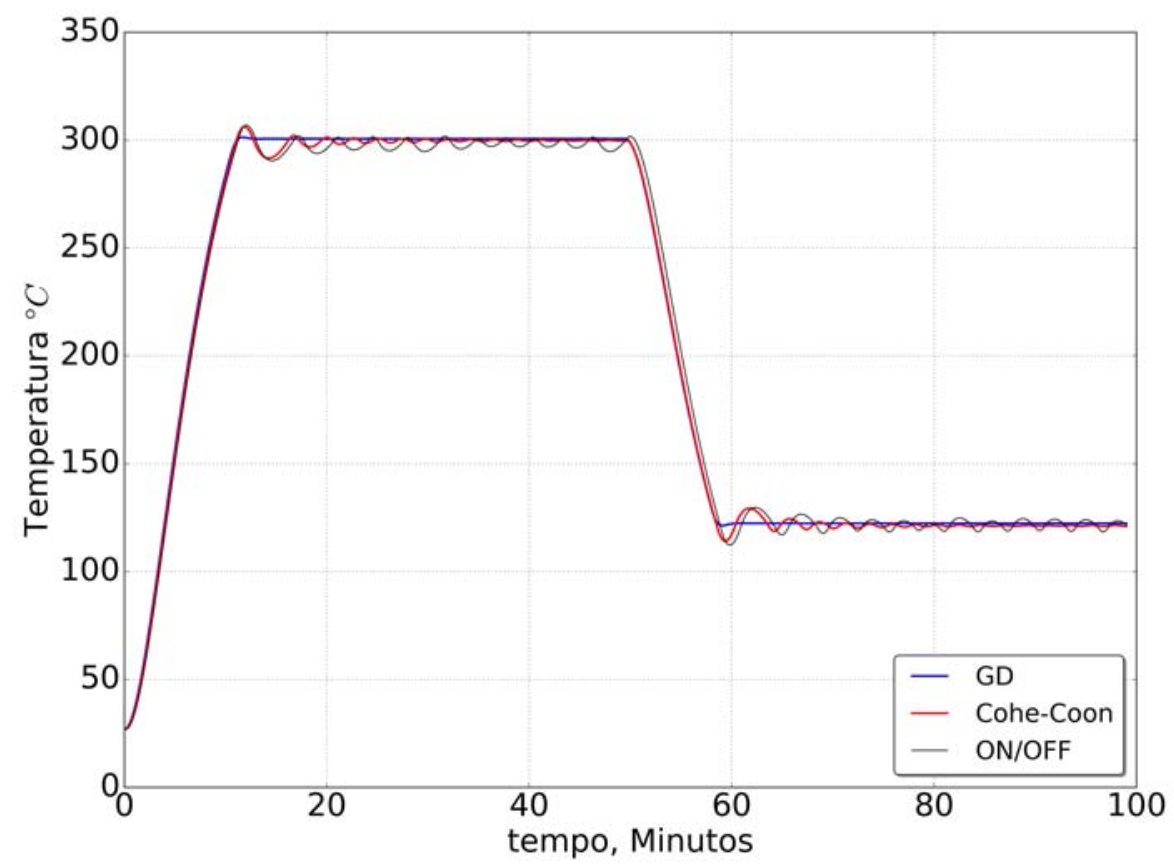

(a) Malha aberta, potência $100 \%$ - Temperatura do ar no centro do forno

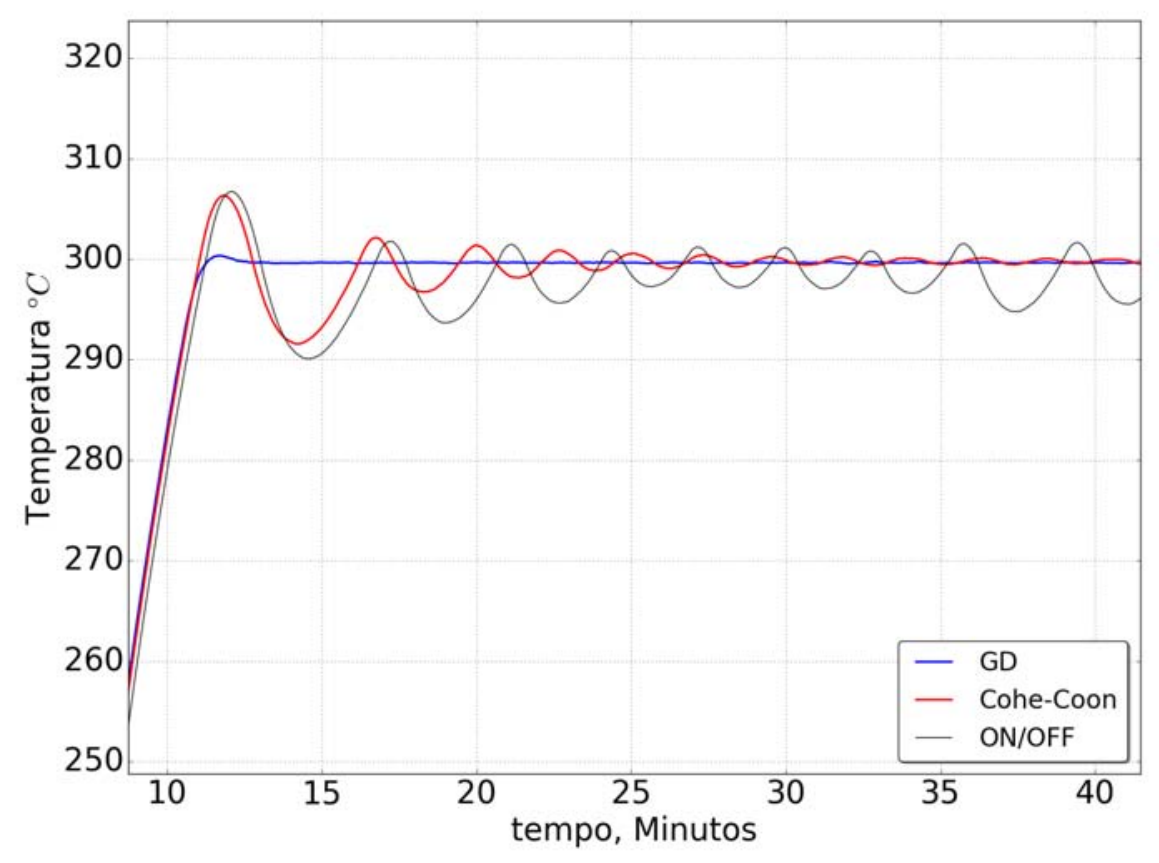

(b) Malha aberta, potência 100\% - Temperatura da esteira

Fonte: Própria autoria. 


\subsubsection{Resultados do controlador}

Com os parâmetros do controlador encontrados, experimentos foram realizados para verificar o funcionamento do controle. O primeiro a ser realizado foi o mesmo da simulação utilizada para se encontrar os parâmetros (seção 5.2.3.1) do controlador, $280{ }^{\circ} \mathrm{C}$ de 0 à 20 minutos, $120{ }^{\circ} \mathrm{C}$ de 20 à 40 minutos, $160{ }^{\circ} \mathrm{C}$ de 40 à 60 minutos $\mathrm{e}$ $180{ }^{\circ} \mathrm{C}$ de 60 à 80 minutos, cujo resultado é apresentado na Figura 32.

Figura 32 - Experimento para verificação da eficiência do controlador PID. Setpoints: $300{ }^{\circ} \mathrm{C} 0-50$ minutos, $120^{\circ} \mathrm{C} 50-100$ minutos, $250{ }^{\circ} \mathrm{C} 100-150$ minutos e $180{ }^{\circ} \mathrm{C} 150-200$ minutos.

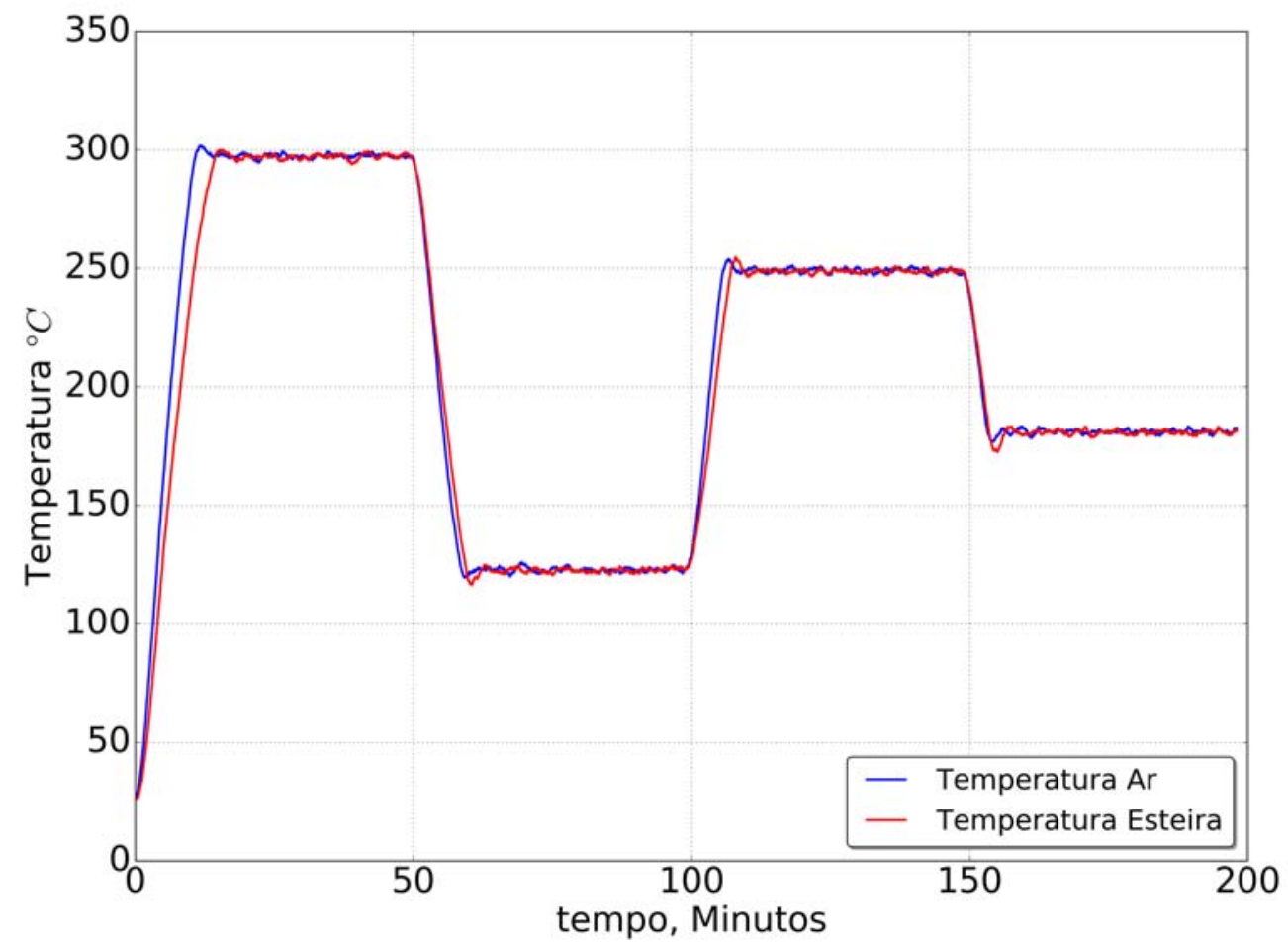

Fonte: Própria autoria.

A Figura 33 mostra o teste feito com os setpoints em $300{ }^{\circ} \mathrm{C}$ de 0 à 50 minutos, $120{ }^{\circ} \mathrm{C}$ de 50 à 100 minutos, $250{ }^{\circ} \mathrm{C}$ de 100 à 150 minutos e $180{ }^{\circ} \mathrm{C}$ de 150 à 200 minutos. Na Figura 34 foi mantida a potência máxima até os 25 minutos e depois ajustado para $180{ }^{\circ} \mathrm{C}$. 
Figura 33 - Experimento para verificação da eficiência do controlador PID. Setpoints: $200{ }^{\circ} \mathrm{C} 0$ - 50 minutos, $300{ }^{\circ} \mathrm{C} 50-100$ minutos e $200{ }^{\circ} \mathrm{C} 100-150$ minutos.

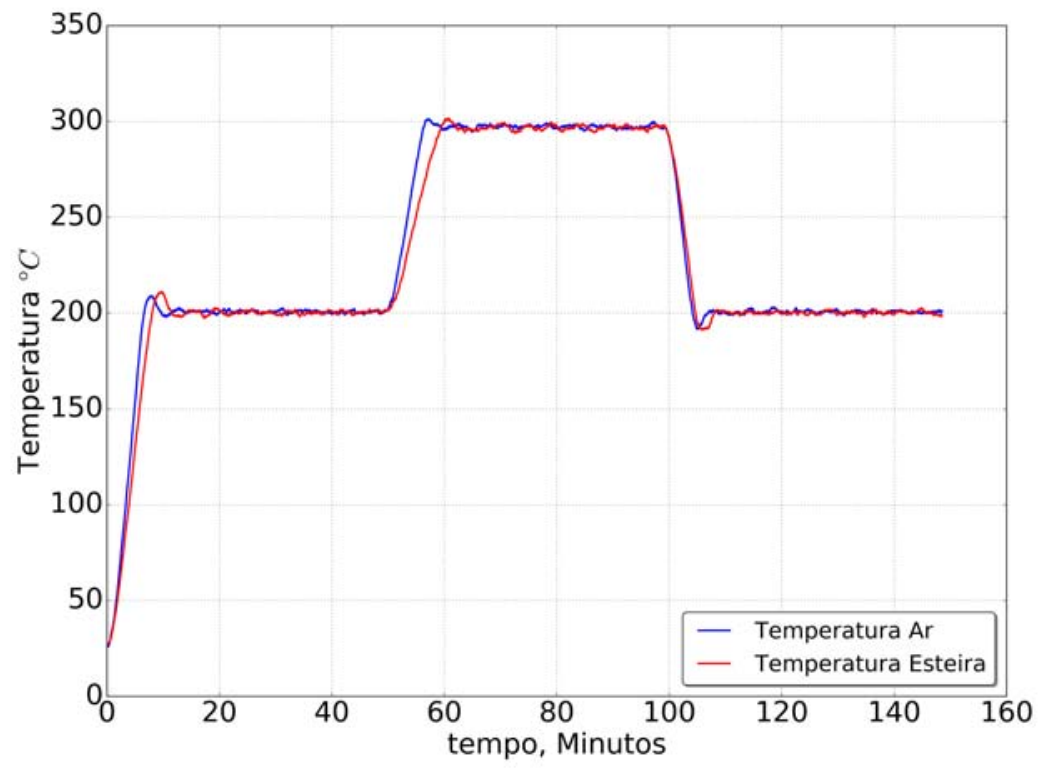

Fonte: Própria autoria.

Figura 34 - Experimento para verificação da eficiência do controlador PID. Setpoints: $220^{\circ} \mathrm{C} 0$ - 50 minutos, $180^{\circ} \mathrm{C} 50-100$ minutos e $150{ }^{\circ} \mathrm{C} 100-150$ minutos.

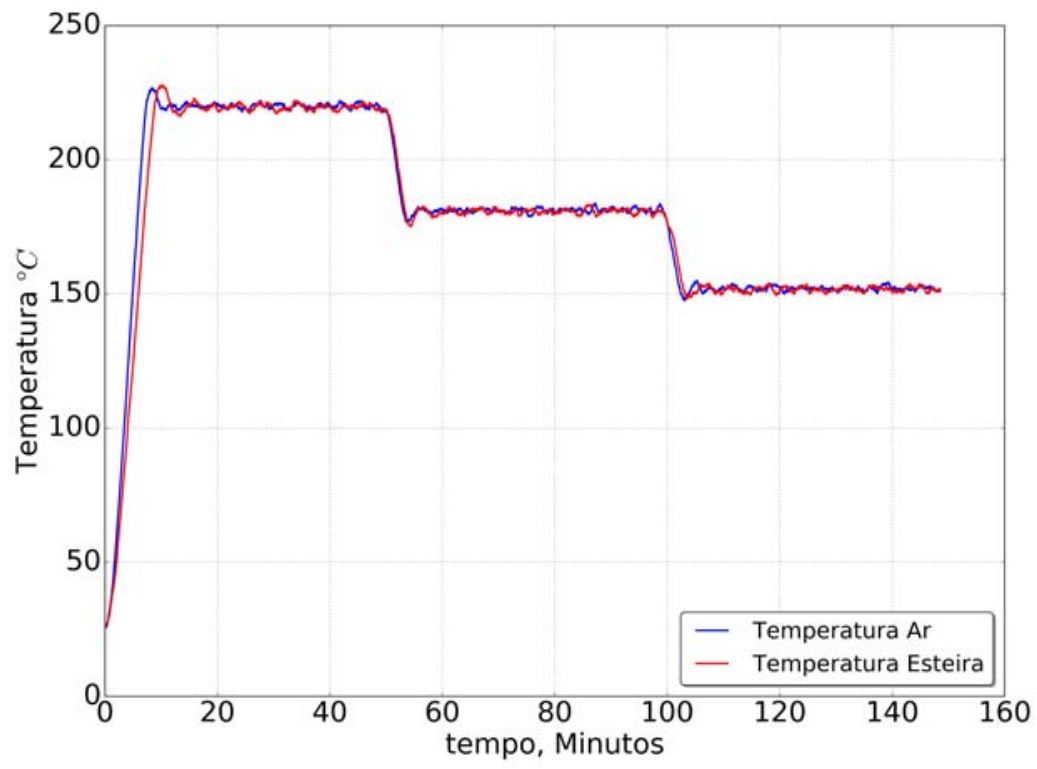

Fonte: Própria autoria. 


\subsection{SISTEMA DE CONTROLE - ESCRAVO}

\subsubsection{PLACA DE CONTROLE}

O esquema elétrico da Figura 11, que contém a instrumentação do forno e a unidade de controle com o Arduino foi convertido em um layout de PCB para a confecção da placa. Na Figura 35 temos as trilhas de cobre e a disposição dos componentes.

Figura 35 - Layout da placa com as trilhas e locais para colocar os componentes.

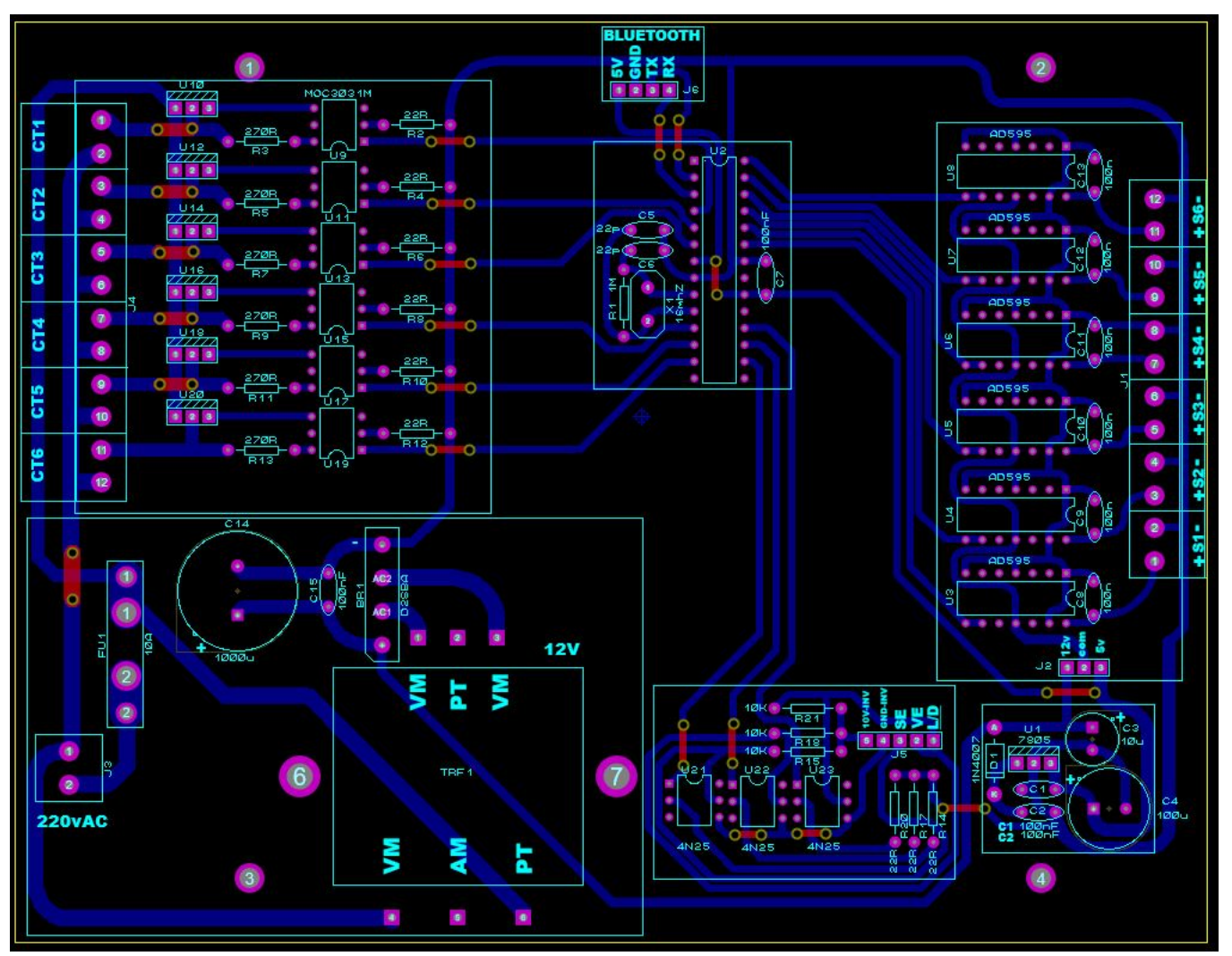

Fonte: Própria autoria.

Os componentes na placa de circuito estão separados em setores, de acordo com a função. No canto superior esquerdo temos controle das resistências, com os contatores e acopladores óticos. No canto inferior esquerdo temos a fonte e regulador de tensão. No canto inferior direito, temos outro regulador de tensão que alimenta a instrumentação do motor da esteira (centro inferior), visto que este motor pode gerar 
ruído elétrico no circuito e portanto o mesmo possui uma alimentação separada.

Na lateral direita da placa está a instrumentação dos sensores termopar, no topo a conexão do bluetooth e finalmente no centro a unidade de controle com o Arduino utilizando um atmega328p-pu.

Antes da confecção da placa, o projeto passou por uma rotina de checagem de erros (ECR - Error Check Rule) e então o circuito foi feito na placa de cobre e os componentes montados. Nas Figuras 36 e 37 vemos a simulação do projeto e a placa já montada com os componentes soldados.

Figura 36 - Projeto da placa com componentes.

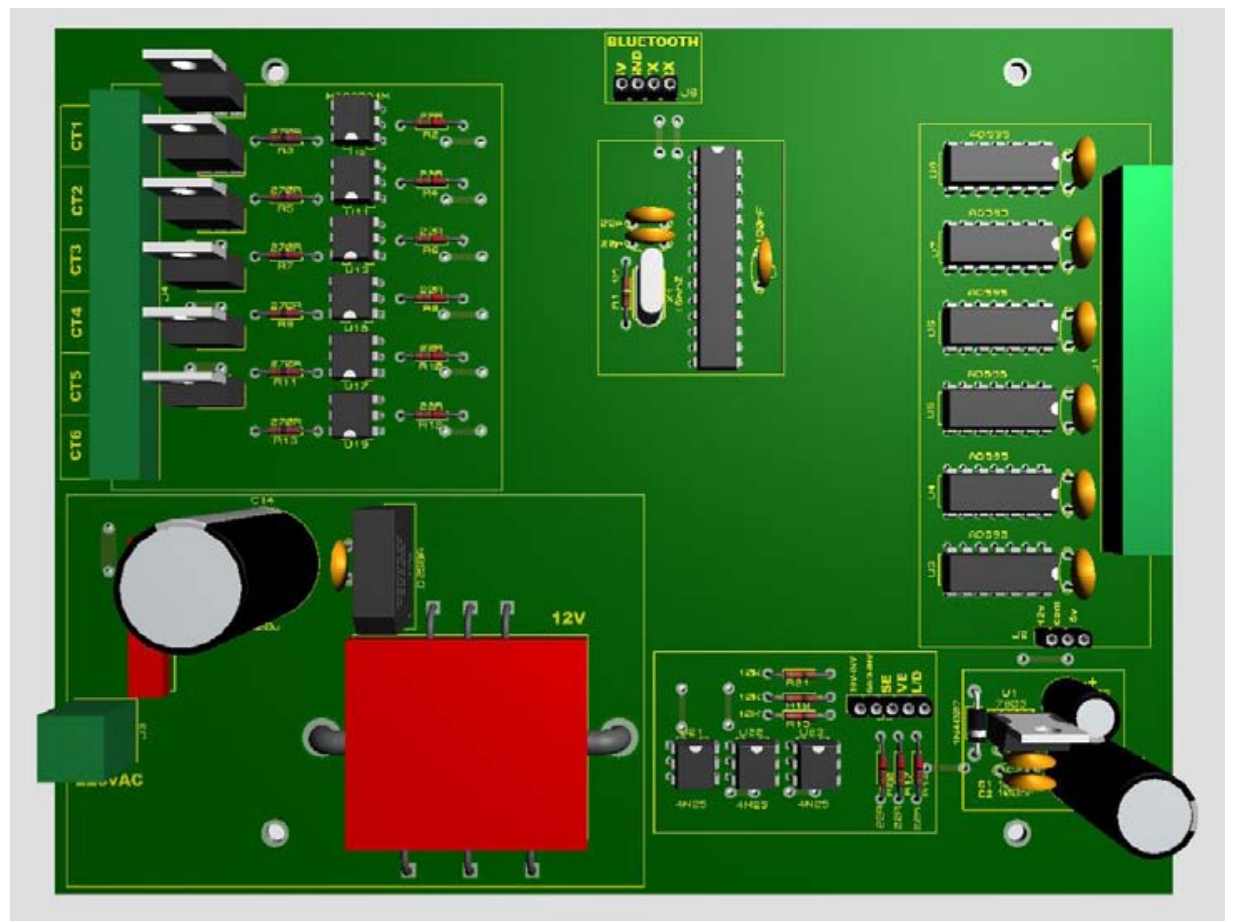

Fonte: Própria autoria. 
Figura 37 - Placa de controle instalada no forno.

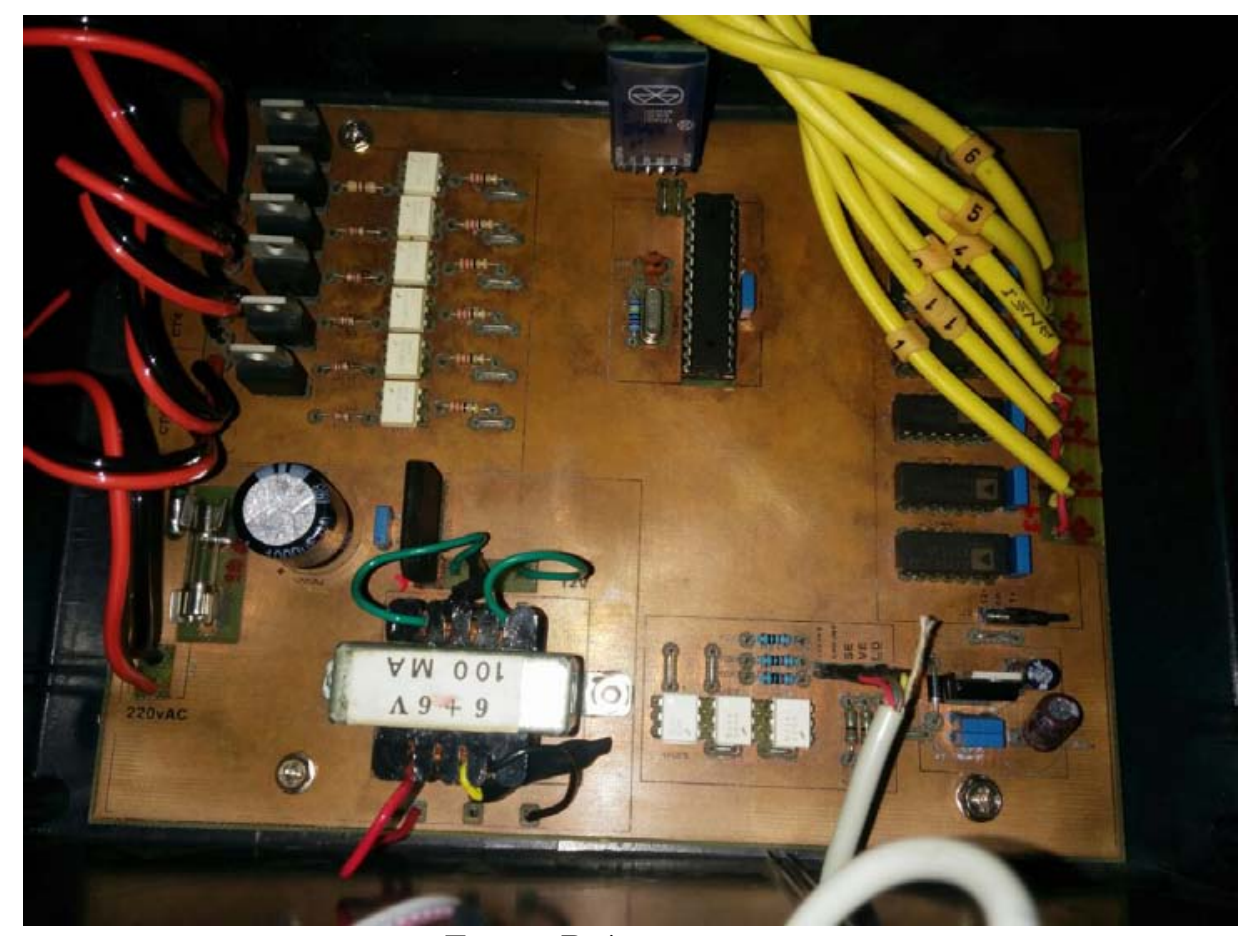

Fonte: Própria autoria.

\subsubsection{SOFTWARE DE CONTROLE}

O software que controla o Arduino e realiza as ações descritas na Seção 4.2.1.3 está disponível no repositório Atzingen (2016a) e condensa todas as funções e classes em uma biblioteca com nome controleProcesso.

Todas as funcionalidades do controle do forno foram embutidas na biblioteca, de acordo com o padrão de estilo, modularidade e simplicidade requisitado para incorporação da biblioteca no repositório oficial da IDE. Com os requisitos atingidos, a biblioteca foi aceita no repositório e pode ser obtida e instalada automaticamente pelo software como ilustra a Figura 38 
Figura 38 - Biblioteca para a plataforma Arduino, disponível via gerenciador de pacotes da IDE.

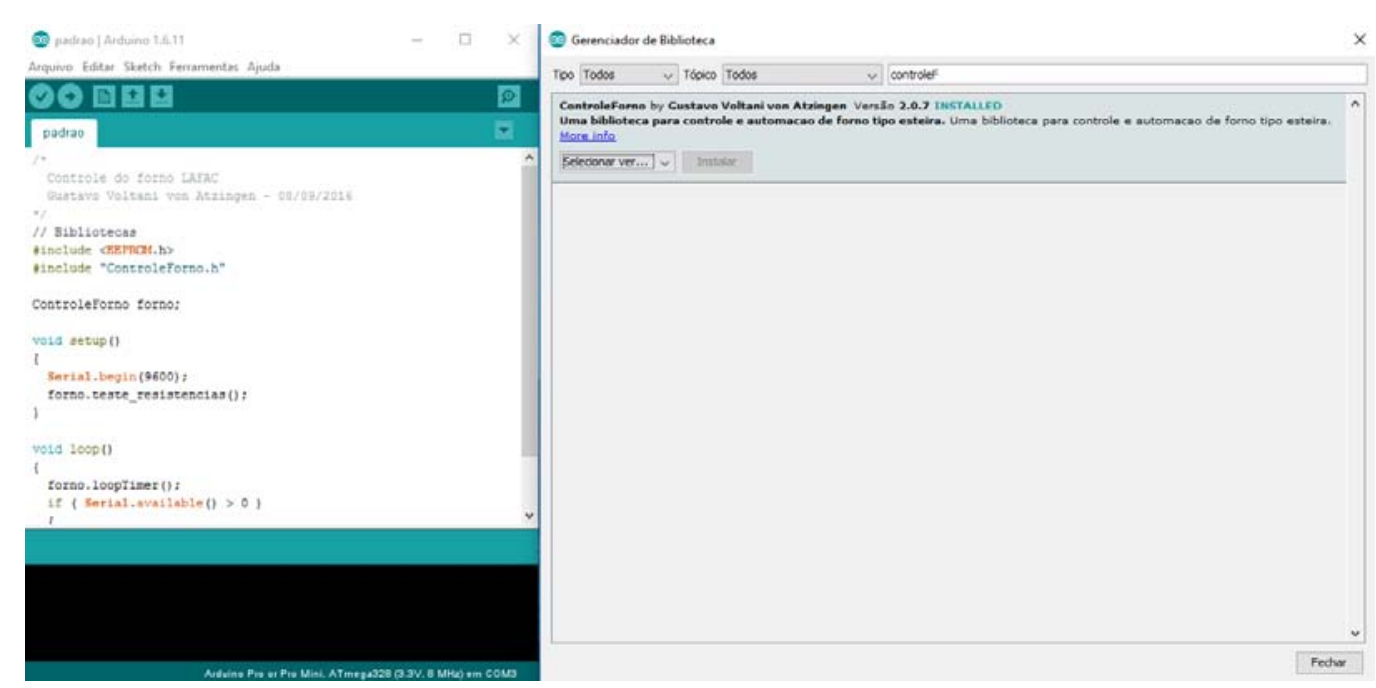

Fonte: Própria autoria.

Com isto, quando a biblioteca for atualizada no repositório, automaticamente será liberada uma nova versão no software do Arduino que tiver a biblioteca instalada, facilitando as atualizações. A padronização do software em uma biblioteca também trouxe a vantagem de abstrair a maior parte da complexidade do usuário do programa, mas permitindo que muitas mudanças possam ser feitas caso experimentos de outro tipo sejam realizados neste forno ou mesmo como uma base para que outros sistemas de controle sejam feitos utilizando as classes da biblioteca, já que a mesma está disponível sobre licença MIT.

\subsection{SISTEMA DE CONTROLE - MESTRE}

O software de controle mestre é responsável pelo controle geral do sistema, realizando o comando do microcontrolador no forno, as simulações da temperatura do alimento e do forno, os cálculos do controle PID, e a interação com o usuário via display de 5 polegadas, tela de controle acesso VPN ou aplicação web para uso em celulares, tablets ou navegadores web. Nas Figuras 39 e 40, vemos os três tipos de 
acesso: web, VPN e display Figura 39a, 40 e 39b.

Figura 39 - Formas de acessar a interface gráfica.

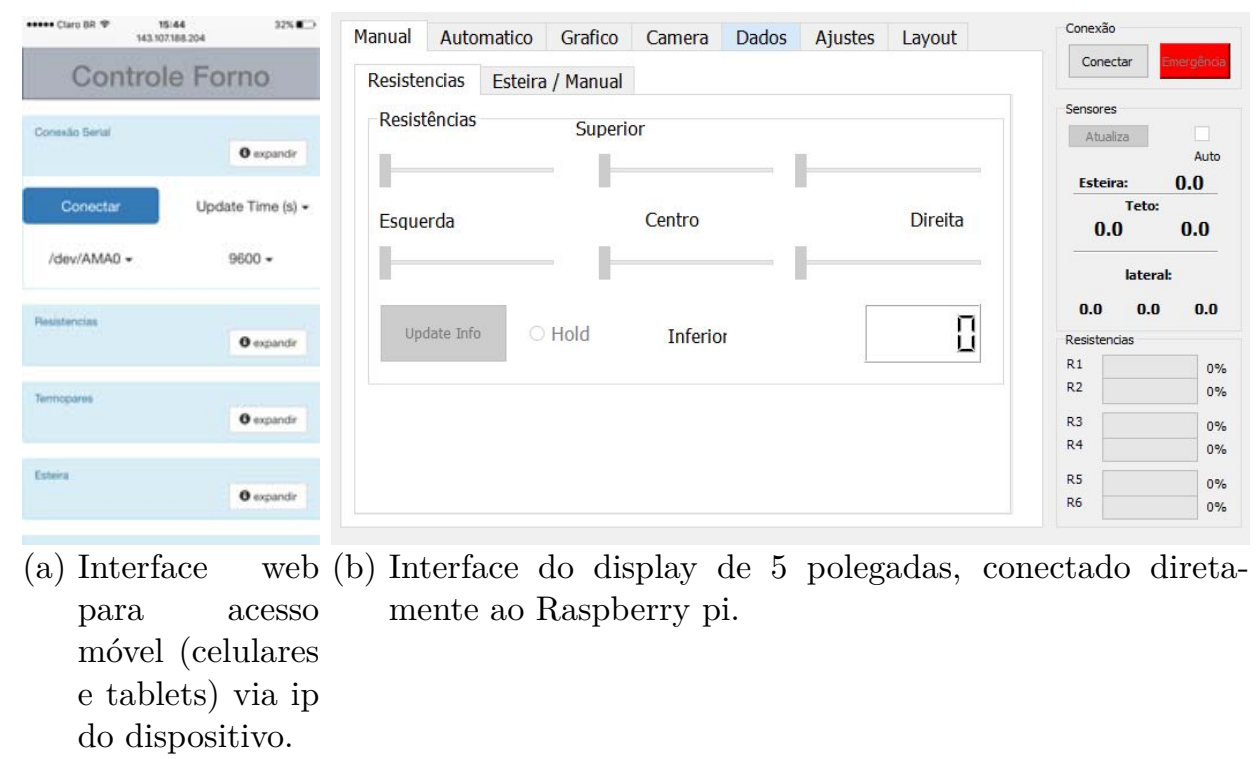

Fonte: Própria autoria.

O display de 5 polegadas, que fica conectado em cima do Raspberry pi (Figura 39b), possui uma resolução de 800x480 Pixels e por esta razão a interface gráfica para ele foi desenvolvida com esta mesma resolução, de modo que ocupe a tela toda em modo full screen. Foi colocado um serviço no SO que inicia o programa junto com o sistema e as opções de uso do desktop (barra de tarefas, menu de inicialização entre outros) foram desabilitadas dando ao usuário o controle da interface sem a percepção de estar usando um aplicativo num sistema operacional (Debian Jessie).

O aplicativo web possui uma quantidade limitada de controles, possibilitando apenas o ajuste da conexão serial, os comandos manuais das resistências e esteira, leitura dos sensores e visualização da câmera. Este modo foi desenvolvido para acessos rápidos e uso simples do forno, já que pode ser utilizado por qualquer dispositivo que possua um navegador e acesso a internet. O controle total do software é via VPN, onde usuário tem controle do SO pelo desktop remoto e o programa pode ser utilizado com teclado e mouse (Figura 40). 


\subsubsection{CONTROLE MANUAL}

Na aba manual, o usuário pode controlar as potências das resistências individualmente, controlar a velocidade da esteira e enviar comandos de texto manualmente para o forno (estes mesmos controles estão disponíveis no aplicativo web). Como muitos experimentos requerem alterar várias resistências simultaneamente, um radiobutton "Hold" foi colocado para que os dados não sejam enviados enquanto o mesmo esta selecionado (Figura 40). Quando ele é desmarcado, todos os controles são enviados de uma vez, facilitando a realização de experimentos que necessitem de mudanças simultâneas.

Figura 40 - Interface de controle, tela de controle manual.

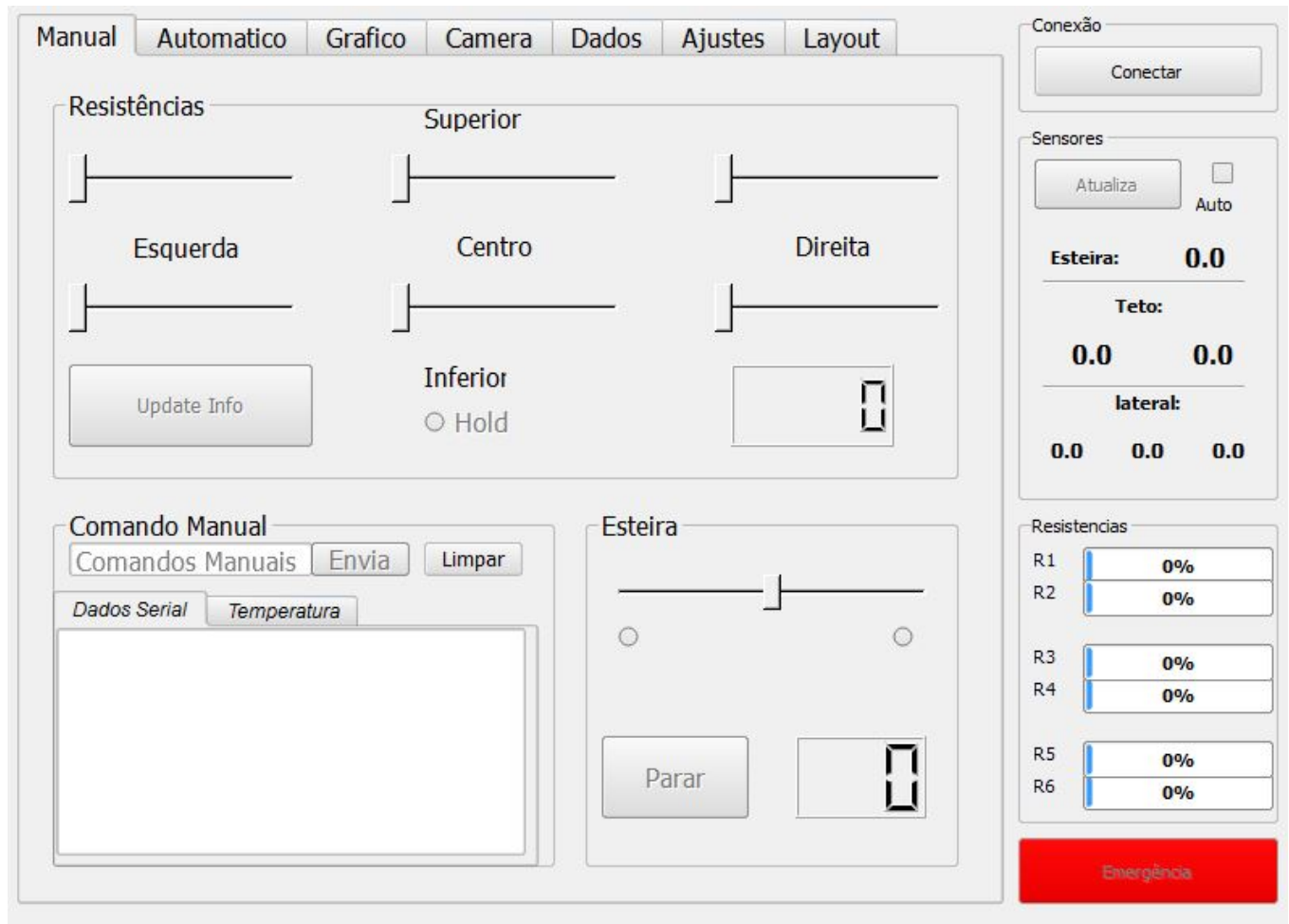

Fonte: Própria autoria. 


\subsubsection{CONFIGURAÇÕES}

Na aba Ajustes estão a maior parte das opções de configuração do sistema, separados nos grupos Serial, Gráfico, Microcontrolador, PID e Câmera (Figura 41, sentido horário).

No grupo Serial, , o usuário poderá escolher as opções de nome da porta serial e Baudrate da comunicação. O software detecta e lista as portas seriais disponíveis no SO, deixando selecionada por padrão a última opção do usuário quando esta existir.

No grupo gráfico, são escolhidos quais sensores serão visualizados (seção 5.4.4) bem como a taxa de atualização dos mesmos. No grupo Câmera, as opções de resolução e taxa de atualização são escolhidas, além de uma opção de salvar a imagem. Estas imagens são utilizadas para visualização do forno quando ele está sendo operado remotamente e também para utilização na montagem da simulação térmica (Figura 20).

No grupo Microcontrolador, as opções período do controle PWM e cálculo de média das leituras dos sensores é escolhida. Como estas opções são feitas no microcontrolador e não no software principal, o valor mostrado abaixo dos controles é alterado sempre que receber o estado do controle vindo do microcontrolador. 
Figura 41 - Interface de controle, tela de ajustes.

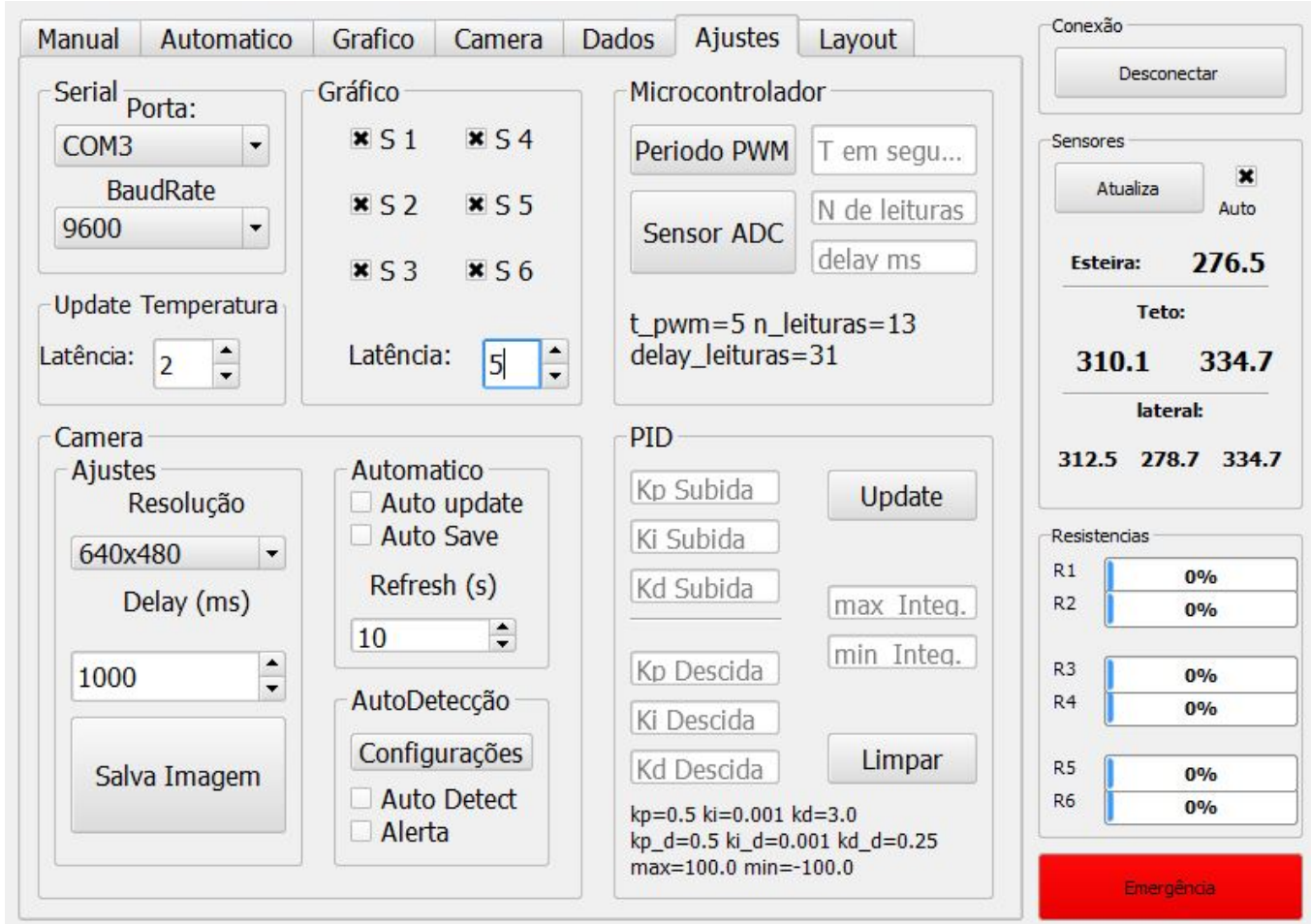

Dado Recebido: SP321 | Dado Recebido: SP552 | Dado Recebido: SP280 | Dado Recebido: SP642 | Dado Recebido: SP450 | Dado Recebido: SP770 | Dad /l/

Fonte: Própria autoria.

\subsubsection{ARMAZENAMENTO DOS DADOS}

O banco de dados possui 4 tabelas: calibracao, configuracao, perfil e sensores. As funções de interação com o banco de dados estão organizadas em arquivos de código fonte (scripts), todos dentro da pasta source|banco de códigos fonte do controle principal (Figura 16), sendo que nesta pasta, cada script é responsável pelo controle de uma das tabelas do banco de dados.

Na tabela calibracao, as calibrações linear dos termopares, relacionando tensão com temperatura podem ser adicionadas, apagadas ou acessadas. Pela interface gráfica (Figura 42), na aba Dados, o usuário pode selecionar, adicionar ou remover calibrações.

Na tabela config e no aruqivo cfg.p ficam salvas as configurações de escolha do 
usuário, como por exemplo, qual a ultima calibração escolhida, qual o perfil térmico do forno, tipo de alimento entre outros, de forma que as alterações feitas fiquem salvas e o controlador possa tirar proveito delas ao abrir novamente o controle, melhorando a experiência do usuário.

A tabela perfil salva os tipos de perfil térmico e alimentos que poderão ser utilizados (seção 5.4.5). Pela GUI também podem ser adicionados e removidos perfis térmicos e novos alimentos (Figura 42).

Figura 42 - Tela de controle dos dados da interface gráfica com as opções de seleção e exportar dados, seleção de experimentos e calibração dos sensores.

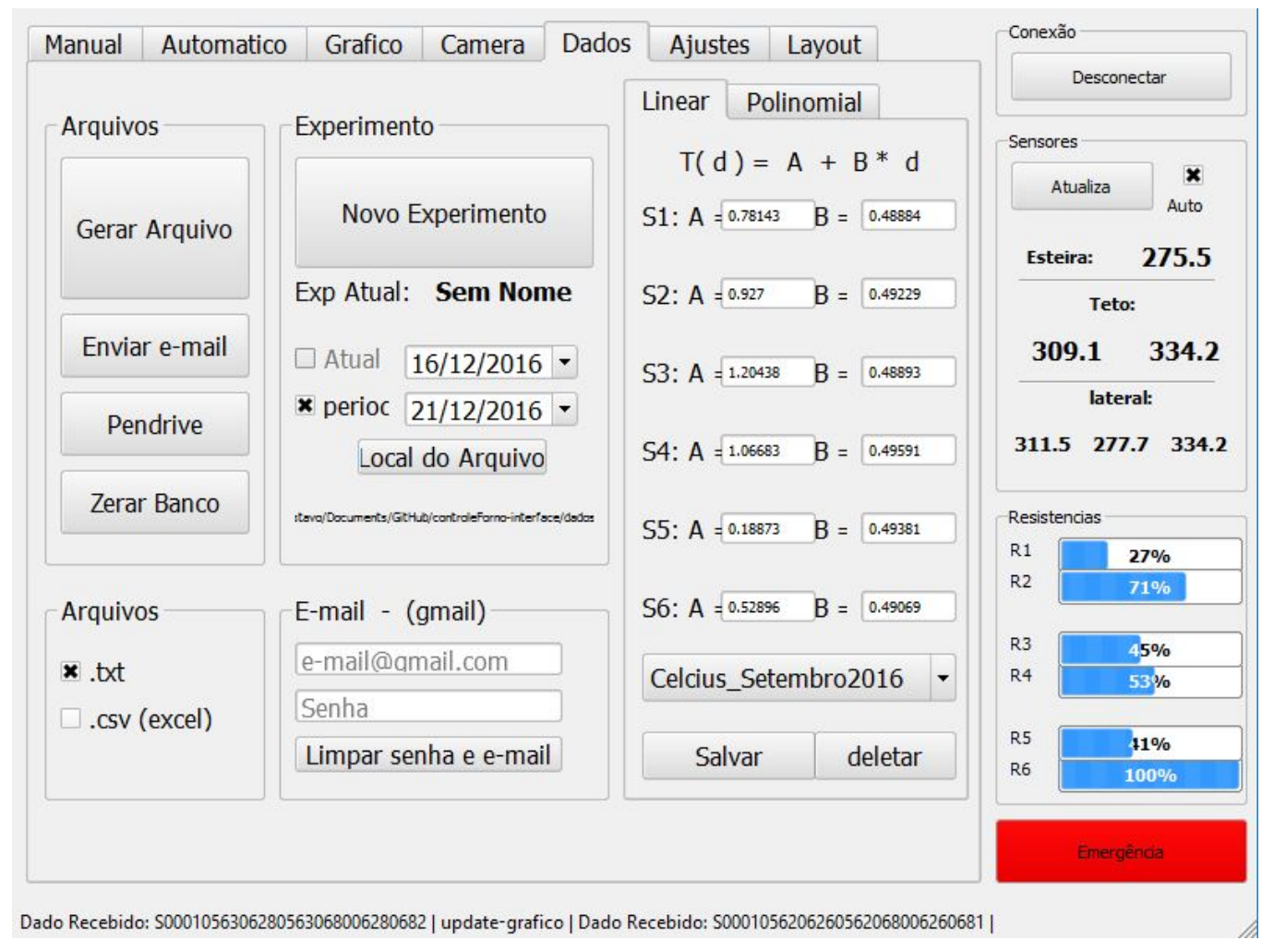

Fonte: Própria autoria.

A tabela sensores é a responsável por guardar todos os dados de temperatura, a hora e o status do forno sempre que uma nova informação é recebida da unidade escrava. Caso um experimento esteja em andamento e o usuário tenha dado um nome para ele, este também é salvo no banco. Na aba Dados, o usuário tem a opção de criar 
ou resgatar experimentos pelo grupo Experimento (Figura 42), podendo selecionar o experimento por nome ou por período. Os dados que alimentam os gráficos (Seção 5.4.4) também dependem desta seleção.

O usuário poderá acessar as informações da tabela sensores escolhendo o nome do experimento ou período. As informações são salvas em arquivos, com as opções .txt ou .csv para uso no Excel em uma pasta a sua escolha, tendo por padrão a pasta dadosExperimento (Figura 16). O arquivo salvo pode ser enviado por e-mail por meio da GUI, ou então salvo em um pendrive (figura 42). Também existe a possibilidade de apagar os dados do banco de dados (Neste caso um backup é feito e os dados apagados).

\subsubsection{VISUALIZAÇÃO DOS DADOS}

Na aba Grafico é possível visualizar os gráficos dos sensores de temperatura de um experimento anterior selecionado ou do atual em andamento. Para o experimento em andamento, o gráfico é atualizado a cada $n$ segundos automaticamente, com este valor sendo escolhido pelo usuário (Seção 5.4.2), sendo 5 segundos o valor padrão. A taxa mínima de atualização que pode ser escolhida é de 1 segundo, que foi escolhido como um valor adequado para não sobrecarregar o processador com o desenho gráfico enquanto outras tarefas estão ocorrendo simultaneamente no programa.

Outra opção de visualização na aba Grafico é a simulação do forno, sendo mostrado um gráfico de cores na parte inferior a uma superposição com a imagem da câmera na parte superior. Os valores mínimos e máximo para a escala de cores pode ser alterado, iniciando por padrão com os valores máximo e mínimo da temperatura simulada. Para não sobrecarregar o sistema, existe uma opção de número de leituras de temperatura para que a simulação seja mostrada, que por padrão é 5 , mostrando a imagem apenas uma em cada 5 vezes que um dado é recebido. 
Figura 43 - Interface de controle, tela com display gráfico das temperaturas nos sensores.

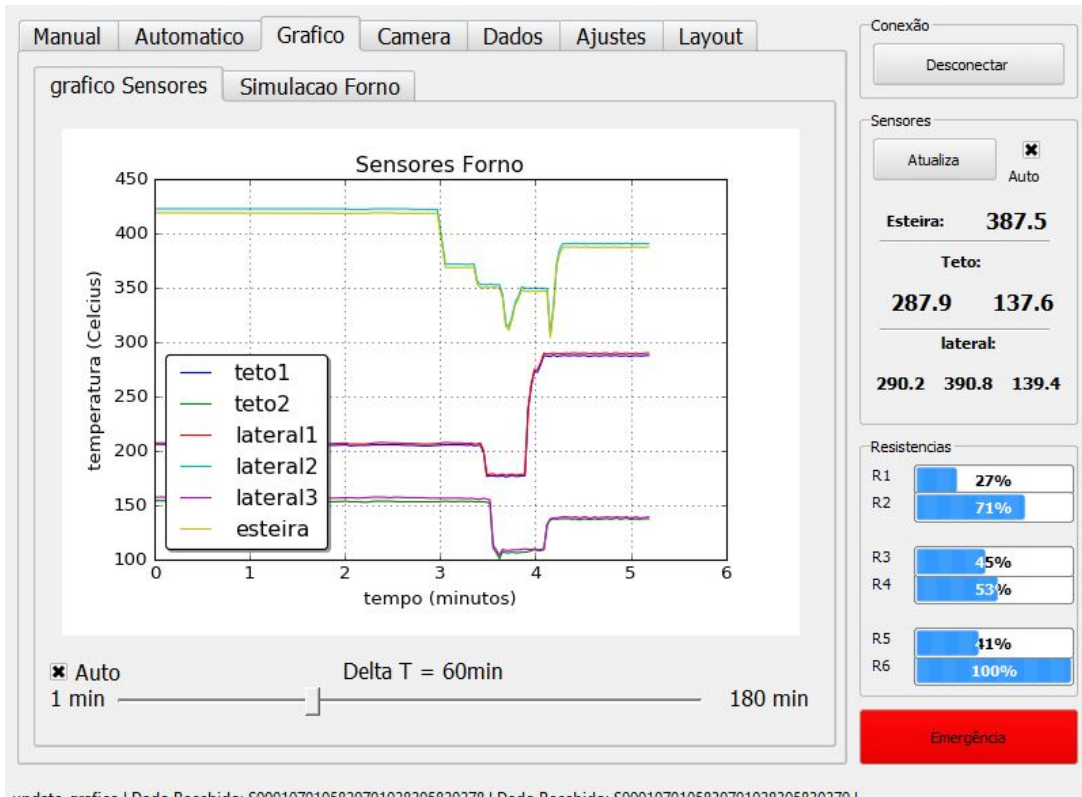

Fonte: Própria autoria.

Figura 44 - Interface de controle, tela com visualização da simulação do perfil térmico do forno e sobreposição na imagem do mesmo.
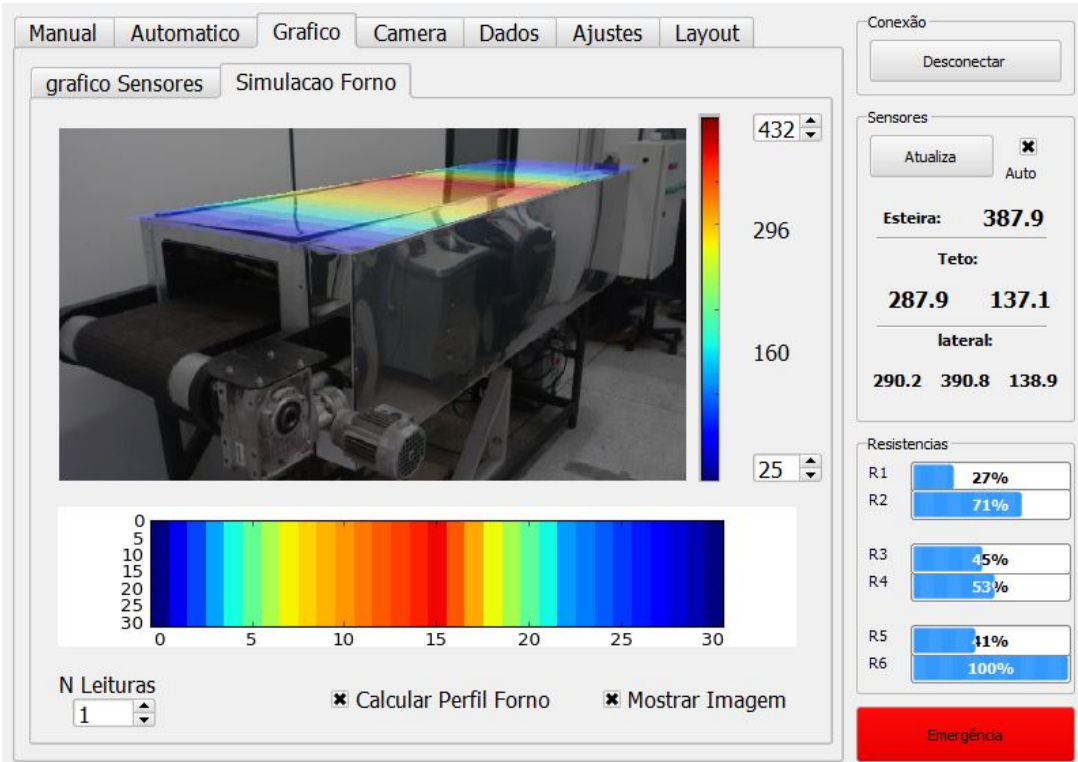

Dado Recebido: S0001079105830792028205830278 | Dado Recebido: 50001079205830792028305830279 |

Fonte: Própria autoria. 


\subsubsection{CONTROLE AUTOMÁTICO}

\subsubsection{Potência do forno $x$ tempo}

No modo automático por perfil de potência, o forno funciona baseado em um perfil independente de potência em função do tempo. O usuário pode adicionar, remover ou escolher entre os perfis existentes, que é mostrado no gráfico ao lado da escolha (Figura 45).

Figura 45 - Interface de controle, tela do controle automático com perfil tempo x potência.

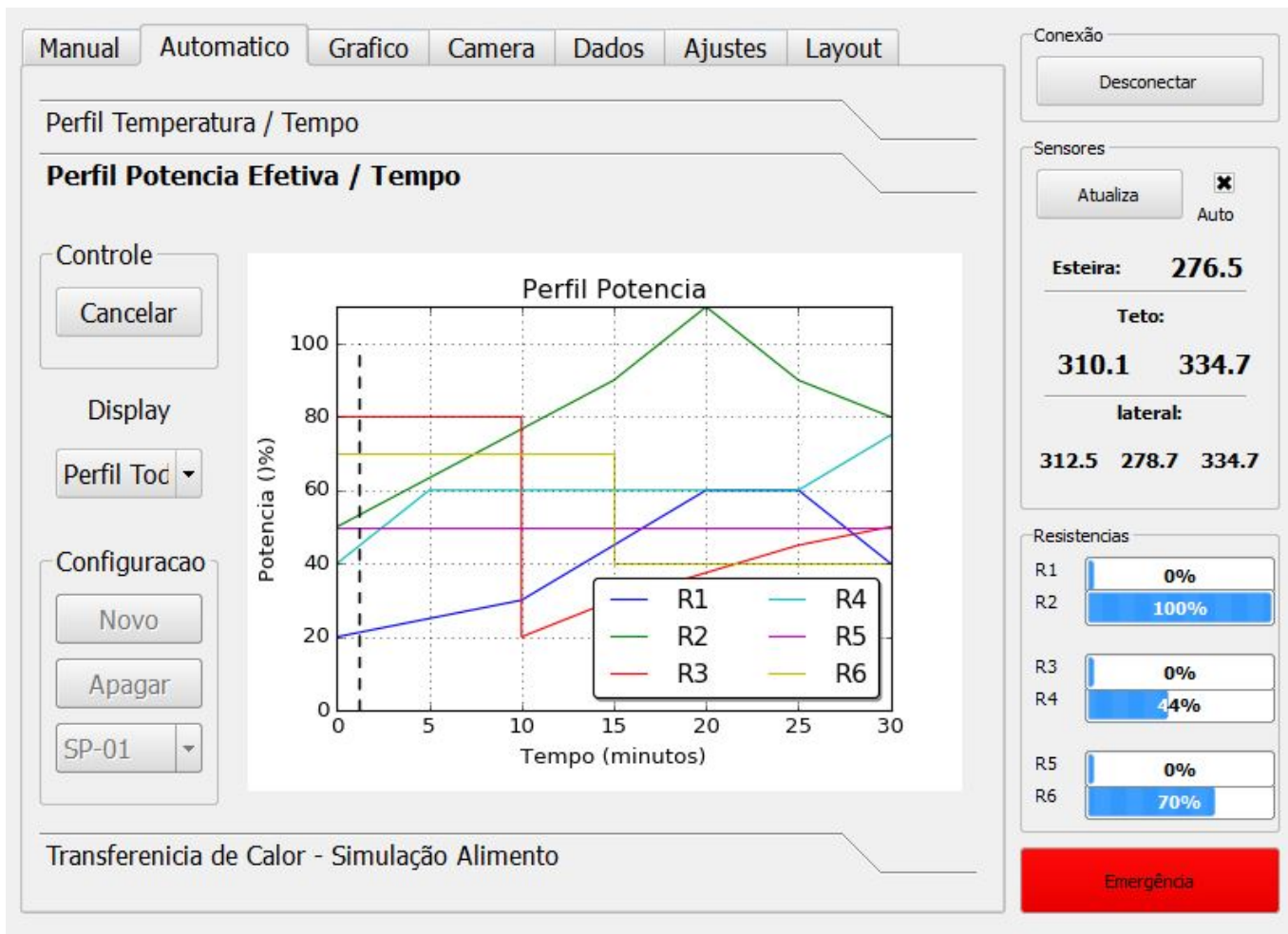

update-grafico | Dado Recebido: Erro de recebimento: string invalida | Erro verifica_dado-7 | Erro resultado_dado-else | Dado Recebido: S0001056306: $/ / 2$ Fonte: Própria autoria.

\subsubsection{Temperatura no forno $X$ tempo}

O controle pelo perfil de temperatura por tempo segue o mesmo modelo de interface do perfil por potência, no entanto é escolhida a temperatura do ar e da esteira 
em função do tempo (Figura 46). Como a temperatura no ar próxima ao alimento não é conhecida, é utilizado um método numérico (seção 4.4.1) para estimar este valor. Com estes valores, o controle PID é acionado (seção 4.3.1).

Figura 46 - Interface de controle, tela do controle automático com perfil tempo x temperatura.

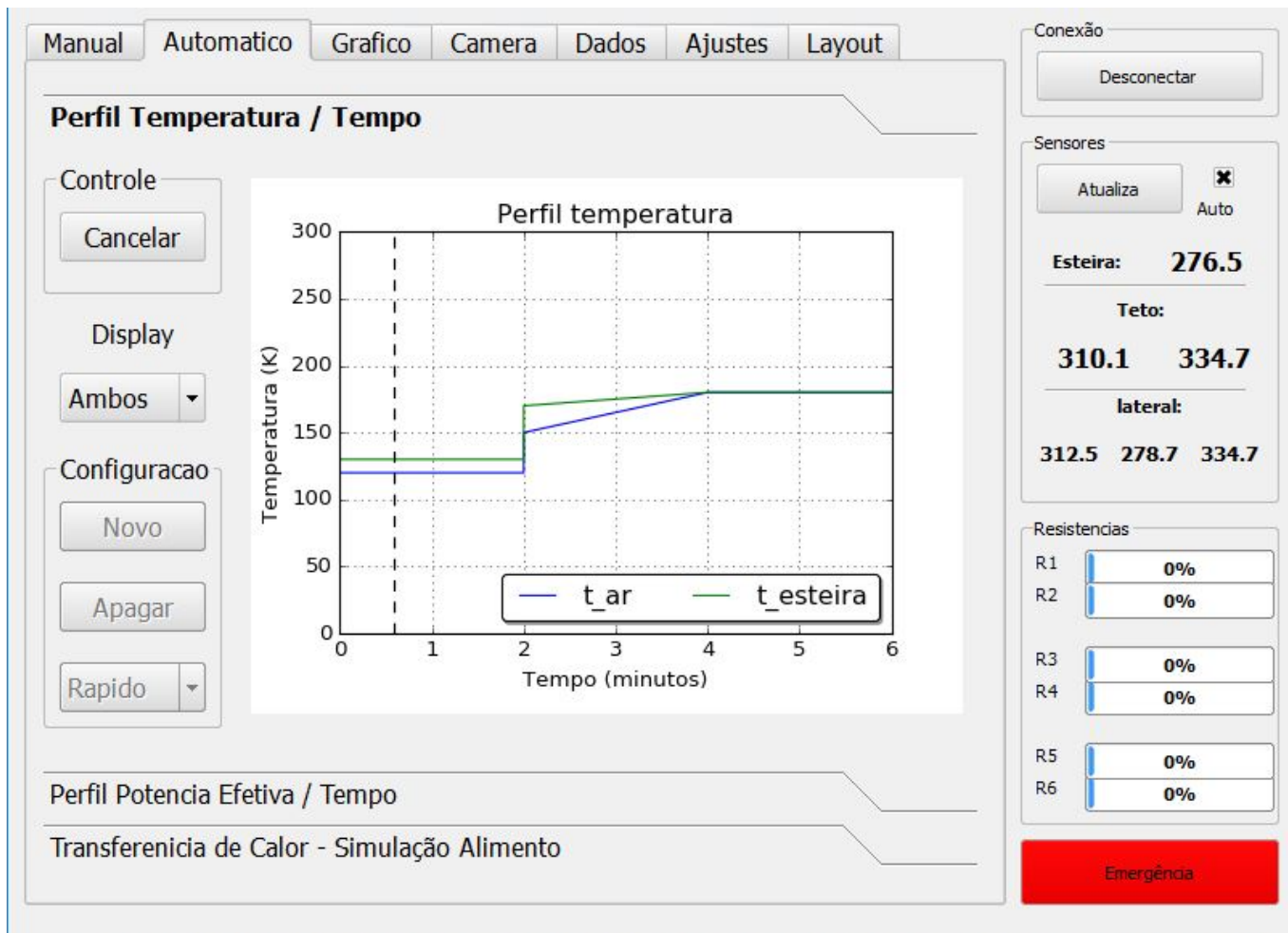

Dado Recebido: S0001056406280564068106280682 | Dado Recebido: S32 | Dado Recebido: S52 | Dado Recebido: S22 | Dado Recebido: S62 | Dado Rece //is

Fonte: Própria autoria.

\subsubsection{Temperatura no alimento}

Para o controle pela transferência de calor, é realizado uma simulação numérica para estimar a temperatura no alimento. O controle PID é utilizado para se estabilizar a temperatura num valor desejado na superfície do alimento e o forneamento é terminando quando a temperatura interna chegar ao valor escolhido. 



\section{CONCLUSÕES}

O algoritmo de simulação do perfil térmico do forno em uma dimensão se mostrou condizente com as medidas experimentais e o tempo de execução do algoritmo no SBC utilziando a ferramenta f2py foi uma ordem de grandeza abaixo tempo requerido pelo controle PID, não comprometendo a performance do software de controle e possibilitando a simulação em tempo real. Os resultados da simulação da temperatura no alimento também concordaram com o software Comsol, e o tempo de execução do algoritmo no SBC (Raspberry pi 3) permite realizar o controle térmico do alimento em tempo real.

O controlador PID foi capaz de levar e manter a temperatura ao valor desejado, funcionando em conjunto com a simulação e comunicando com a unidade escrava para manter os perfis de temperatura no alimento selecionados pelo usuário do sistema e com isso realizar um processo de forneamento com o perfil térmico desejado pelo controlador do forno.

Com estes resultados concluiu-se que é possível utilizar computação de baixo custo (Raspberry pi e Arduino) para realizar o controle e automação de um forno em escala piloto para processamento de alimentos utilizando simulação em tempo real, possibilitando o acesso e controle de forma remota ou local. 



\section{CONSIDERAÇÕES FINAIS}

O sistema de controle possui dois softwares que foram disponibilizados sobre licença livre MIT com o intuito de que o software ou parte dele seja utilizado, alterado e/ou modificado por outros pesquisadores e desenvolvedores. A biblioteca criada para o controle escravo está disponibilizada no repositório oficial de bibliotecas do Arduino e possui flexibilidades de uso como escolha do número de atuadores, quantidade e posição dos sensores e escolha do período PWM, para que possa ser adaptada a outros tipos de forno ou controladores de temperatura de processo lento. Espera-se que este software possa ser útil em futuros experimentos realizados neste tipo de forno bem como em outros tipos de controladores, possibilitando o uso através da abstração da biblioteca.

O software mestre, escrito em Python2.7, também foi organizado em classes e fuções separadas por suas especificidades de forma que partes específicas, como por exemplo leitura serial, tratamento de dados, rotina numérica, entre outros, possam ser reutilizados em outros projetos do mesmo grupo de pesquisa ou de terceiros.

Na escolha da SBC, além das características de hardware da placa, o tamanho da comunidade e suporte ao sistema oferecido pela companhia que fabrica a SBC é tão importante quanto suas especificações. Tais fatores também tiverem importância na escolha do Raspberry pi, visto que foram testadas outras placas que possuíam hardware similar porém não tinham o suporte e estabilidade da plataforma oferecida pela comunidade do Raspberry pi.

Com a conclusão deste trabalho abre-se a oportunidade para futuras pesquisas. A temperatura simulada no forno foi comparada com valores experimentais em função da profundidade, porém experimentos com sensores que acompanham o alimento podem validar o modelo de aquecimento do alimento, que outros autores citados neste trabalho usaram mas sem o controle em tempo real. 
Outros modelos de aquecimento e propagação de calor no forno em duas e três dimensões e com a adição de convecção (forçada ou natural) podem ser realizados e comparados com o modelo $1 \mathrm{~d}$ deste trabalho, porém o aumento da complexidade do modelo exige um processador com maior poder computacional que o SBC deste sistema.

O sistema desenvolvido pode ser testado em fornos de maior dimensão em aplicações industriais, sendo sugerido a implementação deste em linhas de produção de alimento com sistema de esteira que ainda não possuam um controle automatizado. Espera-se que este trabalho possa ser útil para empresas de processamento de alimentos, principalmente pequenas e médias, que busquem por melhorias nos seus processos de forneamento. 


\section{REFERÊNCIAS}

ABIA. A Força do Setor de Alimentos. Associação Brasileira das Indústrias de Alimentos, v. 1, n. 1, p. 1-3, 2013. Disponível em: <http://abia.org.br/vst/ AForcadoSetordeAlimentos.pdf $>$. Citado na página 21.

ARAÚJO, A. et al. Integrating arduino-based educational mobile robots in ros. In: IEEE. Autonomous Robot Systems (Robotica), 2013 13th International Conference on. [S.1.], 2013. p. 1-6. Citado na página 47.

AROGBA, S. S. Effect of temperature on the moisture sorption isotherm of a biscuit containing processed mango (mangifera indica) kernel flour. Journal of Food Engineering, Elsevier, v. 48, n. 2, p. 121-125, 2001. Citado 2 vezes nas páginas 36 e 37.

ATZINGEN, G. V. von. controleForno. Faculdade de Zootecnia e Engenharia de Alimentos, 2016. Disponível em: < https://github.com/Atzingen/controleForno >. Citado 3 vezes nas páginas 62, 67 e 105.

ATZINGEN, G. V. von. controleForno-interface. Faculdade de Zootecnia e Engenharia de Alimentos, 2016. Disponível em: < https://github.com/Atzingen/ controleForno-interface $>$. Citado na página 62.

BAIK, O. et al. Modeling the thermal properties of a cup cake during baking. Journal of Food Science, Wiley Online Library, v. 64, n. 2, p. 295-299, 1999. Citado na página 83.

BARRETT, S. F. Arduino microcontroller processing for everyone! Synthesis Lectures on Digital Circuits and Systems, Morgan \& Claypool Publishers, v. 8, n. 4, p. 1-513, 2013. Citado na página 47.

BENNETT, S. A history of control engineering, 1800-1930. [S.l.]: IET, 1986. ISBN 978-0-86341-047-5. Citado na página 29.

BERDAHL, E.; LLIMONA, Q. Tangible embedded linux. In: ACM. Proceedings of the 7th International Conference on Tangible, Embedded and Embodied Interaction. [S.l.], 2013. p. 407-410. Citado 2 vezes nas páginas 50 e 52 .

BOULET, M. et al. Cfd modeling of heat transfer and flow field in a bakery pilot oven. Journal of food engineering, Elsevier, v. 97, n. 3, p. 393-402, 2010. Citado na página 35 .

BUECHLEY, L. et al. The lilypad arduino: using computational textiles to investigate engagement, aesthetics, and diversity in computer science education. In: ACM. Proceedings of the SIGCHI conference on Human factors in computing systems. [S.l.], 2008. p. 423-432. Citado na página 48. 
CAMPINAS, N. de Estudos e Pesquisas em Alimentação. Universidade Estadual de. Tabela Brasileira de Composição de Alimentos (TACO). [S.l.]: Unicamp Campinas, 2011. Citado 2 vezes nas páginas 83 e 87.

COMSOL, A. Comsol multiphysics user's guide. Version: September, v. 10, p. 333, 2005. Citado na página 84 .

CORPORATION, A. energy. Ovens, Prepared for Southern California Edison Technology Assessment. [S.l.]: Foodservice Equipment, 1991. Citado 2 vezes nas páginas 34 e 35 .

COVINGTON, M. J.; CARSKADDEN, R. Threat implications of the internet of things. In: IEEE. Cyber Conflict (CyCon), 2013 5th International Conference on. [S.l.], 2013. p. 1-12. Citado na página 52.

DESBOROUGH, L.; MILLER, R.; NORDH, P. Regulatory control survey. Honeywell, unpublished, 2000. Citado na página 28.

D'AUSILIO, A. Arduino: A low-cost multipurpose lab equipment. Behavior research methods, Springer, v. 44, n. 2, p. 305-313, 2012. Citado na página 48.

F2PY. Provide connection between Python and Fortran languages. F2py, 2007. Disponível em: <https://sysbio.ioc.ee/projects/f2py2e/>. Citado na página 73.

FGV. Quais setores estão sendo beneficiados e quais são os que mais estão sofrendo com a crise? Fundação Getúlio Vargas, 2016. Disponível em: <http: //ejfgv.com/2016/06/02/setores-estao-beneficiados-sao-estao-sofrendo-crise/>. Citado na página 21.

FIESP. Balança comercias do agronegócio. Fundação Getúlio Vargas, 2016. Disponível em: <http://www.fiesp.com.br/indices-pesquisas-e-publicacoes/ balanca-comercial/>. Citado na página 21.

FISHER TODD BELL, J. N. D. Commercial Cooking Appliance Technology Assessment. Commercial Cooking Appliance Technology Assessment, v. 1, n. 5011.02.26, p. 1-29, 2002. Disponível em: <http://www.fishnick.com/equipment/ techassessment/Appliance_Tech_Assessment.pdf $>$. Citado 2 vezes nas páginas 34 e 35 .

FUlleR, S. H.; MILletT, E. C. o. S. G. i. C. P. N. R. C. L. I. The Future of Computing Performance: Game Over or Next Level ? The National Academies Press, 2011. ISBN 9780309159517. Disponível em: $<$ http://www.nap.edu/openbook.php?record_id=12980>. Citado na página 44.

GULATI, T.; DATTA, A. K. Enabling computer-aided food process engineering: Property estimation equations for transport phenomena-based models. Journal of Food Engineering, Elsevier, v. 116, n. 2, p. 483-504, 2013. Citado na página 34.

HAGHIGHI, M.; CLIFF, D. Sensomax: An agent-based middleware for decentralized dynamic data-gathering in wireless sensor networks. In: IEEE. Collaboration Technologies and Systems (CTS), 2013 International Conference on. [S.l.], 2013. p. 107-114. Citado 2 vezes nas páginas 52 e 53. 
HALEY, T. A.; MULVANEY, S. J. Advanced process control techniques for the food industry. Trends in Food Science $\&$ Technology, Elsevier, v. 6, n. 4, p. 103-110, 1995. Citado 2 vezes nas páginas 24 e 27.

HAWKE, I. Numerical Methods. Creative Commons attribution license,, 2014. ISBN CC-BY 4.0. Disponível em: <http://openedx.seas.gwu.edu/courses/GW/ MAE6286/2014_fall/wiki/GW.MAE6286.2014_fall/>. Citado na página 44.

HAYAKAWA, K.; HWANG, P. Apparent thermophysical constants for thermal and mass exchanges of cookies undergoing commercial baking processes. LebensmittelWissenschaft + Technologie $=$ Food science + technology, 1981. Citado 3 vezes nas páginas 35,36 e 83.

HEEKS, R.; ROBINSON, A. Ultra-low-cost computing and developing countries. Communications of the ACM, ACM, v. 56, n. 8, p. 22-24, 2013. Citado na página 49.

HOEHN, R.; SBENATY, S. M. Designing, building, and testing a microcontrollerbased system for industrial applications. In: Proceedings of the 2005 ASEE Gulf-Southwest Annual Conference. [S.l.: s.n.], 2005. Citado na página 45.

IBGE. Produção Física da Indústria, por Classe e Gênero. Ministério do Desenvolvimento, Indústria e Comércio, 2013. Disponível em: <http://www.mdic. gov.br/arquivos/dwnl_1337260114.pdf > . Citado na página 21.

ILLÉS BALÁZS, B. I. Numerical study of the gas flow velocity space in convection reflow oven. International Journal of Heat and Mass Transfer, Elsevier, v. 70, p. 185-191, 2014. Citado na página 35.

ILYUKHIN, S. V.; HALEY, T. A.; SINGH, R. K. A survey of automation practices in the food industry. Food Control, Elsevier, v. 12, n. 5, p. 285-296, 2001. Citado 2 vezes nas páginas 33 e 45 .

INSIDER, B. Here's how the Internet of Things will explode by 2020.

Tech Insider, 2016. Disponível em: <http://www.businessinsider.com/ iot-ecosystem-internet-of-things-forecasts-and-business-opportunities-2016-2>. Citado na página 53.

JÄMSÄ-JOUNELA, S.-L. Future trends in process automation. Annual Reviews in Control, Elsevier, v. 31, n. 2, p. 211-220, 2011. Citado 2 vezes nas páginas 23 e 24.

KAISER, V. Modeling and simulation of a multi-zone band oven. Food Technology, INST FOOD TECHNOLOGISTS SUITE 300221 N LASALLE ST, CHICAGO, IL 60601-1291, v. 28, n. 12, p. 50, 1974. Citado na página 36.

KNOSPE, C. PID Control. Control System Magazine, v. 1, n. 33, p. 30-41, 2006. Citado na página 28.

KREITH, F.; MANGLIK, R. M.; BOHN, M. S. Principios de transferencia de calor. [S.1.]: Cengage Learning Editores, 2012. Citado na página 82. 
KULACKI, F.; KENNEDY, S. Measurement of the thermo-physical properties of common cookie dough. Journal of Food Science, Wiley Online Library, v. 43, n. 2, p. 380-384, 1978. Citado na página 83.

LAU, O.-W.; WONG, S.-K. Contamination in food from packaging material. Journal of Chromatography A, Elsevier, v. 882, n. 1, p. 255-270, 2000. Citado na página 34 .

LEE, I.; LEE, K. The internet of things (iot): Applications, investments, and challenges for enterprises. Business Horizons, Elsevier, v. 58, n. 4, p. 431-440, 2015. Citado na página 53.

LOSTIE, M. et al. Study of sponge cake batter baking process. part i: Experimental data. Journal of Food Engineering, Elsevier, v. 51, n. 2, p. 131-137, 2002. Citado 2 vezes nas páginas 36 e 37 .

MACK, C. The multiple lives of moore's law. IEEE Spectrum, IEEE, v. 52, n. 4, p. 31-31, 2015. Citado na página 44.

MARTIN, L. The promise of the maker movement for education. Journal of Pre-College Engineering Education Research (J-PEER), Purdue University Press, v. 5, n. 1, p. 4, 2015. Citado na página 47.

MAZIDI, M. A. et al. Embedded systems. New Delhi, Personal Education, 2009. Citado na página 46.

MCCLURE, P. et al. Modelling the growth, survival and death of microorganisms in foods: the uk food micromodel approach. International journal of food microbiology, Elsevier, v. 23, n. 3, p. 265-275, 1994. Citado na página 34.

MCROBERTS, M. Arduino básico. [S.l.]: Novatec Editora, 2011. Citado na página 49.

MILECKI, A. 45 years of mechatronics-history and future. In: Progress in Automation, Robotics and Measuring Techniques. [S.l.]: Springer, 2015. p. 127-136. Citado na página 45.

MINORSKY, N. Directional stability of automatically steered bodies. J. Amer. Soc. Naval Eng, v. 1, n. 34, p. 280-309, 1922. Citado na página 28.

NICOLAS, V. et al. Modelling heat and mass transfer in deformable porous media: Application to bread baking. Journal of Food Engineering, Elsevier, v. 130, p. 23-35, 2014. Citado 2 vezes nas páginas 34 e 35.

OGATA, K.; MAYA, P. Á.; LEONARDI, F. Engenharia de controle moderno. [S.1.]: Prentice Hall, 2003. Citado na página 28.

OPENCV. open source computer vision and machine learning software library. http://opencv.org/, 2016. Disponível em: <http://opencv.org/>. Citado na página 79. 
ÖZILGEN, M.; HEIL, J. Mathematical modeling of transient heat and mass transport in a baking biscuit. Journal of food processing and preservation, Wiley Online Library, v. 18, n. 2, p. 133-148, 1994. Citado na página 36.

PEREIRA, L. A. M. Desenvolvimento de uma linha experimental de escala reduzida para produção de biscoitos utilizando uma rede de multi sensores com protocolo ZIG-BEE. 1-117 p. Tese (Doutorado) — Universidade de São Paulo, 2012. Citado 3 vezes nas páginas 57, 59 e 61 .

POWELL, A. Democratizing production through open source knowledge: from open software to open hardware. Media, Culture 85 Society, Sage Publications, v. 34, n. 6 , p. 691-708, 2012. Citado na página 46.

QUEIROZ, S. Obstáculos ao investimento em P\&D de empresas estrangeiras no Brasil. Revista USP, v. 1, n. 89, p. 244-255, 2011. Citado na página 21.

REAS, C.; FRY, B. Processing: a programming handbook for visual designers and artists. [S.l.]: Mit Press, 2007. v. 6812. Citado na página 48.

RUIZ, A. U.; BRITTO, J. N. de P.; SOUZA, K. S. G. de. Qualificando o caráter regressivo da especialização industrial do Brasil. Revista Econômica, v. 1, n. 1, p. 244-255, 2014. Citado na página 21.

SABLANI, S. et al. Modeling of simultaneous heat and water transport in the baking process. LWT-Food Science and Technology, Elsevier, v. 31, n. 3, p. 201-209, 1998. Citado na página 36.

SAGUY, I. S. et al. Challenges facing food engineering. Journal of Food Engineering, Elsevier, v. 119, n. 2, p. 332-342, 2013. Citado na página 23.

SAKIN, M.; KAYMAK-ERTEKIN, F.; ILICALI, C. Simultaneous heat and mass transfer simulation applied to convective oven cup cake baking. Journal of food engineering, Elsevier, v. 83, n. 3, p. 463-474, 2007. Citado 3 vezes nas páginas 35, 36 e 83.

SCIPY. Python-based ecosystem of open-source software for mathematics, science, and engineering. scipy.org, 2017. Disponível em: < https://www.scipy.org/>. Citado 2 vezes nas páginas 72 e 98 .

SELMAN, J. D. Process monitoring and control on-line in the food industry. Food control, v. 1, n. 04, p. 36-39, 1990. Citado 2 vezes nas páginas 26 e 32.

SIMPSON A. TEIXEIRA, S. A. R. Advances with intelligent on-line report control and automation in thermal processing of canned foods. Food Control, v. 1, n. 18, p. 821-833, 2006. Citado na página 27.

TEIKARI, P. et al. An inexpensive arduino-based led stimulator system for vision research. Journal of neuroscience methods, Elsevier, v. 211, n. 2, p. 227-236, 2012. Citado 3 vezes nas páginas 50, 52 e 53 . 
TEMEL SEMIH YAGLI, S. G. S. Discrete Time Controls Systems Recitation Report. Middle East Technical University, 2013. Disponível em: <http: //www.eee.metu.edu.tr/ ee402/2013/EE402RecitationReport_4.pdf $>$. Citado 3 vezes nas páginas 32,72 e 98 .

TRYSTRAM, F. C. G. Food processing control - Reality and problems. Food Research International, v. 1, n. 27, p. 173-185, 1994. Citado 2 vezes nas páginas 25 e 26 .

VRIES, U. d.; SLUIMER, P.; BLOKSMA, A. A quantitative model for heat transport in dough and crumb during baking. STU-Information (Sweden), STU, 1989. Citado 2 vezes nas páginas 35 e 36.

YOUNG, D. M. A bound for the optimum relaxation factor for the successive overrelaxation method. Numerische Mathematik, Springer, v. 16, n. 5, p. 408-413, 1971. Citado 2 vezes nas páginas 74 e 77.

ZANONI, B.; PIERUCCI, S.; PERI, C. Study of the bread baking process-ii. mathematical modelling. Journal of Food Engineering, Elsevier, v. 23, n. 3, p. 321-336, 1994. Citado na página 35. 


\section{A APÊNDICE}

A.1 DIAGRAMA PLACA DE CONTROLE 


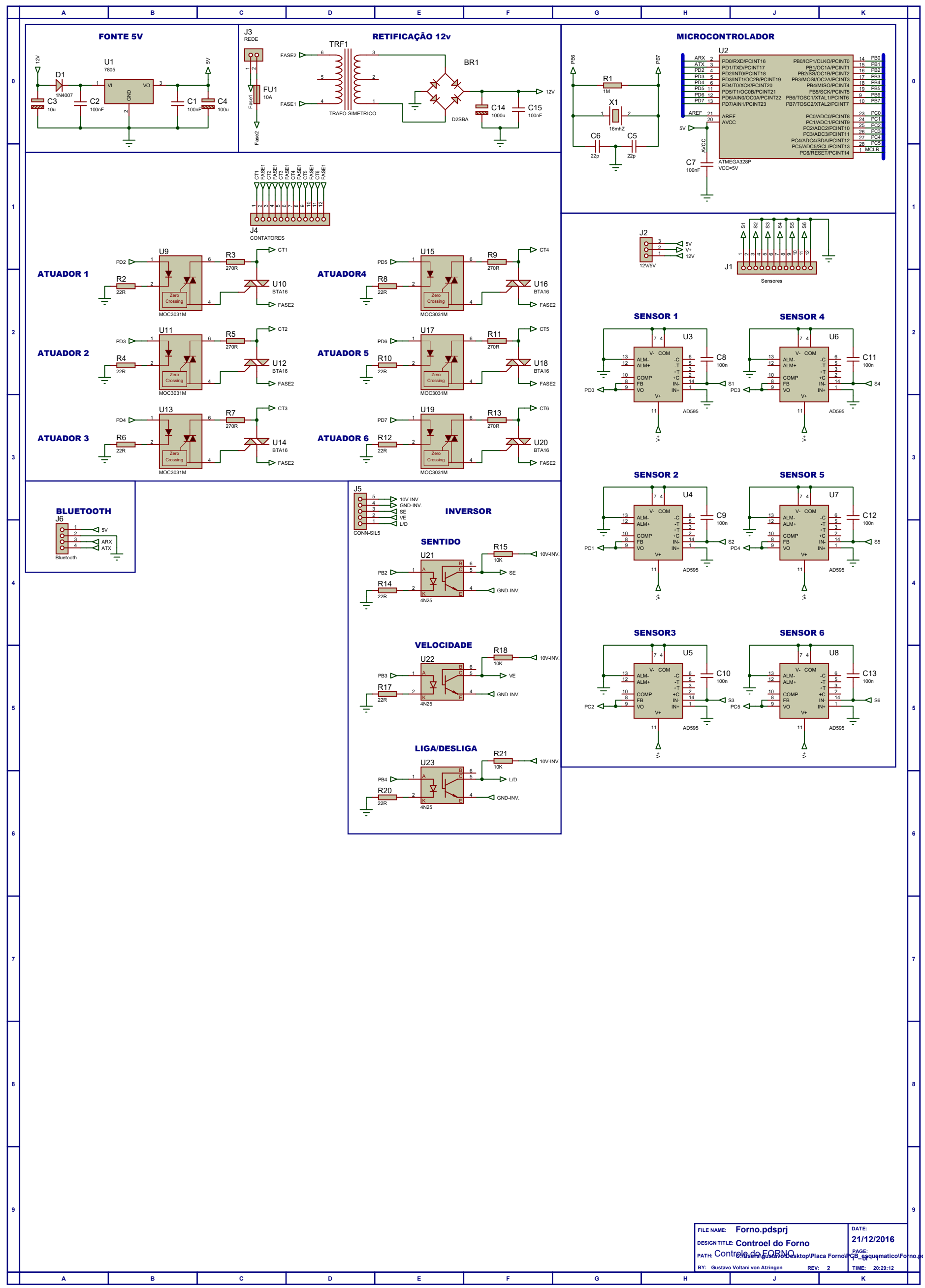




\section{A.2 CONTROLE PID}

\section{A.2.1 CONTROLADOR}

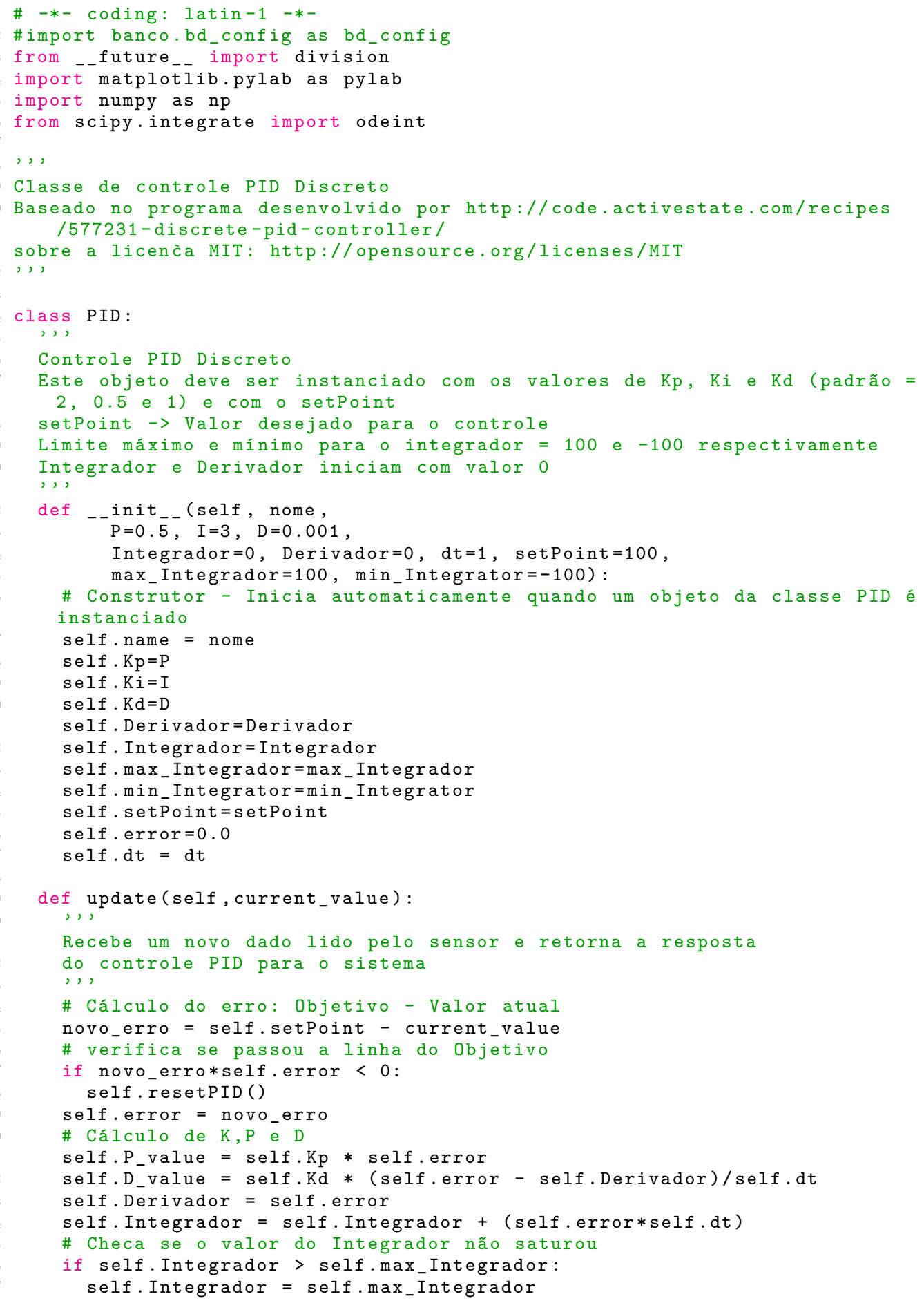




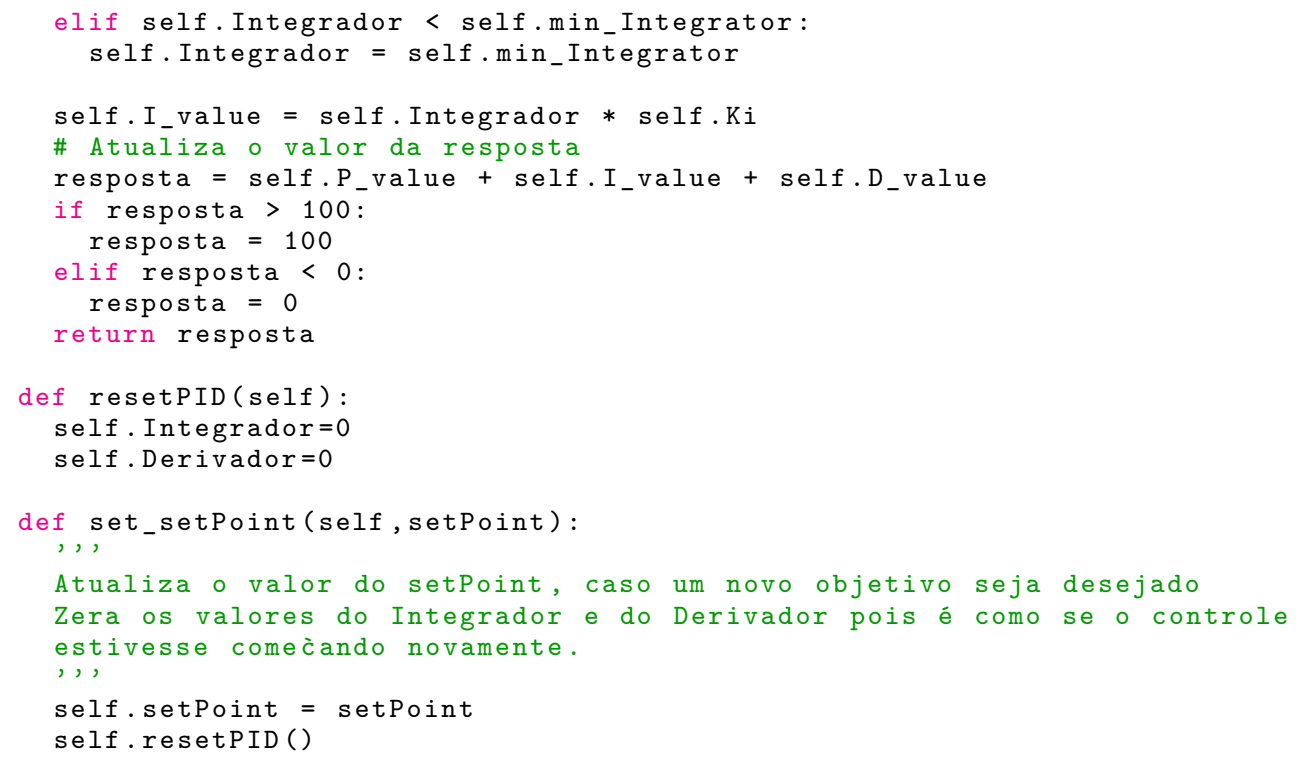

\section{A.2.2 MODELO-RESPOSTA}

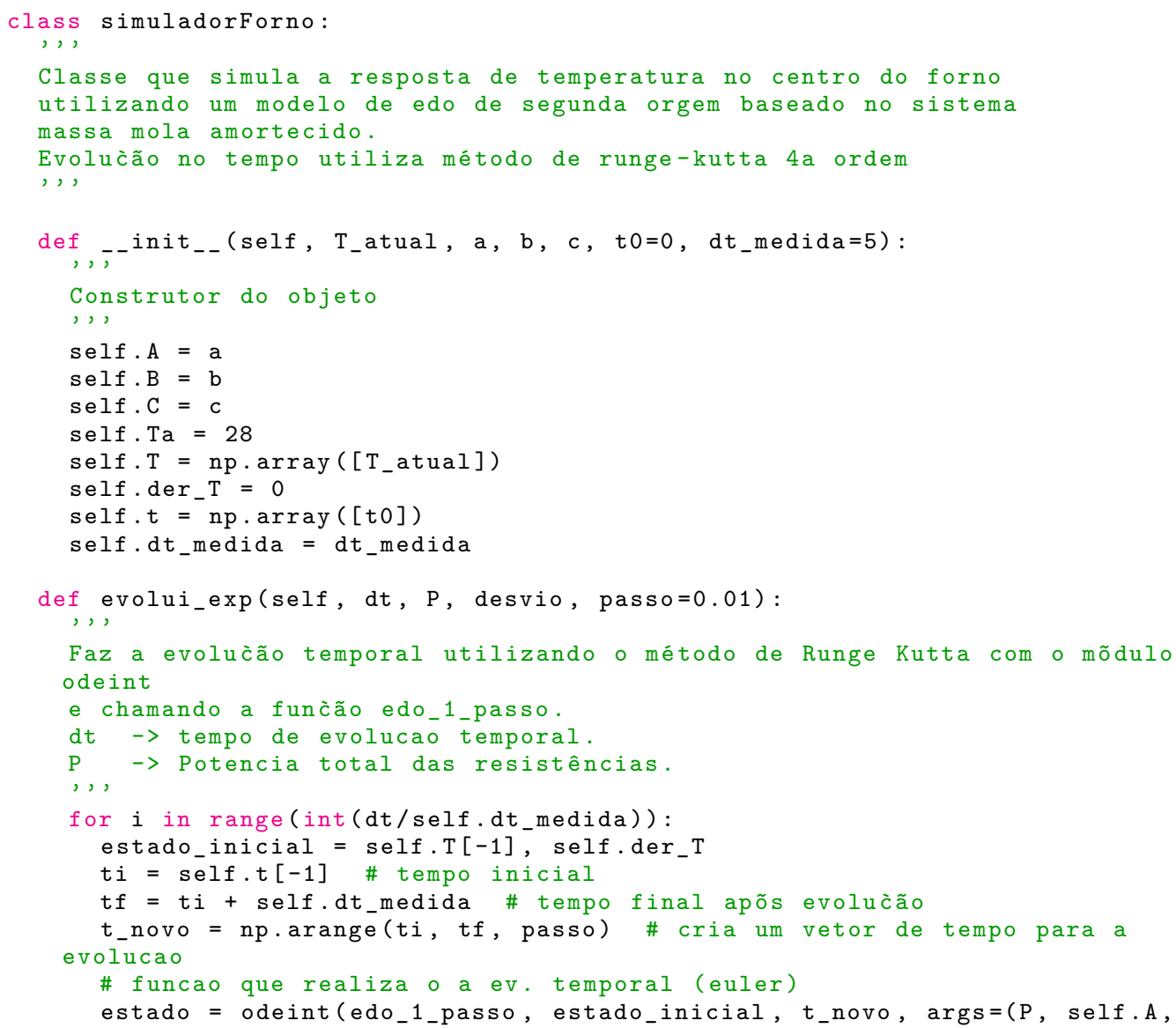




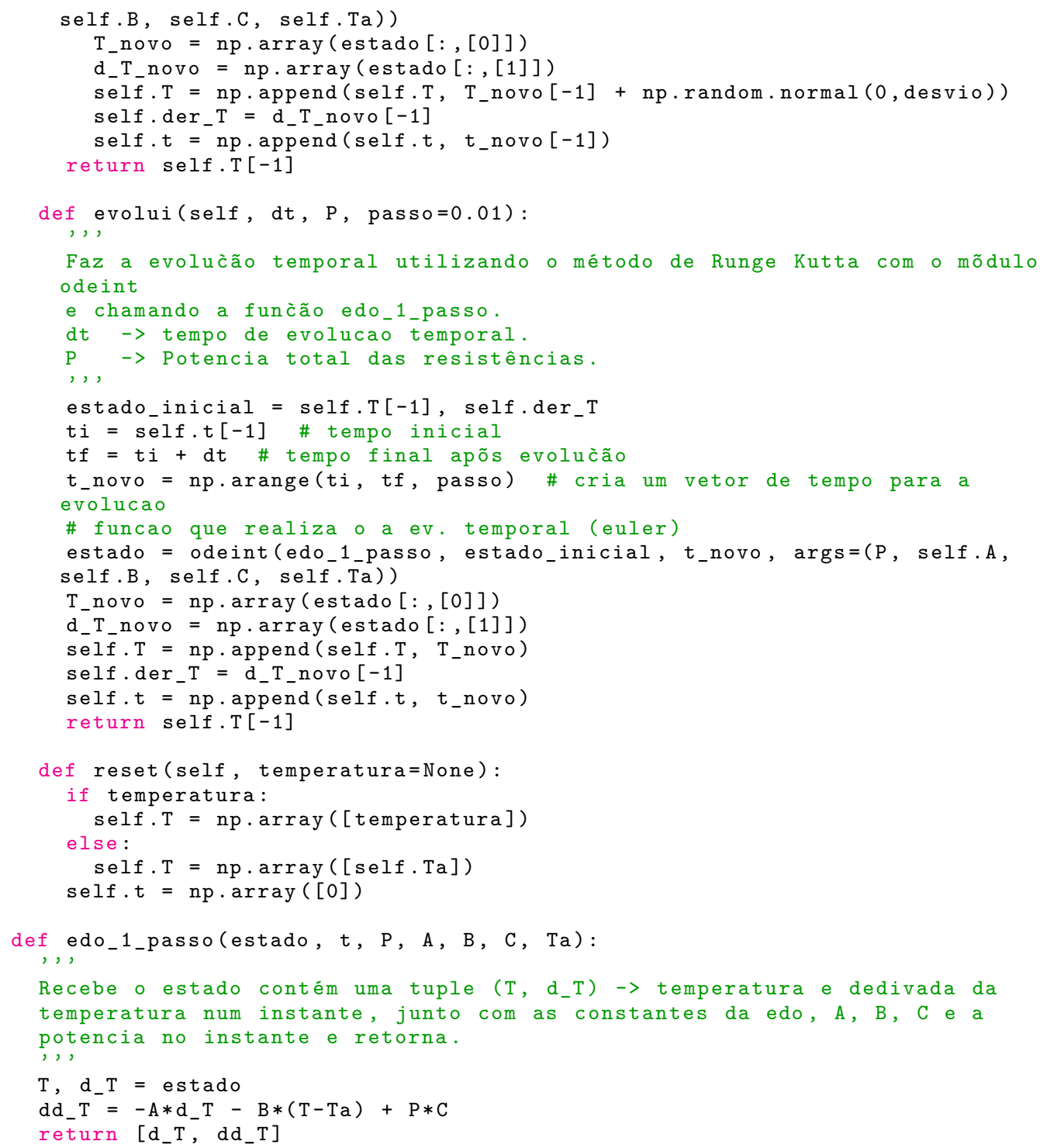

\section{A.3 DIFERENÇAS FINITAS 1D FORNO - PYTHON}

\section{A.3.1 SOR PYTHON2.7}

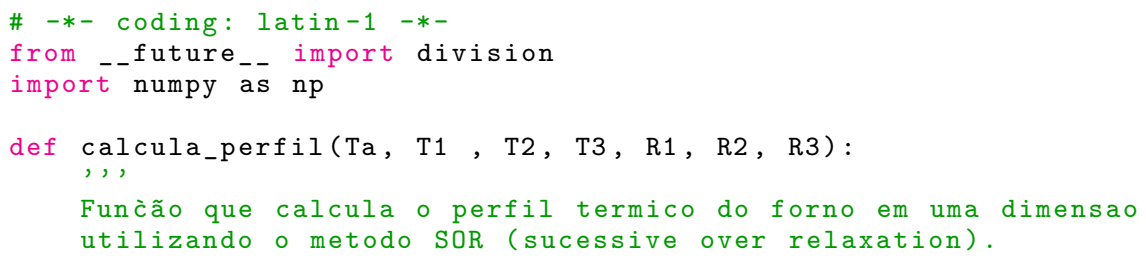




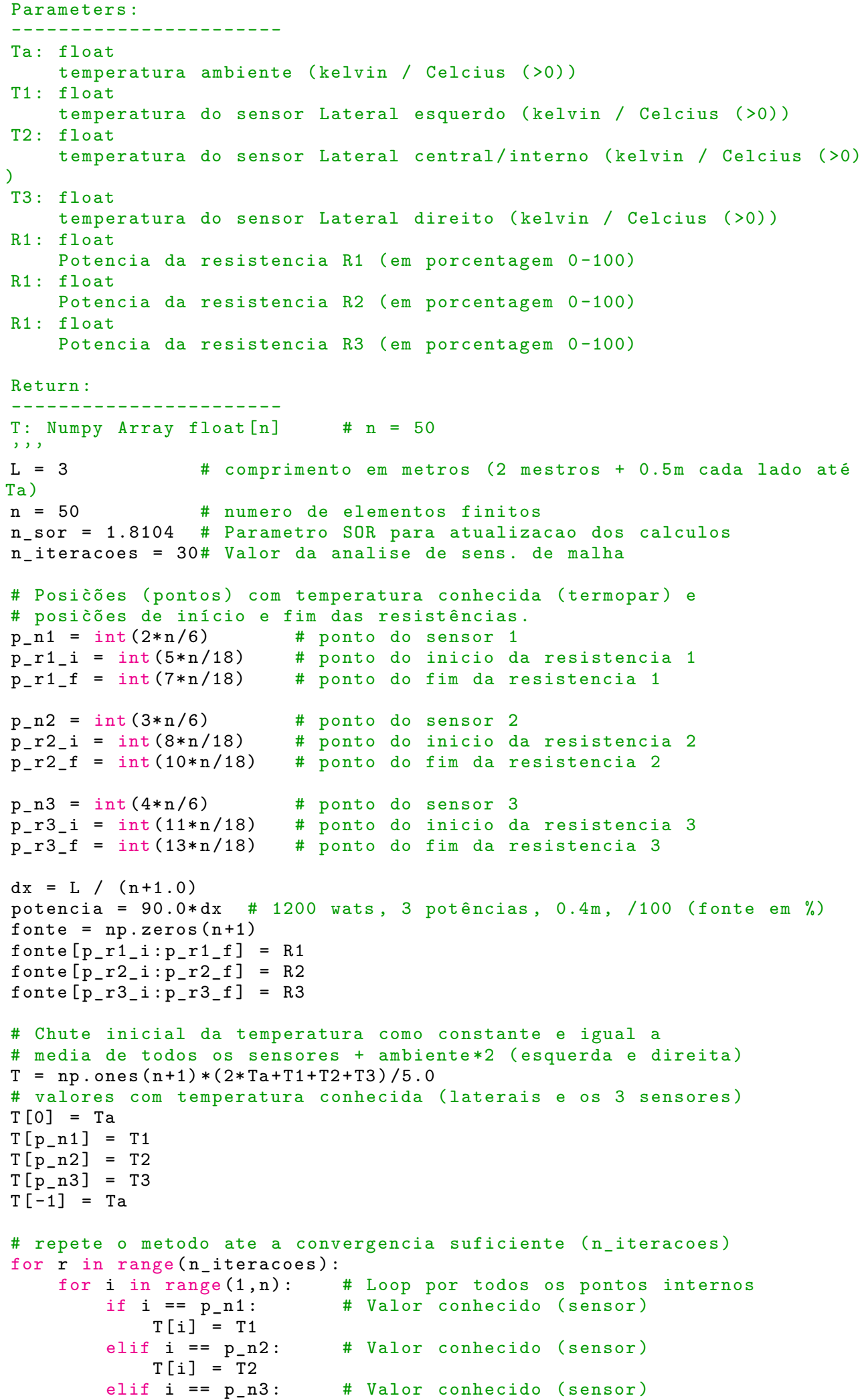




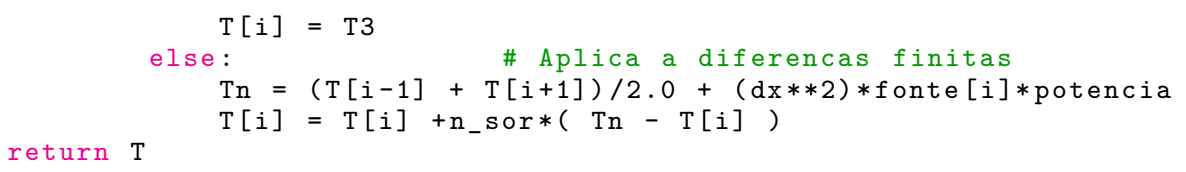

\section{A.3.2 SOR FORTRAN90}

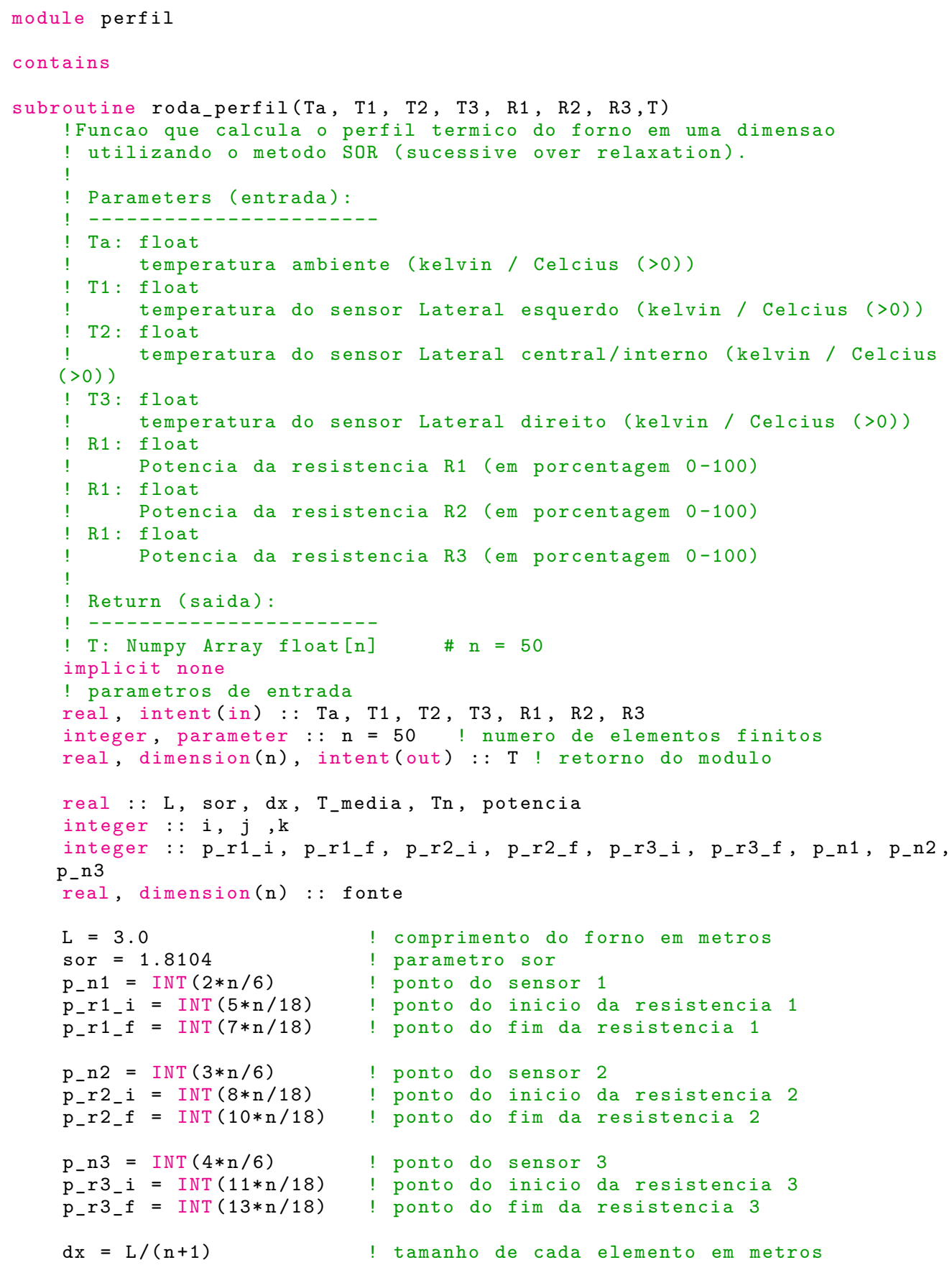




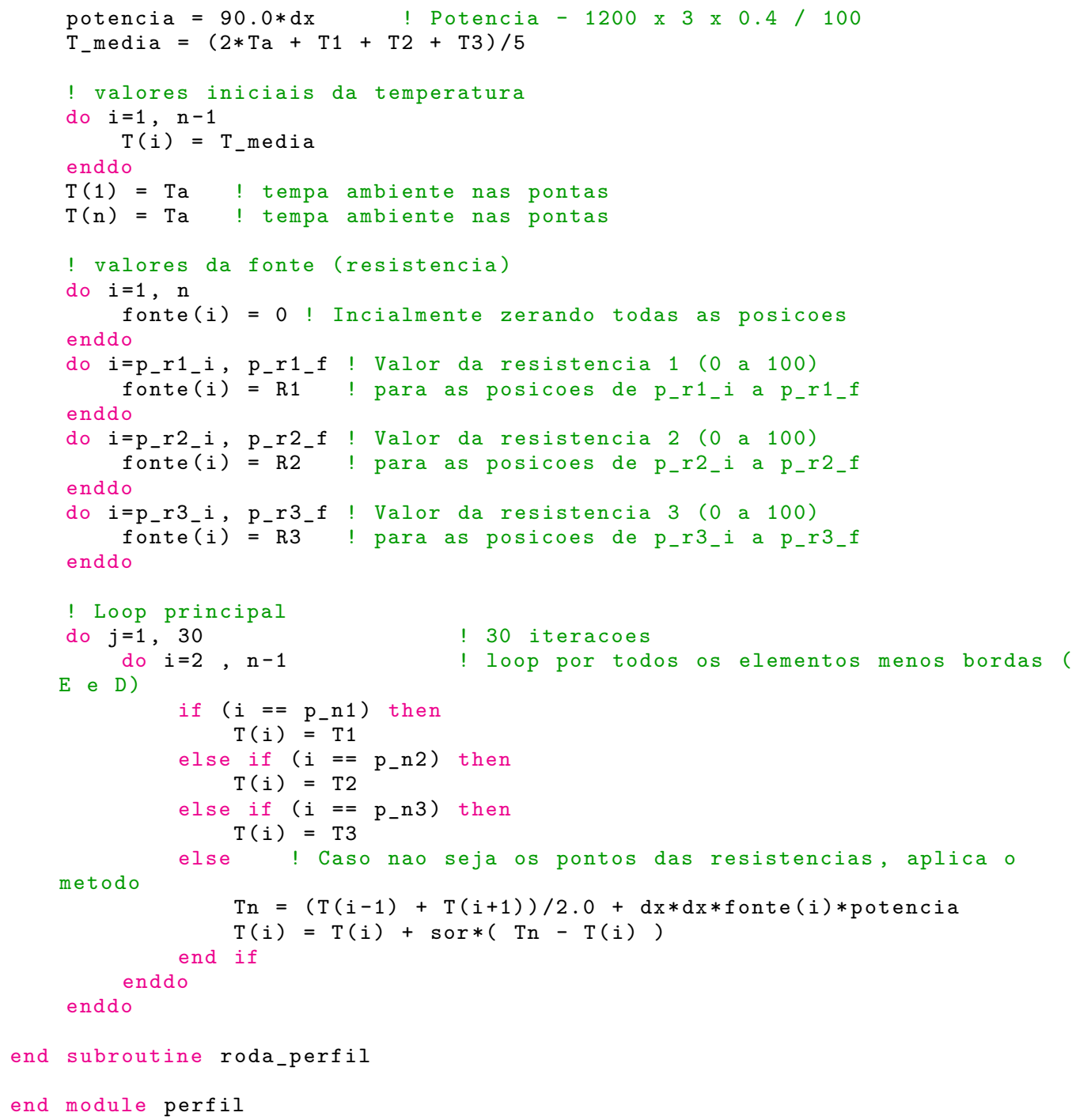

\section{A.3.3 ANÁLISE DE MALHA}

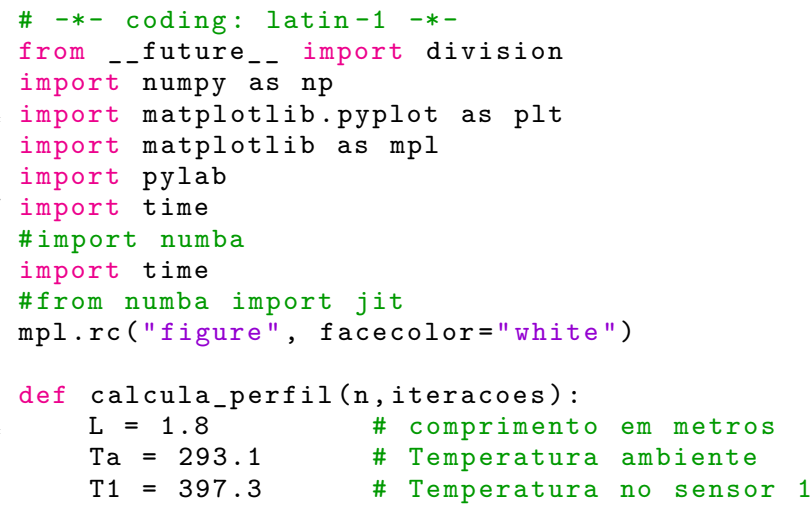




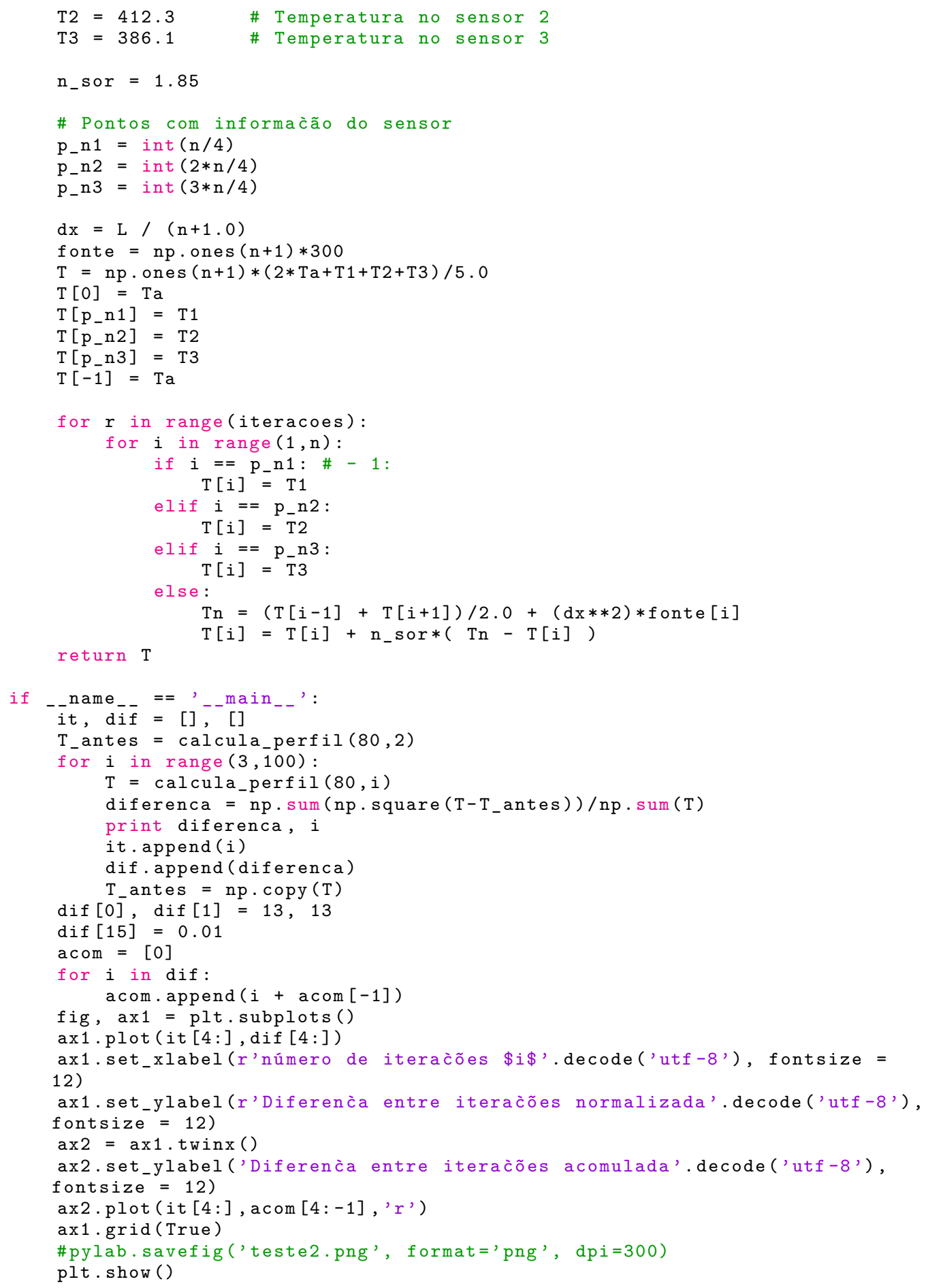

\section{A.3.4 GRÁFICO E IMAGEM DO FORNO}




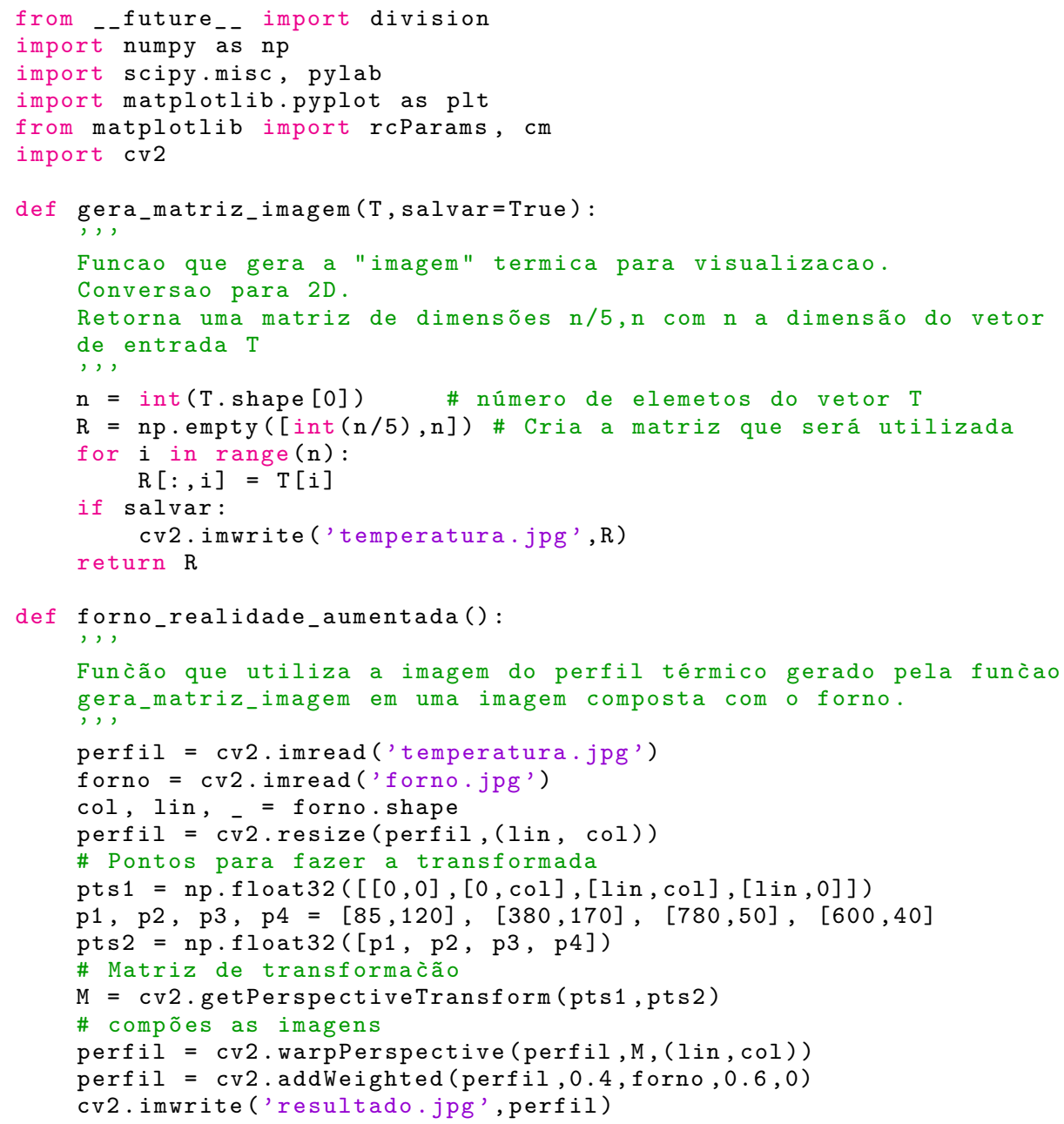

\section{A.4 DIFERENÇAS FINITAS CILINDRICA ALIMENTO}

\section{A.4.1 PYTHON 2.7}

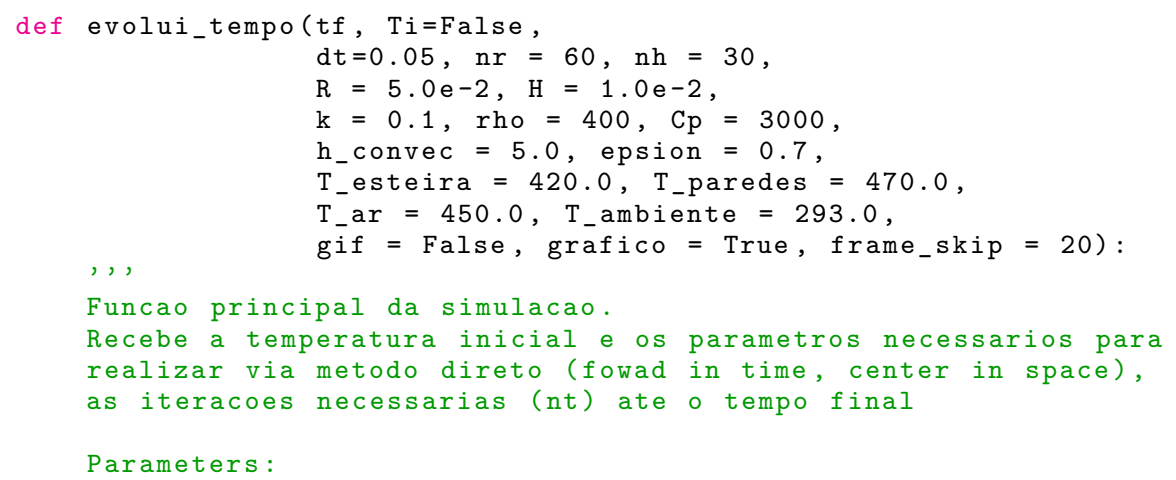




\section{tf : float}

tempo em segundos em que o sistema ira evoluir $\mathrm{To}=0$.

0 numero de iteracoes (time steps) dependera de tf e dt

$(t f / d t)$ em segundos

Ti: numpy Array (nr, nh) || none

Vetor com a temperatura de entrada.

Quando esta matriz nao e passada a funcao cria uma matriz

com a temperatura ambiente (inicio da evolucao temporal).

$d t:$ float

time step (em segundos)

nr: int

numero de elementos discretos na direcao radial

$\mathrm{nh}$ : int

numero de elementos discretos no eixo z (altura)

R: float

Raio do alimento em metros

H: float

Altura do alimento em metros

$k$, rho, sigma, h_convec, epsilon: float

Constantes Fisicas do alimento

T_esteira, T_paredes, T_ar, T_ambiente: float

Valores das temperaturas para a simulacao (Kelvin)

git, grafico: boolean (DEBUG)

Variaveis que quando verdadeiras mostram o grafico e animacao

do perfil termico do alimento.

frame_skip: int (DEBUG)

Apenas utilizada quando grafico=True. Pula frames do grafico para nao carregar o processamento desnecessariamente.

Return:

$\mathrm{T} \rightarrow$ numpy Array ( $\mathrm{nr}, \mathrm{nh})$

, ,

$\begin{array}{ll}\mathrm{pi}=\mathrm{np} \cdot \mathrm{pi} & \# 3.14159 \ldots \\ \text { sigma }=5.67032 \mathrm{e}-8 & \# \text { constante }\end{array}$

alpha $=\mathrm{k} /(\operatorname{rho} * \mathrm{Cp}) \quad$ \# constante alpha a partir de $\mathrm{k}$, rho e Cp

$\mathrm{dr}=\mathrm{R} /(\mathrm{nr}+1) \quad$ \# tamanho fisico do elemento em $r$

$\mathrm{dh}=\mathrm{H} /(\mathrm{nh}+1) \quad$ \# tamanho fisico do elemento em $\mathrm{h}$

if not Ti: \# Caso nao exista a temperatura de entrada, assume inicio da

\# evolucao temporal com temperatura matriz de temperatura mbiente

\# cria a matriz da temperatura inicial - array of float else:

$\mathrm{T}=\mathrm{np}$.ones $((\mathrm{nh}, \mathrm{n} r)) * \mathrm{~T}_{-}$ambiente \# dimensao 2 , size $\mathrm{nr}+1, \mathrm{nh}+1$

$$
\mathrm{T}=\mathrm{Ti}
$$

\# matriz para valores de $r$ en funcao, montadas em uma matriz concatenada

\# de colunas para operacao vetorizada no loop

$r_{-}$cilindrico $=1 / \mathrm{np} . \mathrm{tile}(\mathrm{r}+\mathrm{dr},(\mathrm{nh}, 1))[1:-1,1:-1]$

\# Numero de vezes que o metodo sera aplicado (fowad in time)

$n t=\operatorname{int}(t f / d t)$

\#\#\#\#\#\#\# Condicoes de contorno de Dirichilet \#\#\#\#\#\#\#\#\#\#\#\#\#\#\#\#\#\#\#\#\#

\# (fora do loop pois estes valores nao sao afetados).

\# Temperatura da esteira - Inferior

$\mathrm{T}[0,:]=\mathrm{T}_{-}$esteira

for $n$ in range(nt):

$\operatorname{Tn}=\mathrm{T} . \operatorname{copy}() \quad \#$ Cria uma nova matriz

$\mathrm{T}[1:-1,1:-1]=\operatorname{Tn}[1:-1,1:-1]+\operatorname{alpha} *(।$

$(\mathrm{dt} / \mathrm{dh} * * 2) *(\operatorname{Tn}[2:, 1:-1]-2 * \operatorname{Tn}[1:-1,1:-1]+\operatorname{Tn}[:-2,1:-1])+\backslash$

$(\mathrm{dt} / \mathrm{dr} * * 2) *(\operatorname{Tn}[1:-1,2:]-2 * \operatorname{Tn}[1:-1,1:-1]+\operatorname{Tn}[1:-1,:-2])+\backslash$

$\left.\left(d t /\left(d r * r_{-} c i l i n d r i c o\right)\right) *(\operatorname{Tn}[2:, 1:-1]-\operatorname{Tn}[1:-1,1:-1])\right)$

\#\#\#\#\# Condicoes de contorno: \#\#\#\#\#\#\#\#\#\#\#\#\#\#\#\#\#\#\#\#\#\#\#\#\#\#\#\#\#\#

\# Direichilet

\# Mista em todas as outras:

\# Radiacao + converccao

$\mathrm{T}[:,-1]=\mathrm{T}[:,-2]+\mathrm{dt} *\left(\operatorname{epsion} * \operatorname{sigma} *\left(\mathrm{~T}_{-}\right.\right.$paredes $\left.* * 4\right)-(\mathrm{T}[:,-1] * * 4)$ 


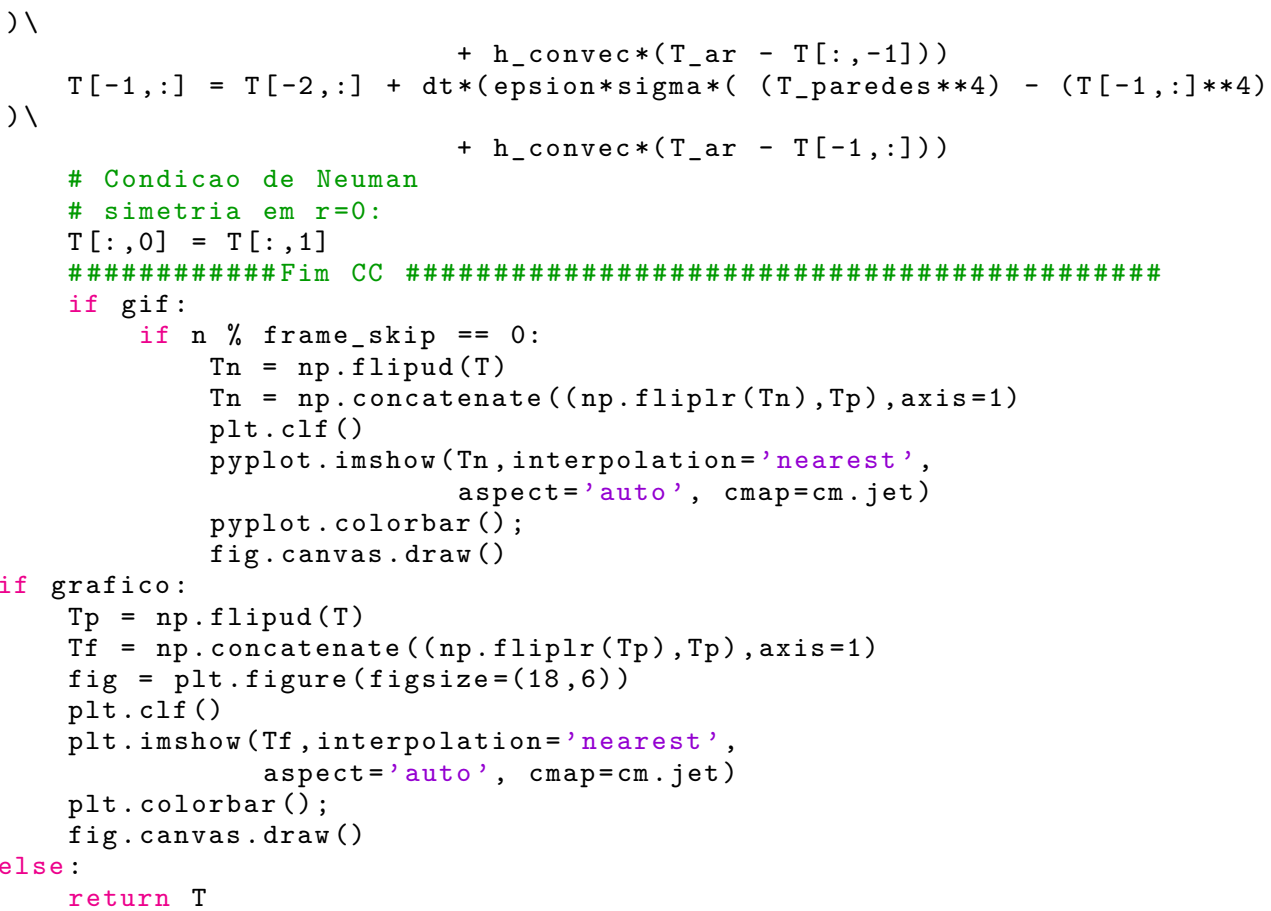

\section{A.4.2 FORTRAN - F90}

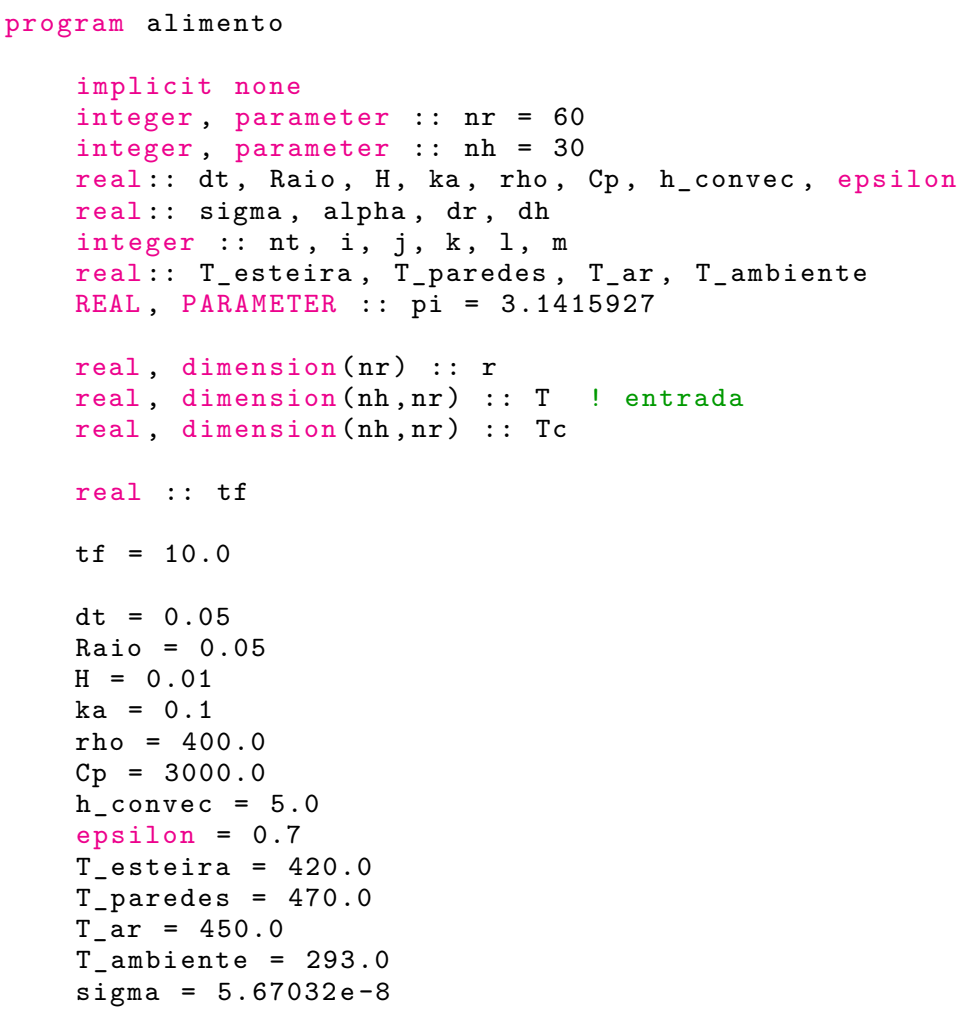




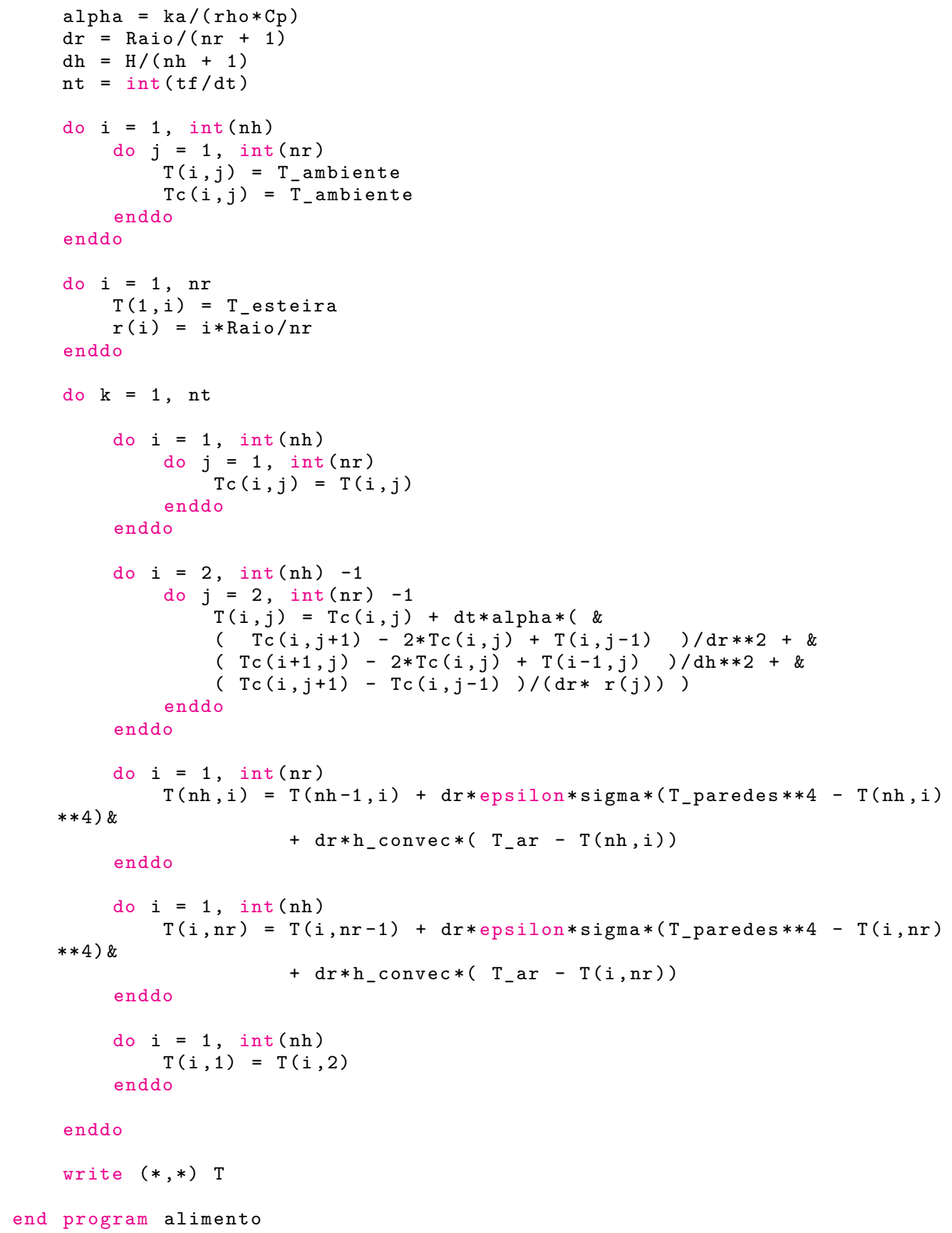

